\title{
LONG-TERM FOLLOW-UP OF PEDIATRIC PATIENTS UNDERGOING HEMATOPOIETIC STEM CELL TRANSPLANTATION
}

\author{
Julia Lopes Garcia ${ }^{1,2}$, Antonio Vaz de Macedo ${ }^{3,4}$, Polliany Roberta Dorini Pelegrina ${ }^{5}$, Rita de Cássia \\ Barbosa Tavares ${ }^{6}$, Roseane Vasconcelos Gouveia ${ }^{7}$, Adriana Seber ${ }^{7}$
}

\author{
1. Hematopoietic Stem Cell Transplantation Unit, Instituto de Tratamento do Câncer Infantil, Instituto da Criança, Hospital \\ das Clínicas da Faculdade de Medicina da Universidade de São Paulo, Brazil; \\ 2. Hematology and Bone Marrow Transplantation Unit, Hospital Israelita Albert Einstein, São Paulo, Brazil. \\ 3. Hematology Clinic, Hospital da Polícia Militar, Belo Horizonte, MG, Brazil \\ 4. Bone Marrow Transplant Unit, Hospital Luxemburgo, Instituto Mário Penna, Belo Horizonte, MG, Brazil. \\ 5. Bone Marrow Transplant Unit, Hospital Pequeno Príncipe, Curitiba-PR, Brazil. \\ 6. Bone Marrow Transplant Center- CEMO, Instituto Nacional de Câncer, Rio de Janeiro, RJ, Brazil. \\ 7. Pediatric Bone Marrow Transplant Unit, Hospital Samaritano, São Paulo, SP, Brazil.
}

Correspondence to: antoniovmac@hotmail.com

\begin{abstract}
Hematopoietic stem cell transplantation (HSCT) offers the opportunity for cure to patients with malignant and non-malignant diseases. Given the myriad advances in the past few decades, coupled with the rising numbers of transplants worldwide, the number of long-term survivors, many of whom are free of the disease for which they were transplanted, is constantly increasing. Despite the improved prognosis observed overall, long-term outcome may be undermined by transplant-associated morbidity and mortality. Long-term survivors may present a variety of complications, comprising physical, psychological, social, and economic arenas, with a deep impact on quality of life. Therefore, drawing greater attention to and raising awareness of the potential long-term effects of HSCT is key to providing a tailored approach to pretransplant counseling and to devising appropriate recommendations for post-transplant screening, prevention, and timely treatment of secondary events. In 2020, the Brazilian Group for Pediatric Bone Marrow Transplantation of the Brazilian Society for Blood and Marrow Transplantation and Cellular Therapy (SBTMO) convened a task force to provide updated, evidence-based guidance for the long-term follow-up of pediatric patients undergoing $\mathrm{HSCT}$, the results of which are presented here.
\end{abstract}

Keywords: Hematopoietic Stem Cell Transplantation. Counseling. Long-Term Follow-Up. Quality of Life. Pediatric. Consensus Guidelines.

\section{INTRODUCTION}

Hematopoietic stem cell transplantation (HSCT) offers the opportunity for cure to patients with malignant and non-malignant diseases. The number of long-term survivors, many of whom are free of the disease for which they were transplanted, is continuously increasing. Despite the improved prognosis of HSCT, long-term outcome may be undermined by transplant associated morbidity and mortality. Long-term survivors can present a variety of complications, impairing physical and psychological performance, normal integration into family and so- cial life, and quality of life. Raising awareness of the potential long-term effects of HSCT is key to providing a tailored approach to pretransplant counseling and to devising appropriate recommendations for post-transplant screening, prevention, and timely treatment.

In this chapter we will be discussing some of the main topics related to the long-term follow-up of patients undergoing HSCT. 


\section{OCULAR COMPLICATIONS}

Post-HSCT ocular complications are considered common, especially after allogeneic HSCT (allo-HSCT) and can be classified as referring to the posterior or anterior segments'.

Risk factors, early diagnosis, prevention, and treatment:-Whenever possible, an ophthalmological evaluation should be carried out before HSCT, with the objective of identifying changes, and serve as a basis for future evaluations. In young children, there is also the difficulty of verifying the reduction in visual acuity, reinforcing the importance of regular follow-up with the ophthalmologist ${ }^{2}$.

The anterior segment presents complications more frequently, reaching $33 \%$ of the cases, represented by cataract and keratoconjunctivitis sicca ${ }^{1}$.

Cataract: Posterior subcapsular cataract is the most common, with an incidence of up to $19 \%$ in 4 years after HSCT in patients who do not receive total body irradiation (TBI). The incidence is even higher in patients undergoing $\mathrm{TBI}$, especially in a single dose (non-hyperfractionated), the highest dose rate (> $0.04 \mathrm{~Gy} / \mathrm{min}$ ) was also identified as a risk factor ${ }^{2}$. In addition, patients who have used corticosteroids, especially for a prolonged period of time, are also at risk of this complication².

Surgery is standard treatment, and early diagnosis and setting of the appropriate time for surgery are important in children, especially those under 7 years of age, in order to prevent irreversible amblyopia ${ }^{3}$.

Keratoconjunctivitis sicca: It is commonly diagnosed in the post-transplant period and may resemble Sjogren's syndrome, with tear hyposecretion, thinning of the superficial epithelium, and keratinization of the cornea and conjunctiva, which may progress to ulceration and perforation of the cornea ${ }^{4}$. It is a complication more related to ocular graft-versus-host disease (GVHD), although it is not exclusively associated with it. TBI and drugs used in conditioning, immunoprophylaxis (such as methotrexate), or GVHD treatment may be responsible for its development.

The posterior segment refers to microvascular retinopathy, optic disc edema, hemorrhages, and infections, such as cytomegalovirus (CMV) retinitis, varicella, or toxoplasma. These complications have an estimated incidence of $10 \%$ and occur most frequently in the first year after HSCT ${ }^{1}$.

Ischemic microvascular retinopathy: Its clinical presentation can occur from an asymptomatic form to complaints of blurred vision and change in color vision. This complication may have an abrupt, gradual, or progressive onset, and may affect one or both eyes. May occur in patients who have undergone an autologous or allogeneic transplant, and the risk factors associated with it are TBI conditioning, carmustine, busulfan, and cyclosporine prophylaxis's. Spontaneous regression may occur, and permanent loss of visual acuity is rare. The removal or reduction of immunosuppression may lead to resolution of retinal lesions in many cases ${ }^{5}$.

Retinal hemorrhage and retinal detachment: Retinal hemorrhage and detachment usually occur as a consequence of other pathologies, such as CMV retinitis and neovascularization due to ischemic retinopathy. The best way to treat it is to keep platelet levels above 50.000/ul and correct possible coagulopathies. Retinal detachment is a rare posterior segment complication and is responsible for $<1 \%$ of ocular complications after HSCT. Treatment depends on the underlying disease and includes laser photocoagulation, cryotherapy and various surgical techniques ${ }^{6}$.

Recurrence of the underlying disease: Ocular involvement related to recurrence of the disease is a rare event, but that can happen ${ }^{7}$. In view of the suspicion, the patient should be evaluated by an experienced ophthalmologist, and imaging and biopsy may be required to confirm the diagnosis ${ }^{8}$.

Glaucoma: Classically, glaucoma is known as a late complication of irradiation used in conditioning regimens, with an average interval of 22 months for the onset of this complication. Prolonged corticosteroid use is also a risk factor?.

Other late complications involving the eyes are related to chronic GVHD, as described in the accompanying chapter on GVHD.

\section{ORAL COMPLICATIONS}

The main acute oral complications occur due to chemotherapy used in conditioning regimens, or due to the presence of GVHD with involvement of the oral cavity. Therefore, it is important that these patients are regularly followed up by dentists.

Developmental disorders: Dental changes caused by myeloablative conditioning usually occur after six months of the procedure ${ }^{10}$. Dental development in children undergoing chemotherapy and TBI for HSCT can be significantly compromised. Radiotherapy is an important risk factor for craniofacial development changes, especially when performed before 5 years of age may lead to a reduction in mandible 
growth ${ }^{11}$. Regarding dental disorders, the most frequent findings are dental agenesis, microdontia, teeth with root shortening and alteration in the corona-root ratio.

Fungal and viral infections: Oral fungal infections have been observed in $15 \%$ to $56 \%$ of patients in HSCT, with Candida infections being the most common, and the oropharynx is a site prone to colonization $^{13}$. Candida albicans is the commonest species, usually associated with oral candidiasis. Risk factors for this infection are mucositis, severe and persistent neutropenia, use of broad-spectrum antibiotics and corticosteroids, as well as GVHD and xerostomia ${ }^{12}$.

Infections caused by the herpesvirus family may be common in patients undergoing $\mathrm{HSCT}$, especially recrudescent lesions of human herpes virus type 1 (HHV-1) and human herpesvirus type 6 (HHV-6). CMV may also cause lesions in the oropharynx, without any characteristic clinical presentation ${ }^{13}$.

Later after HSCT, patients may have decreased saliva production, which increases the chance of developing severe cavities and gum disorders. Repeated trauma to the oral mucosa, especially in patients with oral chronic GVHD also increases the chance of developing secondary oropharyngeal carcinoma. Patients and families must be educated to report any new oral lesions and the team following them must always have a high suspicion to promptly diagnose a new cancer.

GVHD: about $30 \%$ to $80 \%$ of patients with post-HSCT GVHD have oral cavity lesions associated with significant symptoms ${ }^{14}$. For further information, please refer to the GVHD chapter.

\section{BONE COMPLICATIONS - OSTEOPENIA AND OSTEOPOROSIS}

Risk factors, early diagnosis, prevention, and treatment:_Osteopenia and osteoporosis are common complications after HSCT. The most common risk factors are prolonged corticosteroid use, hypogonadism, vitamin D deficiency, lack of sun exposure, use of immunosuppressive medications, sedentary lifestyle, family history, conditioning regimen used in HSCT, TBI, among others ${ }^{15}$. Bone mineral density reduction has an incidence of up to $26 \%$ in patients without GVHD and up to $94 \%$ in patients with chronic GVHD ${ }^{14}$.

\section{Diagnosis:}

Bone mass reduction in children is defined as $z>$ 2 standard deviations below population norms of age and gender in densitometry ${ }^{16}$. Osteoporosis in children is defined as the reduction of bone mass associated with a history of fractures (2 or more up to 10 years or more from 3 to 19 years). If the patient presents with a compressive fracture in the spine with no history of trauma that justifies it, it also indicates the establishment of osteoporosis ${ }^{17}$. Several studies have highlighted that fractures are important, despite being an underrecognized manifestation of osteoporosis in children. This usually occurs for two reasons: the first because they are usually asymptomatic, and second, because monitoring with lumbar spine radiography is not routinely performed ${ }^{18}$.

Patients who have used corticosteroids for more than 3 months should perform an $x$-ray of the spine at the time of initiation of treatment and repeat the examination after 3-4 months to avoid the first incident of vertebral fracture. It is also suggested to repeat the test again after 12 months, and from then on, only if the patient maintains exposure to risk factors such as corticosteroids ${ }^{18,19}$.

Treatment: The first line of treatment for bone health maintenance is based on three points: nutrition, physical activity, and treatment of the underlying disease and associated comorbidities ${ }^{20}$. The best nutritional factors for bone health are vitamin D and calcium. However, several other nutrients are also relevant for bone metabolism, such as proteins, potassium, magnesium, copper, iron, zinc and vitamins A, C and K. Post-HSCT patients are at particularly high risk of vitamin $\mathrm{D}$ deficiency due to limited sun exposure, malabsorption and dietary restrictions. The investigation and treatment of possible endocrine changes is also important for these patients ${ }^{21}$.

The initial therapeutic approach is usually conservative. Not all children with symptomatic osteoporotic fractures and chronic diseases require therapy for osteoporosis due to the potential for spontaneous recovery (without specific medications) if risk factors are transient ${ }^{18}$. But children with vertebral fracture(s) and/or low bone density and two or more long bone fractures should be considered for intravenous bisphosphonate thera$\mathrm{py}^{22}$. A retrospective study from Seattle suggested that the use of bisphosphonates associated with vitamin $\mathrm{D}$ and calcium supplementation may reverse osteopenia and post-HSCT osteoporosis ${ }^{23}$. However, these cases should be discussed and followed up together with a pediatric endocrinologist. The use of bisphosphonates may cause some important adverse effects, such as mandible necrosis. 


\section{BONE COMPLICATIONS - AVASCULAR NECROSIS}

Avascular necrosis (AVN) is an important bone postHSCT complication. Risk factors include age $\geq 5$ years at HSCT, female gender, myeloablative conditioning regimens, and exposure to corticosteroids (especially dexamethasone). AVN typically affects the femoral head and can cause severe pain and bone destruction, resulting in significant impairment in quality of life, and eventually requiring joint replacement in many patients ${ }^{24}$. In children, the knees (31\%-40\%) are the most frequently affected site, followed by hips (19\%$24 \%)$, shoulders (9\%), and other locations. Although not so well described, AVN findings on magnetic resonance imaging (MRI) do not always have clinically significant symptoms in children ${ }^{25}$. Performing MRI, referring to physical therapy and evaluating the need for surgery in early strategies should be considered in patients at higher risk for developing AVN, especially with prolonged steroid use due to chronic GVHD, which can mitigate the morbidity associated with this complication ${ }^{26}$. However, the indication of surgery should be discussed with an experienced orthopedist and multidisciplinary team ${ }^{24}$.

\section{INFECTIONS}

\section{Infection prophylaxis and preemptive therapies}

All post-HSCT patients have some degree of immunodeficiency, especially during the first 6 to 12 months after transplantation. Bacterial, fungal and viral infections occur more frequently during this time interval. In the absence of GVHD, most patients have adequate immunological reconstitution one year after transplantation. Patients with chronic GVHD remain immunodeficient for longer and have a high risk of infections ${ }^{27}$.

\section{Pneumocystis jirovecii pneumonia (PCP or PJP)}

Patients undergoing an allo-HSCT should receive prophylaxis against PCP for at least 6 months after transplantation or until all immunosuppressive drugs have been discontinued, which may subsequently occur $^{28}$. The preferred drug is sulfamethoxazole and trimethoprim, and patients allergic to sulfa should be desensitized whenever possible. If desensitization is not feasible, dapsone can be administered at a dose of $2 \mathrm{mg} / \mathrm{kg}$ once daily (maximum $100 \mathrm{mg} /$ day). Before starting treatment with dapsone, patients should be tested to rule out G6PD deficiency ${ }^{27}$.

\section{VARICELLA ZOSTER}

After primary infection with the varicella zoster virus $(\mathrm{VZV})$, it establishes latency in the dorsal ganglia and can be reactivated over time as herpes zoster in immunocompetent individuals or as a severe episode of chickenpox in immunocompromised patients. The use of corticosteroids, immunosuppressive drugs, chronic GVHD, transplants from alternative donors and cord blood are risk factors for VZV reactivation after $\mathrm{HSCT}^{29}$.

There is a recommendation for all VZV seropositive patients (by vaccine or disease) to receive prophylaxis with acyclovir or valacyclovir during the first year after transplantation or up to 8 months after the end of systemic immunosuppression, whichever is longer ${ }^{28}$.

Patients exposed to chickenpox or zoster during the first year after transplantation or during the use of immunosuppressive drugs should be clinically evaluated. Those seronegative to VZV and who do not receive prophylactic acyclovir should be treated with valacyclovir on days 3 to 22 after exposure, unless treatment with ganciclovir, foscarnet or cidofovir is being administered for another reason. In seronegative patients, administration of varicella zoster immunoglobulin (VZIG) within 96 hours of exposure should also be used, if available, in addition to valacyclovir, as described above ${ }^{27}$.

\section{ENCAPSULATED BACTERIA}

Patients with chronic GVHD are highly susceptible to recurrent bacterial infections, especially from encapsulated organisms such as Streptococcus pneumoniae, Haemophylus influenzae and Neisseria meningitidis ${ }^{28}$.

Long-term prophylaxis is recommended in this scenario and, due to the emergence of penicillin resistance (and the concomitant need for prophylaxis for PCP in these patients), sulfamethoxazole and trimethoprim is recommended as a first-line drug for chemoprophylaxis for infections by encapsulated bacteria. Patients receiving systemic immunosuppressive therapy for chronic GVHD should receive antibiotic prophylaxis against encapsulated bacterial infections for at least 6 months after discontinuation of all immunosuppressive drugs ${ }^{27}$.

\section{Antimicrobial prophylaxis for asplenic patients}

Patient education is essential to prevent fatal infections in asplenic patients. Patients who have had splenic irradiation, sickle cell disease and chronic GVHD may also have completely lost their splenic function. Studies have shown that $11 \%$ to $50 \%$ of post-splenectomy patients remain unaware of their increased risk of severe infection or the appropriate health precautions that should be taken ${ }^{27}$. Antimi- 
crobial prophylactic regimens are the same as for the prevention of encapsulated bacteria in patients with chronic GVHD and include daily sulfamethoxazole and trimethoprim or twice daily Penicillin V. As penicillin $\mathrm{V}$ does not offer PCP protection, another prophylaxis for PCP shall be performed ${ }^{27}$.

The duration of prophylaxis for patients without GVHD is up to 6 months after immunosuppression or up to 6 years or 2 years after splenectomy (which happens later). Patients with GVHD should be on prophylaxis for up to 1 year of HSCT or 6 years or 2 years after splenectomy (which happens later).

Sickle cell anemia: all patients with sickle cell anemia should receive penicillin prophylaxis daily for two years after transplantation or until the tenth anniversary, whichever takes longer to happen ${ }^{27}$.

These patients should have the anti-pneumococcal, anti-meningoccocal and anti-haemophylus titers checked after they get the post-transplant revaccination. Despite prophylaxis or after it is discontinued, invasive fulminant infections still do occur. Education must be over emphasized for patients in all routine visits to seek medical attention should they develop fever or feel sick, to tell the healthcare provider that they do not have a functional spleen, and that they do need to receive antibiotics.

\section{CYTOMEGALOVIRUS (CMV)}

\section{CMV infection is a potentially serious complica- tion after HSCT.}

Risk factors for CMV infection: these are related to the CMV serological status of the recipient and the donor, the degree of Human Leukocyte Antigen (HLA) compatibility between recipient and donor, characteristics of the conditioning regimen, T-cell depletion, the development of GVHD, and immune reconstitution after transplant ${ }^{30}$.

Patients with a positive immunoglobulin $\mathrm{G}(\mathrm{IgG})$ serological status who receive the stem cells from an IgG-negative donor have the worst outcomes in allogeneic transplants. On the other hand, IgG-negative patients receiving the graft from donors also IgG-negative, rarely develop any CMV-related complication $^{31}$. Thus, if possible, a CMV-negative seronegative donor should be selected for a seronegative recipient and a CMV-positive donor for a CMV-positive patient ("CMV matched donor").

CMV reactivation: it is defined as the detection of the virus DNA in the blood or a new episode of antigenemia in patients who had lgG+ serology prior to HSCT.
CMV disease: this requires detection of CMV in tissues by molecular or virological methods in patients with CMV-related symptoms ${ }^{32}$. May include variable clinical manifestations such as interstitial pneumonia, enteritis, hepatitis, retinitis, encephalitis, and a CMV syndrome that includes cytopenia and fevers.

CMV disease-related mortality is on average $40-50 \%$ but can reach $86 \%$ in cases of severe pneumonia. In the case of CMV pneumonitis, the use of immunoglobulin should be considered.

Febrile CMV syndrome: it is diagnosed when patients have fever $(>380 \mathrm{C})$ lasting more than two days and CMV is detected in their blood samples, but not in their tissues ${ }^{32}$.

Diagnosis: The diagnostic methods for CMV infection are pp65 antigenemia - Agpp65 (sensitivity $89 \%$, specificity $100 \%$ ) or polymerase chain reaction - PCR (sensitivity from 95 to 100\%) for the early detection of CMV replication. There is a current trend of antigenemia to be substituted by molecular methods, particularly in post-transplant monitoring of CMV viral replication ${ }^{33}$.

PCR should be normalized for quantification according to the World Health Organization (WHO) standard as $\mathrm{UI} / \mathrm{ml}$ results, and each center should establish its cut-off for preemptive therapy.

Weekly follow-up by PCR or antigenemia is suggested in patients transplanted up to $\mathrm{D}+100$, but in highrisk patients (related mismatched HSCT, unrelated donors, cord blood, persistent immunodeficiency in haploidentical transplants), monitoring should be extended until D+180.

Treatment: The current best strategy to decrease morbidity and mortality is the early initiation of preventive therapy against $\mathrm{CMV}^{28}$. First-line preemptive treatment should be performed with ganciclovir $5 \mathrm{mg} / \mathrm{kg} /$ dose every 12 hours $^{32}$. In early post-HSCT reactivation, for which this medication cannot yet be used due to its myelotoxicity, the use of foscarnet $60 \mathrm{mg} / \mathrm{kg} /$ dose every 8 hours or $90 \mathrm{mg} / \mathrm{kg} / \mathrm{dose}$ every 12 hours can be evaluated. Unfortunately, however, there is a huge difficulty in accessing foscarnet for patients in the Brazilian unique health system (SUS), which limits the therapeutic options for these patients.

Treatment should be maintained for at least 14 days until the patient has at least one negative test. Increased CMV-DNAemia (or Agpp65) in the first two weeks of preemptive therapy does not require a change in therapy. However, if this is sustained for 
more than two weeks, a ganciclovir dose increase ( 7.5 to $10 \mathrm{mg} / \mathrm{kg} /$ dose) and immunosuppression reduction (when possible) can be evaluated.

\section{Monitoring during treatment:}

Complete blood count with leukocyte count and differential should be performed before the beginning of the treatment and then tart of treatment, $2-3$ times a week during treatment with valganciclovir or ganciclovir.

If the neutrophil count is $<<1.500 / \mathrm{mm}^{3}$, a blood count should be performed daily.

If leukocytes $<1.000 / \mathrm{mm}^{3}$ before the start of treatment or during treatment, the use of foscarnet should be considered ${ }^{27}$.

Renal function should always be followed (at least once a week) and adjustments should be made as needed.

\section{Other therapeutic options:}

- Cidofovir ( $5 \mathrm{mg} / \mathrm{kg}$ once a week) is a second line of treatment and can be considered on occasion. However, it is also a medication that is difficult to access for patients in the Brazilian unique health system.

- Valgancyclovir: Some randomized trials have already used it for patients after a HSCT, although it has not yet been officially approved for these patient ${ }^{28}$. Its use should be considered for patients with good oral intake, no active intestinal GVHD, no significant liver disease and no severe diarrhea. However, it is expensive and not widely available.

\section{Valgancyclovir dose ${ }^{27}$ :}

$\geq 40$ a <50kg: $675 \mathrm{mg}$, oral every 12 hours

$\geq 30$ a <40kg: $450 \mathrm{mg}$, oral every 12 hours

$\geq 20$ a <30 kg: $450 \mathrm{mg}$, oral every $12 / 12$ hours ou 14 $\mathrm{mg} / \mathrm{kg}$ every 12 hours

$\geq 15$ a <20 kg: $225 \mathrm{mg}$, oral $12 / 12$ hours (= $1 / 2$ tablet)

ou $14 \mathrm{mg} / \mathrm{kg}$ every 12 hours

$\geq 10$ a $<15 \mathrm{~kg}: 14 \mathrm{mg} / \mathrm{kg}$, oral, every 12 hours

\section{Prophylaxis:}

The use of CMV prophylaxis with letermovir has encouraging results in adult patients but requires further studies in the pediatric population ${ }^{34}$. Some randomized studies have shown that high doses of acyclovir or valacyclovir may reduce the risk of CMV infection, but not CMV disease ${ }^{35,36}$.

\section{FUNGAL INFECTIONS}

Invasive fungal infection (IFI) is an important cause of morbidity and mortality in patients after HSCT. Pathogens can usually be divided into three groups: Candida, Aspergillus and other fungi (Zygomycetes, Fusarium species, and Scedosporium species). Over time, and with the introduction of prophylaxis, there has been a change in the infectious profile of these patients: Candida species were previously more common, but currently, Aspergillus, has emerged with a relevant prevalence ${ }^{29}$.

Risk factors: age at transplant, diagnosis, type of transplant, stem cell source, prolonged neutropenia, the use of high doses of corticosteroids, severe acute and chronic GVHD, and fungal infection before transplantation $^{37}$.

Prophylaxis: Options include fluconazole, voriconazole, micafungin and liposomal amphotericin B. In children over 13 years of age, posaconazole is also an option ${ }^{38}$.

Fluconazole can be used ${ }^{29}$ up to D+75 after HSCT; this strategy has been shown to reduce the incidence of candidemia and candidiasis-related mortality ${ }^{27}$. However, risk factors and patient history should always be evaluated to define the best prophylactic option.

In the presence of GVHD treated with increased immunosuppression (including the use of corticosteroids at a therapeutic dose $\geq 0.3 \mathrm{mg} / \mathrm{kg}$ per day of prednisone or equivalent), prophylaxis against fungal infections is recommended ${ }^{38}$. 
TABLE 1: Doses of antifungals ${ }^{38}$ :

\begin{tabular}{|c|c|c|}
\hline & Dose & Comments \\
\hline Fluconazole & 8 to $12 \mathrm{mg} / \mathrm{kg}$ (maximum $400 \mathrm{mg}$ ) & Active only against yeasts \\
\hline Voriconazole & $\begin{array}{l}2 \text { to }<12 \text { years or } 12-14 \text { years and }<50 \mathrm{~kg}: 8 \mathrm{mg} / \mathrm{kg} \text { every } 12 \\
\text { hours (on the first day } 9 \mathrm{mg} / \mathrm{kg} \text { ) IV or } 9 \mathrm{mg} / \mathrm{kg} \text { oral every } 12 \text { hours } \\
\geq 15 \text { years or } 12-14 \text { years and } \geq 50 \mathrm{~kg}: 4 \mathrm{mg} / \mathrm{kg} \text { every } 12 \text { hours (on } \\
\text { the first day } 6 \mathrm{mg} / \mathrm{kg} \text { ) IV or } 200 \mathrm{mg} \text { oral every } 12 \text { hours }\end{array}$ & $\begin{array}{l}\text { Important to perform serum } \\
\text { monitoring } \\
\text { (Target dosage: minimum } \\
\text { concentration } 1-5 \mathrm{mg} \mathrm{L} \text { ) }\end{array}$ \\
\hline Micafungin & $\begin{array}{c}1 \mathrm{mg} / \mathrm{kg} / \text { day (or in children } \geq 50 \mathrm{~kg} \text {, } \\
50 \mathrm{mg} \text { ) IV }\end{array}$ & $\begin{array}{l}\text { The spectrum includes Candida } \\
\text { spp and Aspergillus spp; approved } \\
\text { for prophylaxis of invasive Candida } \\
\text { infections in neutropenic patients }\end{array}$ \\
\hline $\begin{array}{l}\text { Liposomal } \\
\text { amphotericin }\end{array}$ & $1 \mathrm{mg} / \mathrm{kg}$ IV every day or $2.5 \mathrm{mg} / \mathrm{kg}$ IV 3 times a week & $\begin{array}{l}\text { Alternative option for patients who } \\
\text { do not tolerate triazoles or have } \\
\text { contraindications }\end{array}$ \\
\hline Posaconazole & $600 \mathrm{mg} /$ day oral every 8 hours in teenagers over 13 years of age & $\begin{array}{l}\text { Serum monitoring is desired. Minimum } \\
\text { concentration } \geq 0.5 \mathrm{mg} / \mathrm{L}\end{array}$ \\
\hline
\end{tabular}

\section{Diagnosis:}

- Draw blood cultures for fungi

-Neutropenic patients with $>96 \mathrm{~h}$ without focus fever, may undergo imaging (e.g., chest CT scan for possible fungal infection $)^{38}$.

- Galactomannan: is a component of the cell wall released by Aspergillus spp. Twice-weekly monitoring in children at high risk of IFI can be considered for early diagnosis of invasive aspergillosis ${ }^{38}$

\section{Empirical treatment:}

Neutropenic patients with persistent fever ( $>4$ days) of undefined cause and unresponsive to broad-spectrum antibiotics may receive empirical treatment for fungal infections and should maintain the medication until neutropenia is resolved ${ }^{38}$.

\section{Endocrine disorders, gonadal insufficiency, and fertility}

The organs involved in endocrine functions are known to be sensitive to cytotoxic drugs and radiation. Consequently, endocrine complications are among the most important in post-transplant patients, with a potential risk of reducing their survival and quality of life ${ }^{39}$. Previous treatments, type of conditioning, use of TBI and patient age are the factors that most influence late effects.

\section{Gonadal dysfunction}

Puberty disorders post-HSCT are caused by central damage to the hypothalamic-pituitary axisby $\mathrm{TBI}$, or by direct damage to gonads by irradiation or alkylating agents, such as busulfan (BU), cyclophosphamide $(C Y)$ and melphalan (MEL) $)^{39,40,41}$.

\section{Boys:}

Conditioning with cyclophosphamide only or associated with TBI seems to preserve the normal function of Leydig cells, maintaining normal serum testosterone levels. However, these patients usually have evidence of germ cell dysfunction, with increased follicle-stimulating hormone (FSH), volumetric reduction of the testicles, and reduction of spermatogenesis. There seems to be greater harm to post pubertal patients than in pre pubertal patients ${ }^{39,41}$. These patients may require treatment with gradually increased doses of testosterone to promote sexual maturity, but it should be done in collaboration with a pediatric endocrinologist. Those who have passed puberty at the time of transplant may develop primary gonadal insufficiency ${ }^{27}$.

From the age of 10 on, all children should have Tanner's development scores determined as part of an annual physical examination. Children with Tanner stage I or II at age 12 should be referred to a pediatric endocrinologist to assess the need for hormone supplementation ${ }^{27}$. 


\section{Girls:}

The use of busulfan represents a high risk of persistent ovarian failure in about $50 \%$ of the patients $^{39,42}$. As in men, the highest risk of dysfunction occurs in post-pubertal girls at the time of transplant. The protective effect of younger age seems to be due to the large number of primordial follicles in girls under 10 years ${ }^{43}$. Ovarian function recovery was observed after transplantation in 54\% of younger patients (under 26 years of age) conditioned only with cyclophosphamide. The probability of recovery of ovarian function after fractional TBI is $10 \%$ at 6 years after transplant ${ }^{27}$.

Prepubertal girls should be closely monitored for the onset of puberty and, if not occurring around 12 to 13 years, should be referred for complete endocrine evaluation and consideration of hormone supplementation ${ }^{44}$. Estrogen replacement therapy is often critical for the development of secondary sexual characteristics during the transition from adolescence to adulthood and for obtaining peak bone mass in early adulthood. Hormone replacement in prepubertal girls should be performed in collaboration with a pediatric endocrinologist ${ }^{27}$.

\section{Fertility:}

Fertility rates in patients undergoing HSCT in adolescence remain low. It is important that this be reported to patients and family members, and that forms of fertility preservation, such as cryopreservation and gonadal shield, are offered during radiotherapy ${ }^{42,45,46}$

\section{Thyroid Dysfunction}

Thyroid dysfunctions are described as common after HSCT, especially when TBI is used. Clinically, the most common manifestations are compensated subclinical hypothyroidism in 7 to $15 \%$ of patients in the first year of HSCT. Clinical hypothyroidism depends on other factors that determine its incidence: single ablative dose of TBI have a 50\% incidence; those receiving fractionated doses of TBI have an incidence of around 15\%; and patients after conditioning with $\mathrm{BU}+\mathrm{CY}$ have an $11 \%$ of incidence ${ }^{40,44}$. The mean time to diagnosis of hypothyroidism is 4 years after HSCT or exposure to TBI. When thyroid-stimulating hormone (TSH) is elevated with normal thyroxine (T4) levels, evaluation should be repeated in 2 months or therapy should be initiated at the discretion of the treating physician. Patients who initiate thyroid hormone replacement should be reassessed about 6 weeks after initiation of therapy ${ }^{44}$. In addition, thyroiditis and thyroid neoplasms may develop in patients who have received radiation. Patients should be evaluated annually with physical examination and thyroid function tests ${ }^{27}$.

\section{Growth impairment}

The growth process can be affected by a chronic disease or by toxic treatments such as HSCT. Decreased growth rate in these patients is due to the interaction of different factors, such as growth plate lesions, gonadal damage, precocious or delayed puberty, hypothyroidism and growth hormone (GH) deficiency ${ }^{45}$.

GH deficiency and growth failure (decreased growth rate/year) occur in $70-80 \%$ of children who received total body irradiation or cranial irradiation $\geq 1800$ $\mathrm{CGy}^{27,39}$. TBI with a single fraction dose of $10 \mathrm{~Gy}$ or a fractional dose of $12 \mathrm{~Gy}$ may lead to $\mathrm{GH}$ deficiency ${ }^{47}$. The onset of GH deficiency and insufficient growth varies with the age of the child at the time of irradiation. The onset of these problems seems to occur later in younger children than in peri pubertal children. All children should be monitored at least once a year, and those under 14 years of age should have an annual GH test until they develop GH deficiency or are older than 14 years of age, whichever occurs first ${ }^{27}$.

\section{Adrenal insufficiency}

The incidence of adrenal insufficiency is low in patients post-HSCT. It usually occurs by prolonged corticosteroid use, suppressing the pituitary-adrenal axis, but its function tends to gradually recover after corticosteroid suspension. When long-term corticosteroid use occurs, it is necessary to test the pituitary-adrenal axis during corticosteroid discontinuation due to the risk of acute adrenal insufficiency ${ }^{44}$. In addition, it is important to leave those responsible for the patient with a letter that guides the family and other health care professionals about the need to increase the dose of corticosteroids in stressful situations, such as febrile episodes with temperatures $\geq 38.5^{\circ} \mathrm{C}$, major trauma and surgeries. On these occasions, it is advised to double the corticosteroids dose in use for the period in which the fever lasts. When the patient cannot receive oral doses of the medication, intramuscular or intravenous hydrocortisone is indicated. For surgeries, an attack dose in the preanesthetic phase of hydrocortisone $100 \mathrm{mg} / \mathrm{m}^{2}$, IV, followed by infusion during surgery of over $100 \mathrm{mg} / \mathrm{m}^{2}$ of hydrocortisone. Of note, patients with pre-HSCT adrenal insufficiency (e.g., adrenoleukodystrophy) are also at higher risk during stress situations.

\section{Metabolic syndrome}

Metabolic syndrome, including insulin resistance, glucose intolerance, hypertension, obesity and dyslipidemia, is an important risk factor for cardiovascular disease in individuals after $\mathrm{HSCT}^{39}$. TBI can induce metabolic syndrome through effects on the hypothalamic integrity or attenuating the ability to 
develop adipose tissue to accommodate caloric excessive intake ${ }^{48}$.

Post-HSCT patients have a high risk of developing abdominal adiposity, insulin resistance (52\%), glucose intolerance (26\%), type II diabetes mellitus (17\%), dyslipidemia (26.9\%), and systemic arterial hypertension. All these items are important risk factors for the development of life-threatening cardiovascular diseases ${ }^{44,42}$.

The risk of developing type Il diabetes mellitus is three times higher in transplanted patients when compared to a control group. This risk is associated with exposure to TBI, due to changes in mitochondrial function of muscles, liver, and pancreas, resulting in insulin resistance and diabetes. The prolonged use of corticosteroids may also be implicated in this mechanism ${ }^{42,44}$. Post-HSCT patients should undergo an annual assessment of glucose and lipid metabolism, especially if there is a family history of metabolic syndrome ${ }^{39}$.

\section{Post-Transplant Lymphoproliferative Disorders}

Post-transplant lymphoproliferative disorders (PTLD) are a heterogeneous group of lymphoproliferative diseases in the setting of transplantation resulted from proliferation of neoplastic lymphoid or plasmacytic cells in the context of extrinsic immunosuppression after transplantation ${ }^{49,50}$
PTLDs in the hematopoietic stem cell transplantation (HSCT) setting are almost exclusively related to Epstein-Barr virus (EBV) infection.

The pathogenesis of PTLDs is a result of EBV-induced transformation of $B$ cells in the context of impaired anti-EBV cellular immunity due to iatrogenic IS and resulting in an outgrowth of EBV-infected B cells.

PTLDs occur usually between 3- and 6-months post-transplant, when virus-specific T cell immunity has not yet reconstituted and are generally of donor origin. Recipient-derived PTLDs have been described, but they occur mainly in patients with poor graft reconstitution.

T-PTLD after HSCT are quite rare. The frequency of T-PTLDs ranges $4-15 \%$ of all PTLD cases. EBV is present in approximately one-third of T-PTLDs. EBV-negative PTLD occurs after 5 and 10 years after SOT essentially, but it can occur after HSCT as well. These cases must be characterized as malignant lymphoma rather than PTLD and treated with appropriate chemotherapy protocols ${ }^{51}$.

The main risk factors to develop EBV-PTLD after HSCT are described in the table below.

TABLE 2: Risk Factors for the development of PTLD

Pre-transplant risk factors

EBV serology donor/recipient mismatch

Cord blood transplantation

HLA mismatch

Splenectomy

Second HSCT

Post-transplant risk factors

Severe acute (especially steroid-refractory) or chronic GvHD requiring intensive immunosuppressive therapy

High or rising EBV viral load

Treatment with mesenchymal stem cells

Legend: PTLD: post-transplant lymphoproliferative disorder; EBV: Epstein-Barr virus; HLA: Human Leukocyte Antigen; HSCT: hematopoietic stem cell transplantation; GvHD: graft-versus-host disease. 
Primary EBV infection is defined when EBV is detected (nucleic acid or serologically) in an EBV-naïve individual (most often asymptomatic acquisition, or occasionally presenting as infectious mononucleosis). Recurrent EBV DNAemia is diagnosed by detection of EBV deoxyribonucleic acid (DNA) in the blood of a previously infected individual, as defined by detection of EBV-specific lgG-antibodies ${ }^{52}$.

Fever and lymphadenopathy are the most common clinical presentation of EBV-PTLD and rare, if not treated, are associated with rapidly progressive multi-organ failure and death ${ }^{49}$.

EBV-associated disease following transplantation can be categorized as EBV-PTLD or EBV end-organ disease, according to its clinical presentation.

The clinical staging of EBV-PTLD includes: nodal versus extranodal, limited (unifocal) versus advanced (multifocal) disease. The Ann Arbor classification, established for staging of lymphoma, can also be recommended. EBV-PTLD can also be staged according to the Lugano classification by PET-CT in children and adults ${ }^{53}$.

\section{Diagnosis}

The diagnostic work-up of EBV-PTLD includes ${ }^{49}$ :

- physical examination, including an examination for fever, tonsillitis, adenopathy and organomegaly.

- Positron emission tomography (PET) - computed tomography (CT) (PET-CT) imaging.

- Endoscopy in case of gastro-intestinal symptoms

- Tissue biopsy with histological examination, including immunohistochemistry for viral antigens.

The WHO classification is most commonly used, with four types of morphological lesions being recognized: polyclonal early lesions, polymorphic, monomorphic (B-cell or T/Natural Killer [NK]-cell) and classical Hodgkin lymphoma-type PTLD ${ }^{53}$.

\section{- Peripheral blood EBV viral load by PCR.}

EBV-PTLD can be diagnosed as probable or proven. Probable EBV disease: significant lymphadenopathy, hepatosplenomegaly or other end-organ manifestations (without tissue biopsy, but in the absence of other documented cause), together with significant EBV DNAemia. Proven EBV disease: detection of EBV nucleic acids or EBV-encoded proteins in a tissue specimen, together with symptoms and/or signs from the affected organ. Detection of EBV nucleic acid in blood is not sufficient for the diagnosis of EBV PTLD.
The diagnostic approach to EBV-PTLD should, whenever is possible, be based on biopsies of lymph nodes and other sites of suspected EBV disease ${ }^{49,51,54}$

\section{Monitoring EBV DNA in blood}

Prospective monitoring of EBV DNA performed by quantitative PCR is recommended. The whole blood, plasma or serum are appropriate specimens for monitoring EBV DNAemia. Screening for EBV DNAemia should start within the first month after allo-HSCT. However, the incidence of EBV PTLD during the first month after HSCT is estimated to be below $0.2 \%{ }^{50}$. Monitoring should continue for at least 4 months after HSCT or while the patient is immunosuppressed, with a frequency of at least once a week

\section{Management strategies}

Due to the involvement of lymphoid tissue localized throughout the whole body, PTLD needs to be seen as a disseminated disease at diagnosis. Therapeutic approaches applied in the prevention and treatment of EBV-PTLD include administration of rituximab (RTX), reduction of immunosuppression, use of EBV-specific cytotoxic T-lymphocytes (CTLs), donor lymphocyte infusion (DLI), and chemotherapy. There is no antiviral drug effective against EBV so far ${ }^{49}$.

Prophylaxis: it is defined as drug or cellular therapy given to an asymptomatic EBV- seropositive patient to prevent EBV-DNAemia. The rationale for prophylactic use of RTX before or early after allo-HSCT is B-cell depletion. This strategy is only rarely administered and despite the fact that post-transplant RTX reduces the risk of EBV-DNAemia, it has not been shown to have an impact on the incidence of PTLD, transplant-related mortality (TRM), or overall survival (OS) in comparison to preemptive therapy. Therefore, this strategy should be evaluated on an individual basis, depending on transplant center expertise (European Conference on Infections in Leukemia - ECIL-6 - guidelines).

Preemptive Treatment: There is a correlation between rising or high EBV-DNAemia in blood and the development of EBV-PTLD, but it is not a rule. Usually, EBV-DNAemia occurs prior to the beginning of symptoms $\mathrm{s}^{52,55}$.

The available data does not allow the determination of a cut-off for EBV-DNA value for the diagnosis of EBV-PTLD or other end-organ EBV disease in HSCT patients. The kinetics of a rising EBV-DNAemia, together with the evaluation of the patient's immune function are very important to determine the need for preemptive therapy ${ }^{52}$. Local experience based on correlation of clinical and laboratory might be a rationale for each center. 
The primary method for preemptive therapy includes Rituximab, once weekly until blood EBV negativity. Usually, 1-2 doses of Rituximab are sufficient. If possible, Rituximab should be combined with reduction of the immunosuppression. Donor or third-party EBV-CTL is another option but it is not yet available in our country.

Therapy for EBV-PTLD: therapeutic interventions for patients with probable or proven EBV disease. The therapy should be implemented as soon as possible to prevent the risk of multi organ failure. The first line therapy in EBV-PTLD is Rituximab, $375 \mathrm{mg} / \mathrm{m}^{2}$, once weekly for 1 to 4 doses. Reduce the immunosuppressive therapy combined with rituximab must always be considered, if possible ${ }^{56,57 .}$. Cellular therapy as adoptive immunotherapy with in vitro generated donor or third-party EBV-specific CTL, if available ${ }^{59}$.

Second line therapy in EBV-PTLD includes: cellular therapy (EBV-specific-CTLs or DLI) ${ }^{49,54}$. Chemotherapy \pm RTX is a potential option after failure of other methods. The treatment goal is resolution of all signs and symptoms of PTLD, including a negative viral load. Response to rituximab therapy can be identified by a decrease in EBV DNAemia of at least $1 \log 10$ in the first week of treatment.

Administration of RTX results in a positive outcome for over $90 \%$ of patients treated preemptively and over $65 \%$ when it is used as targeted therapy for EBV-PTLD. The use of EBV-CTLs achieves $>90 \%$ of patients treated preemptively and approximately $75 \%$ in therapy of established EBV-PTLD ${ }^{59}$.

\section{Central Nervous System (CNS) PTLD}

CNS PTLD is a particular presentation of the disease because it implicates risk of serious neurological consequences even in case of successful treatment. The current recommendations for treatment of CNS PTLD are extrapolated from the experience with Primary Central System Lymphoma ${ }^{54}$.

Possible therapeutic options include RTX, systemic and/or intrathecal (IT) dose of RTX: 10-30 mg in 3-10 $\mathrm{mL}$ saline administered weekly). T-cell therapy with EBV-CTLs. Radiotherapy. Chemotherapy \pm RTX according to primary CNS lymphoma protocols51

\section{IRON OVERLOAD AFTER TRANSPLANT - DIAGNOSIS, EVALUATION AND MANAGEMENT}

Iron overload/toxicity is an inevitable effect in several diseases characterized by anemia and red blood cell transfusion requirement.
After transplant has reestablished normal hematopoiesis and red cell transfusions are no longer necessary, body iron stores decline over several years ${ }^{60}$. Some patients will be affected by the already acquired iron overload that cannot be eliminated without active intervention even if they're free from transfusions. In this condition the acquired intracellular iron overload continues to disrupt the delicate labile cellular iron (LCI) equilibrium and promotes reactive oxygen species (ROS) generation.

Elevated ferritin estimates $32-58 \%$ of HSCT survivors may be overloaded with iron ${ }^{61}$. It has been also demonstrated in transplanted thalassemia patients that elevated transferrin saturation persists indefinitely without treatment and liver disease progresses even in the absence of other comorbidities ${ }^{62}$.

High liver iron content (above $7 \mathrm{mg} / \mathrm{g}$ ) and ferritin above $1,000 \mathrm{ng} / \mathrm{mL}$ has been associated with decreased survival (Extreme tissue iron overload $(>15$ $\mathrm{mg} / \mathrm{g}$ dry weight) has been associated with extensive organ toxicity in the post-transplant survivors of thalassemia ${ }^{62}$.

\section{Evaluation of iron overload post-HSCT}

Although ferritin measurement is recommended as part of long-term follow-up post-HSCT, it also changes with inflammation and cell injury. Assessment of body iron by MRI is noninvasive and has been calibrated with liver biopsies and ex vivo heart tissue iron measurements, allowing accurate and more frequent assessment of iron overload than liver biopsy $^{63}$. Liver or marrow iron content correlates poorly with the number of transfused red blood cell units.

We recommend iron studies - ferritin, iron, total iron-binding capacity and transferrin saturation at the following timepoints: 100 days, 6 months and 1 year post HSCT and at least yearly if still receiving red blood cell transfusions.

We highlight that biochemical laboratory tests are non-specific and can be very affected by inflammation, infection (elevated ferritin and decreased transferrin saturation) and graft versus host disease (increased iron absorption). So, they should not be used as sole criteria to consider the presence of iron overload that will be confirmed by $T 2{ }^{*}$-weighted MRI $\left(\mathrm{MRI}-\mathrm{T}^{*}\right)^{63}$.

\section{Assessment of tissue iron}

MRI-T2* is highly accurate in measuring tissue iron. It's mainly used to determine iron in the heart and liver but can also evaluate the spleen and pancreas ${ }^{64}$. 
MRI-T2* is the preferred method of evaluation and requires orders for both cardiac and abdominal MRI, specifying the exam is for iron evaluation. All patients should undergo MRI-T2* when being evaluated for iron overload, because of lack of correlations between liver iron concentration (LIC) and laboratory tests.

If the MRI-T2* is not available for all patients, is very recommend for patients that will meet one or more classic criteria used to indicate evaluation of iron overload, listed below:

- Lifetime history of receiving 10 red blood cell (RBC) units or more;

- Transferrin saturation $>45 \%$;

- Ferritin >1000ng/mL;

- Prior iron chelation therapy.

Patients that will need to undergo MRI-T2* to rule out cardiac iron overload during their long term follow up are those with risk factors such as lifetime history of receiving $75 \mathrm{RBC}$ units or more; diagnosis of thalassemia, sickle cell disease and other congenital anemias (Diamond-Blackfan anemia; hereditary sideroblastic anemia).

Endocrine screen - patients with detectable cardiac iron $\left(\mathrm{T}^{*}<20 \mathrm{~ms}\right)$ may benefit from earlier endocrine gland abnormalities screen with fasting glucose,
$\mathrm{TSH}$, free thyroxine (FT4), parathyroid hormone (PTH), FSH, and luteinizing hormone (LH).

Transient elastography - can be ordered if liver fibrosis or cirrhosis is a concern.

Liver biopsy - procedure very risky and should be an exception to be discussed case-by- case.

\section{MANAGEMENT OF IRON OVERLOAD POST-HSCT}

Phlebotomy is the preferred mechanism to remove excess iron after HSCT because normal erythropoiesis is achieved by transplantation. Phlebotomy can be started once engraftment is sustained. The general phlebotomy protocol consists of $6 \mathrm{~mL} / \mathrm{kg}$ of blood removed every 14 days for thalassemic patients, as tolerated. This procedure should not be performed in patients younger than 11 years if hemoglobin is $<9.5 \mathrm{~g} / \mathrm{dL}^{65}$.

For other patients, $5 \mathrm{ml} / \mathrm{Kg}$, as tolerated, can be withdrawn every 3 or 4 weeks. Do not perform phlebotomy if hematocrit $<35 \%$. It can be discontinued if ferritin below $500 \mathrm{ng} / \mathrm{ml}$ or ferritin below $100 \mathrm{ng} / \mathrm{mL}$ for hemoglobinopathy patients. No maintenance therapy is required. The duration of treatment ranges from a few months to several years ${ }^{65}$.

Table 3 depicts the established indications for removal of excess tissue iron.

TABLE 3: Indications for Iron Excess Therapy by Tissue Iron Content

\begin{tabular}{c|c|c|c}
\hline Cardiac T2* $(\mathrm{ms})$ & $\begin{array}{c}\text { LIC } \\
\text { (mg/g dry weight })\end{array}$ & Marrow Iron Content & Mobilization of Iron \\
\hline$>20 \mathrm{~ms}$ & $>15$ & Very high & $\begin{array}{c}\text { Phlebotomy } \pm \\
\text { Single iron chelator }\end{array}$ \\
\hline & $7-15$ & Moderately high & $\begin{array}{r}\text { 1st choice: Phlebotomy } \\
\text { 2nd choice: Single iron chelator }\end{array}$ \\
\hline$<20 \mathrm{~ms}$ & Any & Any & $\begin{array}{r}\text { Phlebotomy + combination iron chelation; Consider } \\
\text { admission if symptomatic or T2* } \\
\text { Erythrocytapheresis for faster removal }\end{array}$ \\
\hline
\end{tabular}

Legend: LIC: liver iron concentration: $\mathbf{T} \mathbf{2}^{*}: \mathbf{T 2}$-weighted magnetic resonance imaging.

\section{CHELATION THERAPY FOR IRON OVERLOAD AFTER HSCT}

If phlebotomy cannot be performed in patients with high iron levels who cannot be treated with phlebotomies, daily subcutaneous administration of deferoxamine can successfully reduce iron stores ${ }^{66,67}$. Two oral iron chelators, deferiprone and deferasirox, have been used in iron-overload patients, but only deferasirox has been tested after transplantation ${ }^{65}$.

Desferal or deferasirox (DFX) starting dose is $20 \mathrm{mg} /$ $\mathrm{kg} /$ day. The dose modification is $5-10 \mathrm{mg} / \mathrm{kg} /$ day increments every 3-6 months if necessary, depending on serum ferritin (maximum $40 \mathrm{mg} / \mathrm{kg} /$ day).

In table 4, we summarize the pros and cons of each therapeutic modality ${ }^{68}$. 
Table 4: Selecting the appropriate post-HSCT iron removal modality

\begin{tabular}{|c|c|c|}
\hline & Phlebotomy & Oral Chelation \\
\hline Strengths & $\begin{array}{c}\text { - Efficient } \\
- \text { Safe } \\
- \text { Inexpensive } \\
\text { - Permits complete iron removal and } \\
\text { normalizes iron body content }\end{array}$ & $\begin{array}{c}\text { - Efficient } \\
- \text { Safe } \\
\text {-Expensive } \\
\text { - Immediate effect on cellular injury } \\
\text { - Hospital access not required }\end{array}$ \\
\hline Weaknesses & $\begin{array}{c}\text { - Requires sustained engraftment } \\
\text { - Immediate effect on cellular injury still remains to be } \\
\text { verified } \\
\text { - Hospital access required } \\
\text { - Venous access is required }\end{array}$ & $\begin{array}{l}\text { - Warning of renal toxicity in the case of } \\
\text { concomitant use of cyclosporine A } \\
\text { - Possible increase in toxicity for low level } \\
\text { of iron burden }\end{array}$ \\
\hline
\end{tabular}

Considering the results of epidemiologic studies in thalassemia and in the normal population in the post-transplant setting, we must consider our goal for iron overload treatment a normal iron level and a normal transferrin saturation ${ }^{62}$.

\section{HEPATOBILIARY AND GASTROINTESTINAL COMPLICATIONS}

\section{Hepatobiliary Complications}

Elevations of serum alanine aminotransferase (ALT), alkaline phosphatase, or bilirubin may occur after day 100, even in children who had signs of liver problems earlier.

The possible presentations drive to four clinical categories $^{69}$ :

-Acute hepatitis: Elevations of serum ALT after day 100 are most caused by drug-induced liver injury (antifungal azoles and sulfamethoxazole/trimethoprim are the most common causes of drug induced liver injury after HSCT in both children or adults), chronic GVHD, an exacerbation of hepatitis B or C, or a herpesvirus hepatitis (VZV, herpes virus simplex - HSV).

It's important to note that some clinical situations demand immediate diagnosis and treatment, such as rapidly rising ALT accompanied by anorexia, abdominal distension, or pain in the abdomen or back, which can suggest visceral VZV infection.

Patients who have indications of hepatitis $B$ before transplant (HBsAg-positive or anti-HBc-positive) or who had a donor who was infected with hepatitis $B$ are at risk of fulminant hepatitis B after the transplant if they did not receive antiviral prophylaxis.
Chronic GVHD can present as an acute hepatitis, usually after tapering or discontinuation of immunosuppressive medications, particularly cyclosporine or tacrolimus, or after $\mathrm{DLI}^{70}$.

It's recommended to give IV acyclovir until VZV hepatitis is excluded for patients with a rapidly rising ALT and those with ALT values $>500 \mathrm{u} / \mathrm{L}$. A PCR for VZV DNA in serum is needed to establish the diagnosis.

-Chronic hepatitis: chronic fluctuations in serum ALT levels without a discrete episode of acute hepatitis may represent drug induced liver injury, hepatitis $B$ or $C$ virus infection, iron overload or chronic GVHD.

-Jaundice / cholestasis: elevated serum bilirubin and elevated alkaline phosphatase can be caused by chronic GVHD, drug-induced cholestasis, acute hepatitis, or biliary obstruction. An ultrasound can evaluate whether the common bile duct is dilated. Some patients have liver involvement as the dominant manifestation of chronic GVHD, and liver biopsy might be needed in order to establish the diagnosis when other manifestations of chronic GVHD are absent, otherwise liver biopsy is not recommended.

- Hepatomegaly or right upper quadrant pain: The sudden beginning of hepatomegaly suggests acute hepatitis, EBV-induced PTLD involving the liver, or in a few cases, Budd-Chiari syndrome.

For indolent hepatomegaly, the differential diagnosis includes metastatic tumor, leukemia infiltration and even constrictive pericarditis or mycobacterial infection (very rare).

Right upper quadrant pain can be caused by acute cholecystitis, biliary obstruction with cholangitis, or fungal liver abscess in rare cases. 
For these signs / symptoms a liver imaging with helical CT X-ray or ultrasound would resolve the diagnosis. Liver biopsy and its technique depend on the clinical situation (diffuse process vs. focal lesion) and the platelet count.

An additional, much less common, late effect is the development of focal nodular hyperplasia. MRI is diagnostic and usually no surgical intervention is required. Routine surveillance is necessary because the risk of malignant transformation is unknown.

\section{Gastrointestinal complications:}

Gastrointestinal complications including graft-versus-host disease (GVHD) can cause high morbidity and mortality in HSCT recipients.

Late posttransplant complications appear after day 100. By this time, recovery of cellular immunity is, generally, complete. The most common complications during this period are chronic GVHD, PTLD, and secondary tumors and tumor recurrence. Late effects can also include toxicity from the treatment regimen, infections resulting from immunodeficien$c y$, endocrine disturbances, growth impairment, and psychosocial adjustment disorders ${ }^{71}$.

GVHD is the most common cause of anorexia, nausea, vomiting and diarrhea after an allogeneic transplant. However, each of these symptoms has a precise differential diagnosis that requires accurate evaluation before concluding that GVHD is the exclusive cause.

Anorexia, nausea and vomiting can be caused by HSV, VZV, and CMV infections and by certain medications such as trimethoprim-sulfamethoxazole, voriconazole, itraconazole, mycophenolate mofetil, cyclosporine or tacrolimus.

Abdominal pain can be caused by visceral VZV infection, biliary sludge syndrome, acute cholecystitis, or rarely, EBV-induced PTLD. Diarrhea occurring more than 3 months after transplant is commonly caused by magnesium - containing medications, unresolved GVHD, or less commonly by an infection (giardiasis, cryptosporidiosis, Clostridium difficile, and others) ${ }^{72}$.

Clinically, chronic GVHD resembles autoimmune collagen disorders, with esophageal, and salivary gland changes, as well as anorexia and weight loss. Nowadays, chronic GVHD is defined as the presence of these features regardless of the time of onset ${ }^{73}$. Gastrointestinal GVHD often runs its course without demonstrating imaging findings, but strictures of the esophagus or small or large bowel are observed in some cases.
Long-term gastrointestinal complications have not been very reported outside of the chronic GVHD context. There are no known long-term effects on the gastrointestinal lumen or mucosa after acute GVHD has been successfully treated.

\section{Neurological complications}

Neurological complications are serious and significantly contribute to morbidity and mortality in children and adults experiencing allogeneic or autologous HSCT.

Approximately $11-59 \%$ of patients who undergo HSCT suffer from neurologic complications ${ }^{74}$ and more than $90 \%$ of the cases who die after HSCT show neuropathological abnormalities in autopsy studies $^{75}$.

Various factors, including underlying disease, the pre-transplant conditioning regimen with high-dose chemotherapy, radiation therapy, vascular complications generated by thrombocytopenia and/or coagulopathy, immunosuppressive therapy, GVHD, infection and disease recurrences, are associated with neurotoxicity ${ }^{76}$.

In many previous studies, GVHD has been identified as a risk factor for neurologic sequelae $\mathrm{e}^{77,78,79,80,81}$ and the prognosis of CNS GVHD is alleged to be very poor $^{82}$. In addition to CNS GVHD, CNS infections and thrombotic microangiopathy (TMA)-associated neurological events can be frequent following the increased use of calcineurin inhibitors (CNIs) and corticosteroids in patients with GVHD ${ }^{82}$

Regarding infectious complications, cerebral aspergillosis and toxoplasmosis after unrelated allo-HSCT are a major challenge associated with a high mortality. Infection caused by varicella zoster is also reported after 1 year of transplant and can lead to a fatal outcome. If the patient presents progressive neurological symptoms after HSCT, the situation requires prompt diagnostic procedures and initiation of antimicrobial therapy if any findings suggestive of CNS infection were seen.

In the late phase ( $\geq 6$ months) after HSCT the possible neurologic complications are CNS relapses of the original disease, neurologic complications of GVHD and second neoplasms.

Neurological manifestations of chronic GVHD are rare and can affect both peripheral and central nervous system. They usually occur several months to years after HSCT after administration of multiple 
potentially neurotoxic drugs, when often infectious and metabolic complications have occurred.

Manifestations of peripheral nervous system, neuromuscular junction and muscle involvement in GVHD include polymyositis, myasthenia gravis (MG) and chronic inflammatory demyelinating polyneuropathy (CIDP) often developing late after HSCT at a time of reduction in immunosuppressive therapy ${ }^{82}$.

MG is rarely reported post-HSCT in children and has a severe clinical presentation ${ }^{83,84}$ which could be controlled only after several lines of treatment including plasma exchange and RTX.

Recent studies analyzing cohorts with a high number of pediatric recipients of HSCT showed increased risk of second neoplasms (SN) among all primary childhood cancer cases ${ }^{85}$. When compared to the general population, the overall standardized incidence ratio of developing SNs was 6.4 with an estimated 30-year cumulative incidence of $9.3 \%$. Radiation has been shown to increase the risk of SNs. Allogeneic hematopoietic stem cell transplantation also increases the risk for SNs in children ${ }^{85}$. The types of tumors reported were neuroblastoma (39\%), lymphoma (26\%), sarcoma (18\%), CNS tumors (14\%) and Wilms tumor (2\%) after a median follow-up of 8 years.

There is also an important concern about cognitive impairment due to total body irradiation, GVHD treatments, and cytotoxic agents ${ }^{86}$. Some children, especially those given cranial irradiation before the transplant, may have learning disabilities. These abnormalities typically begin to appear 24-42 months after the transplant and if it is recognized as a problem, we must refer for psychological testing and special educational instruction should be considered for these children.

TBI can delay the onset of developmental landmarks in very young children. These effects are most severe throughout the first year after transplant, and affected children benefit from occupational therapy to assist their normal development. After they have achieved appropriate developmental landmarks, further development appears to proceed normally. Intelligence quotient (IQ) and ability to succeed in school do not appear to be affected by TBI. However, the issue of cognitive impairment after HCT was not so much studied in pediatric patients.
Neurologic complications commonly occur in pediatric HSCT recipients. Major significant risk factors for mortality in pediatric recipients with neurologic complication were the existence of neurologic sequelae and extensive chronic GVHD.

In generally, clinical symptomatology is highly unspecific, and does not allow for any prediction on the later clinical course. So, a comprehensive diagnostic work-up is recommended in any patient presenting with neurological symptoms. Cerebral imaging and lumbar puncture have a great diagnostic value. In many cases, imaging studies are only able to provide useful information at advanced disease stages. Hence, early presumptive treatment is clearly warranted in order to prevent a fatal outcome.

\section{Chronic pulmonary complications:}

Late pulmonary complications in patients who have undergone bone marrow transplantation may involve both the airways and the pulmonary parenchyma. These complications can be infectious and non-infectious. The most common late noninfectious complications are obliterating bronchiolitis, or bronchiolitis obliterans (BO), obliterating bronchiolitis with organizing pneumonia (BOOP), and idiopathic pneumonia syndrome (IPS) ${ }^{87,88,89}$. BOOP/COP was also called cryptogenic organizing pneumonia (COP) in order to avoid confusion with airway diseases, such as $\mathrm{BO}^{90}$. These late pulmonary complications usually appear within 3 months to 2 years after HSCT. However, the functional consequences often persist for years after $\mathrm{HSCT}^{88}$. Patients undergoing allogeneic bone marrow transplants have higher risks than those who underwent autologous $\mathrm{HSCT}^{88}$. It is also uncommon for these complications to appear after 3 months of HSCT, in recipients of autologous bone marrow transplants ${ }^{88}$. Predisposing factors may include infections, extent and type of chemotherapy and radiation pre-transplant and in the conditioning regimen and GVHD ${ }^{91}$. Patients with chronic GVHD have a higher incidence of late pulmonary complications ${ }^{88}$. Overall survival is worse in patients with pulmonary complications, with significantly higher mortality and morbidity when compared to patients without pulmonary complications $^{88}$. Table 5 illustrates some clinical manifestations, risk factors and interventions to be considered in patients with late pulmonary complications after bone marrow transplantation ${ }^{88}$. 
TABLE 5. Clinical manifestations, risk factors and interventions of late pulmonary complications after $\mathrm{HSCT}^{88}$

\begin{tabular}{llll} 
Organ & Clinical manifestation & Risk factors & Intervention \\
\hline Respiratory tract & Bronchiolitis obliterans & Graft-vs-host disease (GVHD) & Treatment of infection \\
& Bronchiolitis obliterans & Infection & GVHD treatment \\
& organizing pneumonia & Smoking & Fractionated radiotherapy \\
& Restrictive lung disease & Radiotherapy & Steroids \\
& & Chemotherapy & Consider lung transplantation
\end{tabular}

Adapted from: Tichelli A, 2008.

Abnormalities in gas transfer, such as restrictive and obstructive ventilatory defects are common in patients after HSCT. A decrease in forced expiratory volume in 1 second (FEV1) and the FEV1/ forced vital capacity (FVC) ratio is the hallmark of airflow obstruction $^{88}$. Restrictive defects are measured by the total lung capacity and may be associated with impaired diffusing capacity for carbon monoxide $(\text { DLCO })^{88}$. Having evidence of abnormal pulmonary function pre HSCT and chronic GVHD are independent factors of worsening of pulmonary function in the period after $\mathrm{HSCT}^{88}$.

A significant proportion of children have abnormal pulmonary function tests (PFTs) after $\mathrm{HSCT}^{92}$. These alterations are mainly DLCO and total lung capacity, implying restrictive lung disease and diffusion abnormalities; obstructive abnormalities are less frequent in children ${ }^{92}$. In a prospective study of the Late Effects Working Party of the European Society for Blood and Marrow Transplantation (EBMT), the cumulative incidence of PFT alteration in 162 children was $35 \%$ in 5 years, and in most cases pulmonary function deterioration was asymptomatic. The presence of chronic GVHD was the risk factor most involved in this context ${ }^{93}$.

IPS, also known as interstitial pneumonitis, is more common in the early post-transplant period. However, it can occur in long-term survivors and may lead to delayed respiratory failure. Predisposing factors include allogeneic HSCT, exposure to high doses of TBI and GVHD. Patients with extensive chronic GVHD, especially sclerodermoid skin GVHD, have a higher risk of presenting to IPS ${ }^{94}$. Immune compromise delays recovery from infection, allowing greater damage to the lung interstitium ${ }^{91}$. Certain chemotherapy agents (e.g., carmustine, bleomycin, $\mathrm{BU}$, methotrexate) can cause lung toxicity directly or may increase the damaging effects of radiation ${ }^{91}$. Fractionation of irradiation and protection of the lung may decrease irradiation toxicity ${ }^{91}$. Prophylaxis strategies focus on decreasing the risks of infections
post-HSCT, especially in patients with chronic GVHD. The clinical presentation and radiological findings of IPS are nonspecific and do not differ from infectious pneumonia. PFTs show a restrictive pattern, such as decreased total lung capacity and DLCO, with normal FEV1 ${ }^{88}$

$\mathrm{BO}$ is a severe pulmonary manifestation characterized by a nonspecific inflammatory lesion affecting mainly the small airways. In the initial phase it is typically an obstructive disease, but at a more advanced stage, due to progressive peribronchiolar fibrosis, often presents obstructive and restrictive functional changes $^{88}$.

BO occurs in 2-14\% of allo-HSCT recipients and is almost exclusively seen in patients with chronic GVHD, for which it is classified by several authors as pulmonary GVHD ${ }^{73,95,96,97}$. However, BO may arise in patients without any other GVHD manifestation ${ }^{91}$. In such cases, it may be characterized by a new obstructive pulmonary defect, manifested clinically as stress dyspnea, cough or wheezing. Patients may be asymptomatic at the beginning of the disease process. $\mathrm{BO}$ is clinically diagnosed when all of the following criteria described above present together with active GVHD in at least one organ other than the lung: (1) relationship between FEV1 and FVC - FEV1/FVC < 0.7 and FEV $1<75 \%$ of predicted FEV1, (2) evidence of air trapping or small airway thickening or bronchiectasis on high-resolution chest $\mathrm{CT}$, residual volume $>120 \%$, or pathological confirmation of constrictive bronchiolitis and (3) absence of infection in the respiratory tract, documented with investigations (e.g., bronchoalveolar lavage) directed by clinical symptoms. Some experts consider a decrease in FEV1 of $10 \%$ or more over the baseline pre-transplant as a diagnostic criterion for obliterating bronchiolitis or an indication to perform a PFT more frequent$\mid \mathrm{l}^{73,95}$. Treatment of BO includes immunosuppressive agents, such as corticosteroids, CNIs, sirolimus, among others (see chronic GVHD section) ${ }^{98,99}$. Early diagnosis and prompt immunosuppressant treat- 
ment may contribute to a more favorable response. Inhaled corticosteroids with bronchodilator showed benefits in the treatment of $\mathrm{BO}^{100-101}$. A prospective, multicenter study showed that the addition of FAM (inhaled fluticasone propionate, azithromycin and montelucaste) together with prednisone stabilized pulmonary function in $70 \%$ of newly diagnosed patients with $\mathrm{BO}$ and also allowed the reduction of systemic corticosteroids ${ }^{102}$. Prevention of Pneumocystis jirovecii pneumonia and the early treatment of superinfection is an important treatment strategy ${ }^{88}$. However, prognosis of patients with BO remains poor and 5-year survival rates are $<20 \%$ if patients do not respond to initial treatment ${ }^{96,97}$. In most cases, death is attributed to progressive respiratory failure or opportunistic infections ${ }^{88}$.

It is important to emphasize that infants and young children are not able to perform pulmonary function tests. In these cases, the evaluation of $\mathrm{BO}$ will have to be done exclusively by a CT of the chest without contrast to evaluate the areas of air trapping during the expiratory phase of the examination. Depending on the age the children will not be able to coordinate the expiration during the CT scan and in these cases, images can be performed in right and left lateral decubitus, being possible to evaluate the lung that is below, which will be expired. Pulmonary lobules with normal airways increase their density during expiration, while areas with obstructed airways and air trapping remain radiolucent. This provides a characteristic mosaic image that is highly suggestive of obliterating bronchiolitis ${ }^{103-105}$. When no air trapping is seen on expiratory chest tomography, the diagnosis of $\mathrm{BO}$ is very unlikely.

COP, previously known as BOOP, is a clinicopathological syndrome that involves the bronchioles, alveolar ducts and the alveoli and is the result of a variety of toxic, immunological or inflammatory injuries to the lungs. COP presents typically in the first 6 to 12 months after transplantation, although a late onset may occur, mainly in patients with chronic GVHD ${ }^{91}$. Clinical presentation includes nonproductive cough, low grade fever, and dyspnea. Radiological imaging may reveal areas of consolidation with ground glass or nodular infiltrates. In contrast to $\mathrm{BO}$, the pulmonary function tests typically show a restrictive pattern, with decreased total lung capacity and normal DLCO and FEV1 ${ }^{103,106}$. Bronchoscopy with bronchoalveolar washes is useful to rule out pulmonary infection. Biopsy may be required to confirm the diagnosis of COP. The mainstay of treatment is based on corticosteroids, and recovery is expected in $80 \%$ of patients, but relapses are common if steroids are rapidly tapered ${ }^{88,91}$. This complication is rare after transplantation and no specific screening tests are available for early diagnosis and prevention ${ }^{91}$.

Recurrent sino-pulmonary infections may occur in patients with delayed immune reconstitution and chronic GVHD. Appropriate vaccination is recommended, and in patients with ongoing immune deficiency and infections, monitoring of immune globulin levels and replacement therapy should be considered according to indication ${ }^{91}$. Given the high risk of pulmonary infections in patients with a history of toxic lung therapy, especially in patients who have received mediastinal radiotherapy, it is very important to carry out the vaccination schedule with three doses of the pneumococcal conjugated vaccine and a dose of the pneumococcal polysaccharide vaccine 23 (Pneumo 23) ${ }^{107}$. It is also worth mentioning that the influenza vaccine should be applied annually ${ }^{107}$.

Other rare late complications involving the lungs include diffuse alveolar hemorrhage, pulmonary thromboembolism, pulmonary hypertension, pulmonary veno-occlusive disease (VOD), and pleural effusions ${ }^{91}$. The most common causes of pulmonary hypertension are pulmonary arterial hypertension and pulmonary VOD, which is sometimes related to thrombotic microangiopathy associated with bone marrow transplantation ${ }^{108,109}$.

Children who receive total body irradiation are at risk of having restrictive lung disease 5 to 20 years after bone marrow transplantation ${ }^{91}$. Therefore, all patients who underwent transplantation in the pediatric age group should perform pulmonary function tests annually, regardless of whether or not they have respiratory symptoms.

Changes in the values of pulmonary function tests usually precede symptomatology, which makes periodic evaluation with spirometry and/or chest tomography an indispensable monitoring for the follow-up of these patients. The earlier the diagnosis, the lower the impairment of pulmonary function and the better is the prognosis ${ }^{110}$. Childrenin particular may not report initial and frustrated respiratory symptoms, hence the importance of performing the tests in search of possible incipient chronic pulmonary complications.

One study showed a significant decline in FEV1 during the six months prior to the diagnosis of $\mathrm{BO}$, with a lower FEV1 at diagnosis associated with worse surviv$\mathrm{al}^{111}$. Some centers perform pulmonary function tests every three months in patients with active chronic GVHD ${ }^{111}$. When the test shows a significant new obstruction of airflow, it can repeat pulmonary function tests monthly until a stabilization of the patient ${ }^{112,113}$. 


\section{Recommendations $^{9}$}

Routine clinical evaluation by history and physical exam for pulmonary complications is recommended for all patients in D+100, at six months, one year and, yearly thereafter.

Perform clinical evaluations with earlier and more frequent clinic assessments including pulmonary function tests in patients with chronic GVHD. Perform every three months in the first year of diagnosis of chronic GVHD; every six months in the second year and then space according to the evolution of the patient.

\section{Advise and encourage adolescents not to smoke.}

In patients with signs or symptoms of lung compromise pulmonary function test and specific radiological assessment should be performed as clinically indicated. Follow-up evaluations should be guided according to the patient's clinical evolution.

\section{Long-term cardiovascular complications:}

Compared to other post-HSCT complications, the incidence of late cardiovascular effects is lower. However, as cure rates and follow-up times increase, their incidence tends to increase ${ }^{114}$, reaching up to $17 \%$ of patients 15 years after $\mathrm{HSCT}^{115}$. Early complications are related to the disease and its treatment before HSCT, age, type of transplantation and comorbidities. Late complications, up to decades after HSCT, are associated with cardiotoxic chemotherapy used, mainly with the use of cyclophosphamide in the conditioning regimen, mediastinal irradiation, gender, age at HSCT, presence of GVHD and classical cardiovascular risk factors ${ }^{114}$. Late cardiovascular complications occur most commonly after allogeneic HSCT, suggesting an immunological role in the development of atherosclerosis ${ }^{114}$. Endothelial injury may result from persistent vascular inflammation and death of endothelial cells caused by GVHD, leading to atherosclerosis and cardiovascular complications ${ }^{114}$. Cardiac GVHD is very rare and may have pericardial effusion, dysrhythmia (mainly bradycardia), coronary heart disease, and cardiomyolysis ${ }^{116,117}$.

Cardiovascular events after HSCT occur in patients younger than in the general population and are mainly cerebrovascular diseases (stroke, transient ischemic attack, carotid occlusion, and symptomatic lacunar infarctions) and coronary diseases (myocardial infarction, cardiac arteriosclerotic disease, and angina) ${ }^{118}$.

In addition to the usual risk factors (smoking, hypertension, obesity, diabetes, dyslipidemia, and sedentary lifestyle), HSCT recipients have additional risks such as total body irradiation, endothelial damage caused by chemotherapy, GVHD, infectious complications, prolonged use of corticosteroids and other immunosuppressive medications ${ }^{119,120}$.

The prevalence of endocrine factors that increase the chance of cardiovascular complications, such as insulin resistance, glucose intolerance, type 2 diabetes, hypertriglyceridemia and central obesity, are increased in HSCT recipients, even in young people with adequate weight, as a result of prolonged immunosuppressive therapies, exposure to radiotherapy or other frequent complications such as growth hormone deficiency and hypothyroidism ${ }^{114,118,121}$.

In HSCT recipients, the risk of developing cardiovascular complications is five times higher and of dying from cardiac causes is two to four times higher than in the general population ${ }^{118}$. Cardiovascular events are the second cause of late death in some series, second only to recurrence of neoplastic disease ${ }^{118}$.

It is worth mentioning the importance of recognizing that metabolic syndrome, including systemic arterial hypertension, dyslipidemia and diabetes has a high prevalence in patients who have undergone HSCT and this condition is associated with a higher incidence of premature coronary heart disease ${ }^{122}$.

Iron deposition in the myocardium, due to multiple transfusions, may persist for years after $\mathrm{HSCT}^{114,123}$. Therefore, it is essential that patients with elevated ferritin undergo therapy to remove excess iron from the body through regular phlebotomy (therapeutic bleeding) or iron chelators.

Publications of late cardiac complications in transplanted children are rare ${ }^{124}$. In a prospective European multicenter study, the incidence of cardiac damage at five years was $26 \%$ in 119 children undergoing allogeneic HSCT. The use of total body irradiation and anthracycline in chemotherapy before HSCT significantly worsened cardiac function ${ }^{125}$. Another study showed that the children/adolescents most susceptible to cardiac complications were those submitted to unrelated allogeneic HSCT, total body irradiation and chronic GVHD in activity ${ }^{119}$.

As endothelial injury caused by atherosclerosis occurs years before cardiovascular disease ${ }^{118}$, the identification of indirect signs of atherosclerosis after HSCT is extremely important, with the potential to benefit children, improving their survival and quality of life ${ }^{126}$. The increased incidence of cardiovascular events after allogeneic HSCT supports the hypothesis that GVHD may be involved in the process, since in GVHD there is endothelium injury that may be re- 
sponsible for atherosclerotic changes and lead to post-HSCT cardiovascular events. Because of the long latency period between the initial vascular lesion and the cardiovascular clinical manifestation, complications appear only decades after bone marrow transplantation, emerging as a very late event ${ }^{127}$.

FIGURE 1: Diagram of the hypothetical atherosclerotic process occurring in long-term HSCT survivors leading eventually to a therapy-related cardiovascular event ${ }^{128}$

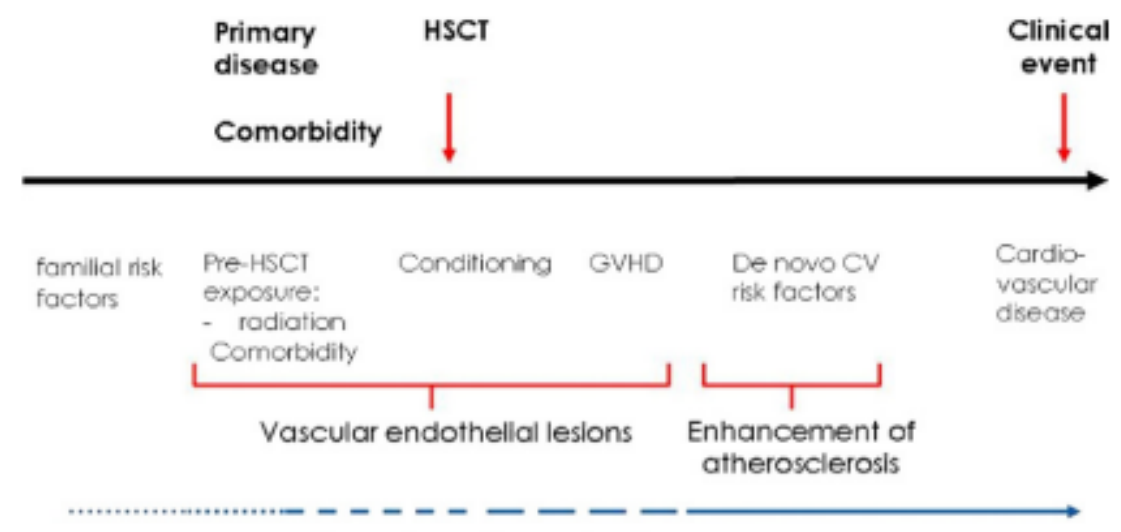

Premature atherosclerotic process

Legend: HSCT: hematopoietic stem cell transplantation. GVDH: graft-versus-host disease; CV: cardiovascular. Adapted from: Rovó A, $2012^{128}$.

Figure 2 illustrates pulmonary, renal, and cardiac complications according to the time elapsed after HSCT, such as delayed events when they occur 3 months to 2 years after transplantation; late events, which occur from 2 years to 10 years after HSCT and very late events when they occur after 10 years of transplantation ${ }^{127}$. Cardiac complications will occur decades after treatment as very late events and many patients may develop asymptomatic cardiac dysfunction. Therefore, the real magnitude of the risk of cardiac events after HSCT will actually only be measured over the course of years ${ }^{127}$.

Thus, as cardiovascular complications can occur after several years of bone marrow transplantation, cardiovascular follow-up should be performed throughout the patient's life, with the involvement of multidisciplinary teams (cardiologist, endocrinologist, pediatric oncologist, nutritionist, among others), in an attempt to detect early and intervene in the lifestyle of these patients to prevent cardiovascular effects.

FIGURE 2. Sequence of appearance of pulmonary, cardiac, cardiovascular, and renal complications after HSCT and main corresponding risk factors. Late complications are subdivided into delayed events (between 3 months and 2 years), late events (between 2 and 10 years), and very late events (> 10 years) ${ }^{127}$

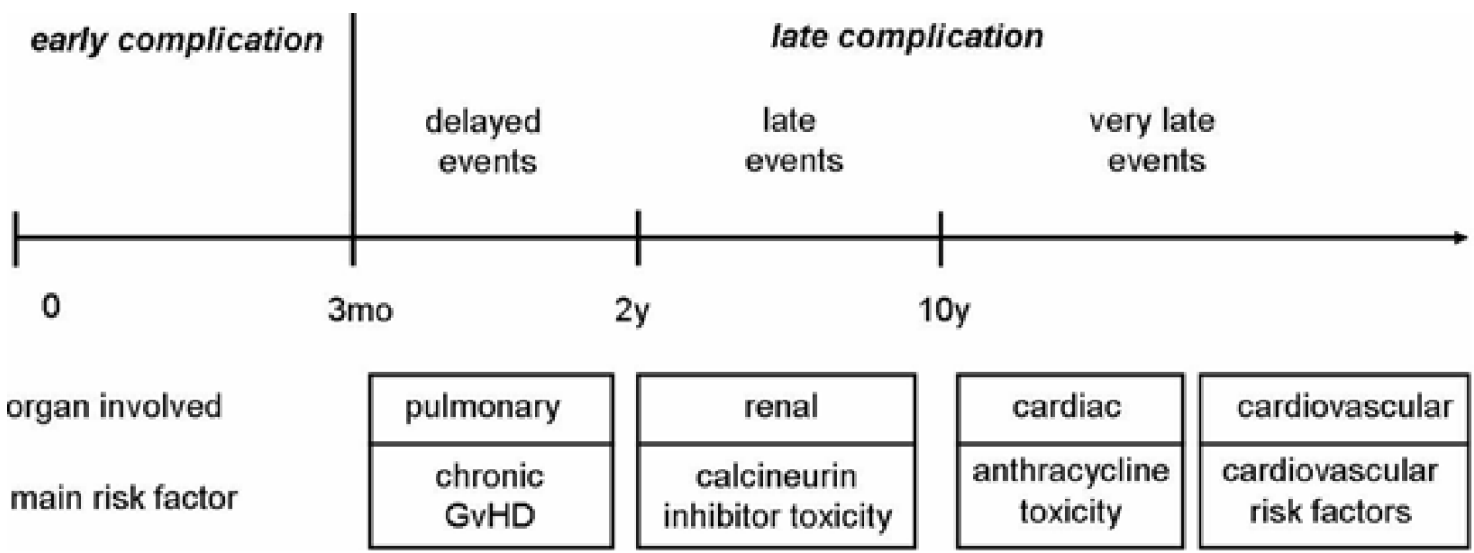

Legend: Legend: HSCT: hematopoietic stem cell transplantation. GVHD: graft-versus-host disease. Adapted from: Tichelli A, $2008^{127}$. 
Early intervention in patients with cardiovascular risk factors may delay the onset of late cardiovascular disease. Therefore, a targeted and regular approach is needed to identify patients at risk. As children and adolescents will have a prolonged life expectancy, a thorough screening of modifiable cardiovascular risk factors and possible early interventions are of paramount importance to prevent premature death and for a better quality of life of these patients ${ }^{128}$. In addition, counseling for a healthy, tobacco-free life- style, with regular exercise, healthy eating and maintaining adequate weight became fundamental as part of the long-term management of transplanted patients ${ }^{129}$.

The recommendations regarding the evaluation and monitoring of cardiovascular function and metabolic profile before, during and after autologous and allogeneic bone marrow transplantation are described in Table 6.

TABLE 6. Recommendations for evaluation and follow-up of cardiovascular function in children and adolescents undergoing bone marrow transplantation

\begin{tabular}{|c|c|c|}
\hline Class & $\begin{array}{l}\text { Level of } \\
\text { evidence }\end{array}$ & Indication \\
\hline I & C & Clinically evaluate for signs and symptoms of heart disease \\
\hline I & B & Analyze accumulated dose of anthracyclines and use of pre-HSCT mediastinal radiotherapy \\
\hline I & B & Assess whether there are a history of thromboembolic events in the family \\
\hline$\| A$ & $\mathrm{C}$ & $\begin{array}{l}\text { Analyze risk-benefit before HSCT in patients with risk factors and perform HSCT in patients with } \\
\text { left ventricular ejection fraction }<55 \% \text { if there is significant benefit }\end{array}$ \\
\hline I & $\mathrm{C}$ & $\begin{array}{l}\text { Perform ECG pre-HSCT, before the use of cyclophosphamide in conditioning, in the infusion of } \\
\text { stem cells and periodically after HSCT ( } 3 \text { months, } 6 \text { months, } 12 \text { months and then annually) }\end{array}$ \\
\hline I & $\mathrm{C}$ & $\begin{array}{l}\text { Periodically evaluate patients undergoing HSCT for signs and symptoms of congestive heart } \\
\text { failure }\end{array}$ \\
\hline I & B & Evaluate ventricular function by transthoracic echocardiogram before HSCT \\
\hline I & $\mathrm{D}$ & $\begin{array}{l}\text { Perform transthoracic echocardiography periodically after HSCT: } 3 \text { months, } 6 \text { months, } 12 \text { months } \\
\text { and then annually or at any time if there are changes in the symptoms }\end{array}$ \\
\hline$\| A$ & D & $\begin{array}{l}\text { Perform three-dimensional echocardiography or cardiac magnetic resonance imaging in cases of } \\
\text { transthoracic echocardiogram limitation }\end{array}$ \\
\hline$\| A$ & $D$ & $\begin{array}{l}\text { Perform stress tests on patients with echocardiogram changes or symptoms suggestive of cardiac } \\
\text { dysfunction or who have risk factors }\end{array}$ \\
\hline
\end{tabular}




\begin{tabular}{|c|c|c|}
\hline$\| A$ & $C$ & $\begin{array}{c}\text { Echocardiogram and ECG every } 3 \text { months in patients with chronic GVHD due to increased risk of } \\
\text { arrhythmias, endothelial injury and pericardial effusion }\end{array}$ \\
\hline I & C & $\begin{array}{l}\text { Pre- and annual endocrine control after HSCT: body mass index, glycemia, triglycerides, } \\
\text { cholesterol, thyroid hormones, insulin }\end{array}$ \\
\hline 1 & $C$ & $\begin{array}{l}\text { Ferritin control before and after HSCT ( } 6 \text { months, } 1 \text { year post HSCT and then annually until normal } \\
\text { values are reached) and perform therapeutic bleeding or use of iron chelators if necessary }\end{array}$ \\
\hline$\| A$ & $C$ & $\begin{array}{c}\text { Perform cardiac MRI after HSCT in patients who are undergoing or wil undergoing treatment to } \\
\text { reduce iron deposition in the heart }\end{array}$ \\
\hline
\end{tabular}

Legend: HSCT: hematopoietic stem cell transplantation; GVHD: graft-versus-host disease; ECG: electrocardiogram; MRI: magnetic resonance imaging. Note: Class I - Consensus; Class IIA - Conflicting evidence, but which favors the procedure; B - Non-randomized studies; C - Case series; D - Expert opinion.

\section{Renal complications:}

Renal dysfunction may occur in patients who underwent bone marrow transplantation in the pre, peri, and post-bone marrow transplantation period. Exposure to nephrotoxic drugs plays an important role in this renal dysfunction. The incidence of chronic kidney disease, defined as a sustained decrease in glomerular filtration rate below $60 \mathrm{ml} / \mathrm{min} / 1.73 \mathrm{~m}^{2}$ for at least three or more months can range from 5 to $65 \%^{130,131,134,135,136}$. Chronic kidney disease usually becomes apparent 6 to 12 months after transplantation, although it can occur earlier as well as much later post-transplantation. Renal failure may present as TMA, glomerulonephritis, nephrotic syndrome, or nephritis by irradiation after exposure to $\mathrm{TB}^{91}{ }^{91}$. Other etiologies include persistent acute kidney injury and BK virus nephropathy ${ }^{137}$. Most patients have an idiopathic form of chronic kidney disease, which is not associated with thrombotic microangiopathy or nephrotic syndrome and has a multifactorial etiology ${ }^{91}$.

Risk factors for chronic kidney disease in bone marrow transplant recipients include advanced age at HSCT, renal function and pre-transplant therapy (e.g., platinum compounds), acute and chronic GVHD, use of TBI in the conditioning regimen, exposure to medications to prevent or treat GVHD (e.g., CNIs), and certain antimicrobial agents (e.g., acyclovir, amphotericin B, aminoglycoside antibiotics) ${ }^{131.132,133}$. Antibiotics and antifungals cause tubular damage rather than glomerular damage. CNIs can cause glomerular thrombosis and tubular injury. A late syndrome of renal damage secondary to calcineurin inhibitors may affect renal arterioles and tubules and can be accompanied by interstitial fibrosis. CMV infection has also been associated with glomerular injury and the use of foscarnet for the treatment of CMV infection may induce even more tubule-interstitial nephritis and irreversible damage due to its crystallization within the renal tubules. Radiation exposure (e.g., TBI) can lead to degeneration and sclerosis of arterioles and secondary destruction of glomeruli and tubules ${ }^{91}$.

Patients with substantial hemorrhagic cystitis in the early post-transplant period have a higher risk of scarring and late contracture of the bladder wall. In patients with hemorrhagic cystitis, research and treatment of polyomavirus and adenovirus is of vital importance, especially in patients using prolonged immunosuppressive therapy. Patients receiving immunosuppressive therapy for chronic GVHD, particularly women with GVHD of the vulva and vagina, are at risk of recurrent urinary tract infections ${ }^{91}$.

The incidence of TMA is 2 to $21 \%$ in patients after HSCT and is characterized by renal dysfunction, thrombocytopenia, neurological dysfunction, hemolytic anemia with schistocytes, elevated lactate dehydrogenase and decreased haptoglobin ${ }^{138,139}$. Risk factors for TMA include TBI, use of calcineurin inhibitors, acute or chronic renal injury associated with $\mathrm{GVHD}^{140}$. TMA often improves with tapering or interruption of calcineurin inhibitors, but full renal function is often not completely restored ${ }^{141}$. In some cases, TMA did not improve until GVHD was treated ${ }^{142}$. 
Nephrotic syndrome occurs in 6-8\% of patients after allogeneic HSCT, with membranous nephropathy in $61 \%$ of cases and minimal change disease comprised $22 \%$ of cases, with a median onset of approximately 14 months and eight months after HSCT, respectively ${ }^{143,144,145}$. Nephrotic syndrome after HSCT is usually related to chronic GVHD and tapering of immunosuppressive medications ${ }^{145}$.

Idiopathic chronic kidney disease comprises most cases of renal dysfunction. The main risk factors involved are acute GVHD, chronic GVHD, acute kidney injury, prolonged use of calcineurin inhibitors and previous autologous $\mathrm{HSCT}^{132,146}$. Whenever possible renal biopsy should be considered with the objective of appropriate diagnostic and therapeutic elucidation of chronic kidney disease ${ }^{147}$.

Systemic arterial hypertension is a frequent complication in patients who have undergone bone marrow transplantation. The main cause of this hypertension is medication, with corticosteroids, cyclosporine, and tacrolimus being the main culprits ${ }^{148}$. In most cases, systemic arterial hypertension is transient during the use of these medications, with blood pressure normalization after their suspension. However, it is essential to perform the diagnosis and appropriate treatment of systemic arterial hypertension in HSCT recipients to minimize damage to target organs, especially in the brain, heart and kidneys ${ }^{148}$.

By performing the proper control and treatment of hypertension, there will be a lower incidence of heart failure, coronary heart disease and strokes. If the patient has a difficult to control systemic arterial hypertension or with any target organ injury it is important to refer him to follow-up with a specialist (pediatric nephrologist).

In the pediatric population, no class of drugs has emerged as a standard for the treatment of systemic arterial hypertension in patients receiving calcineurin inhibitors. The choice of antihypertensive will depend on the experience of each center. Among the drug options, thiazide diuretics can be used, but caution is needed when the patient is on calcineurin inhibitors, as it has a higher risk of metabolic side effects. Calcium channel blockers are also at the top of the list of options; however, it is important to monitor serum levels of cyclosporine and tacrolimus because they may interact with calcineurin inhibitors and can also worsen proteinuria in patients with proteinuria or microalbuminuria. Beta-blockers may decrease sympathetic activity and cause headaches/ migraines induced by calcineurin inhibitors, in addition to tachyarrhythmias. Angiotensin converting enzyme (ACE) inhibitors may be a good choice in patients with chronic kidney disease, proteinuria, or even in diabetic patients. In patients with heart failure, diuretics, ACE inhibitors and angiotensin 2 receptor blockers may be used, but it is necessary to carefully monitor renal function to avoid renal azotemia with loop diuretics. If the patient does not have hyperkalemia, spironolactone may be used. Carvedilol and metoprolol are the beta-blockers of choice for patients with cardiac dysfunction ${ }^{148}$.

In uncomplicated hypertension, without diabetes mellitus, renal dysfunction or cardiac dysfunction, it is recommended to follow blood pressure targets according to table $7^{149,150}$.

TABLE 7: Updated definitions of blood pressure categories and stages in children and adolescents ${ }^{150}$

\begin{tabular}{|c|c|}
\hline For Children Aged 1-13 y & For Children Aged $\geq 13$ y \\
\hline Normal BP: <90th percentile & Normal BP: $<120 /<80 \mathrm{~mm} \mathrm{Hg}$ \\
\hline $\begin{array}{l}\text { Elevated BP: } \geq 90 \text { th percentile to }<95 \text { th percentile or } 120 / 80 \\
\qquad m \mathrm{mg} \text { to }<95 \text { th percentile (whichever is lower) }\end{array}$ & Elevated BP: $120 /<80$ to $129 /<80 \mathrm{~mm} \mathrm{Hg}$ \\
\hline $\begin{array}{l}\text { Stage } 1 \mathrm{HTN}: \geq 95 \text { th percentile to }<95 \text { th percentile }+12 \mathrm{mmHg} \text {, } \\
\text { or } 130 / 80 \text { to } 139 / 89 \mathrm{~mm} \mathrm{Hg} \text { (whichever is lower) }\end{array}$ & Stage $1 \mathrm{HTN}: 130 / 80$ to $139 / 89 \mathrm{~mm} \mathrm{Hg}$ \\
\hline $\begin{array}{l}\text { Stage } 2 \text { HTN: } \geq 95 \text { th percentile }+12 \mathrm{~mm} \mathrm{Hg} \text {, or } \geq 140 / 90 \mathrm{~mm} \mathrm{Hg} \\
\text { (whichever is lower) }\end{array}$ & Stage 2 HTN: $\geq 140 / 90 \mathrm{~mm} \mathrm{Hg}$ \\
\hline
\end{tabular}

Adapted from: Flynn JT, 2017 ${ }^{150}$. 


\section{Recommendations ${ }^{91}$ :}

Blood pressure should be checked at every clinical visit and hypertension should be investigated and treated appropriately in all HSCT recipients

Renal function should be evaluated periodically in all HSCT recipients. Screening tests should include assessment of blood urea nitrogen (BUN), creatinine, and urine protein. Additional evaluations (e.g., renal ultrasound, renal biopsy) should be performed if clinically indicated in patients with late onset acute renal failure or chronic kidney disease post-transplantation. More frequent assessments may be required based on the patient's medical status (e.g., ongoing therapy with calcineurin inhibitors).

In patients with progressive chronic kidney disease, avoid nephrotoxic drugs and consider early referral to a nephrologist for evaluation and treatment.

\section{SECONDARY MALIGNANCIES FOLLOWING HSCT}

As mentioned before, allo-HSCT is a curative option for several malignant and non-malignant disorders of childhood ${ }^{151-157}$. Nonetheless, the high exposure to chemo- and/or radiotherapy at a young age increases the risk of cumulative organ compromise, thus leading to late morbidity and mortality ${ }^{158,159}$. Earlier studies in adults undergoing allo-HSCT, as well as studies among cohorts of both children and adults, have shown an increased risk of late mortality, mainly due to recurrence of baseline disease, subsequent malignant neoplasm, chronic GVHD, infectious complications, and cardiovascular and pulmonary disease ${ }^{160-166}$. Of note, HSCT does not abrogate the inherent risk of malignancy in some disorders, such as Fanconi anemia (FA), dyskeratosis congenita, and other immunodeficiency syndromes ${ }^{156,165,166}$. Extra caution should therefore be taken toward defining the role and optimal timing of HSCT for these patients, given the relatively young age at HSCT, the expected longevity, and the potential for late treatment-related morbidity and mortality ${ }^{167}$.

There are only a handful of studies, with relatively small cohorts, assessing late mortality after allo-HSCT specifically in the pediatric population ${ }^{156,157,168-171}$, with most of the available studies combing adult and pediatric outcomes ${ }^{172}$. Moreover, it remains unclear whether late mortality rates have changed over the past three decades as a consequence of changes in transplant practice (e.g., conditioning platforms and supportive care). The incidence of secondary neoplasms may vary depending on the primary diagnosis (e.g., Fanconi anemia, myelodysplasia), disease status at transplantation, preparative regimens used (e.g., etoposide, high-dose TBI), HLA-mismatch, chronic GVHD, agents used for GVHD prophylaxis or treatment, as well as on certain demographic characteristics (e.g., age, sex, race/ethnicity, smoking status, and transplant time period) ${ }^{162,165-6,168,173}$. Neoplasms at less common sites, such as the oral cavity, liver, central nervous system, connective tissue, bone, thyroid and salivary glands are most frequently diagnosed after $\mathrm{HSCT}^{173}$. The main risk factors associated with individual solid cancers after HSCT are depicted in Table $8^{174}$.

TABLE 8. Main risk factors reported for individual secondary cancers in the HSCT population.

\begin{tabular}{|c|c|}
\hline Site & Risk Factor \\
\hline Skin & cGVHD \\
\hline Squamous cell carcinoma & aGVHD, cGVHD, male, age <18y at HSCT \\
\hline Basal cell carcinoma & Age $<18$ y at HSCT, MAC-TBI, white, CGVHD, attained age \\
\hline Melanoma & MAC-TBI, T-cell depletion, female \\
\hline Thyroid & Radiation conditioning, female, age $₫ 20 y$ at $\mathrm{HSCT}$, cGVHD \\
\hline Oral & $\begin{array}{c}\text { Persistent cGVHD, cumulative duration of IST, including } \\
\text { prophylaxis }>24 \text { mo, history of localized field irradiation, age } \\
<10 y \text { at HSCT, male }\end{array}$ \\
\hline Esophagus & Persistent cGVHD, prolonged IST > $24 \mathrm{mo}$ \\
\hline Stomach None reported & NR \\
\hline
\end{tabular}




\begin{tabular}{|c|c|}
\hline Colorectal & NR \\
\hline Liver & $\begin{array}{c}\text { TBI-based conditioning, younger age }(<34 \mathrm{y}) \text { at HSCT, liver } \\
\text { cirrhosis, chronic hepatitis } C \text { infection }\end{array}$ \\
\hline Lung & Lung Tobacco use prior to transplantation \\
\hline Breast & $\begin{array}{l}\text { MAC-TBI or } \mathrm{Hx} \text { of radiation treatment, longer time since } \\
\mathrm{HSCT} \text {, age }<18 \mathrm{y} \text { at HSCT, use of growth factors, ATG }\end{array}$ \\
\hline Cervix & cGVHD with systemic IST $>3 y$, age $>34 y$ \\
\hline Endometrial & NR \\
\hline Ovary & NR \\
\hline Prostate & NR \\
\hline Testis & NR \\
\hline Brain/CNS & NR (prior Hx of CNS irradiation may increase risk) \\
\hline Sarcoma & NR \\
\hline
\end{tabular}

Legend: cGVHD: chronic graft-versus-host disease; aGVHD: acute GVHD; $y=$ years; $\mathrm{HSCT}=$ hematopoietic stem cell transplant; $\mathrm{MAC}-\mathrm{TBI}=$ myeloablative total body irradiation conditioning; IST = immunosuppressive therapy; mo: months; $\mathrm{Hx}=$ history; ATG: antithymocyte globulin; CNS=central nervous system; NR = none reported.

Adapted from: Inamoto, $2015^{174}$.

FA patients are particularly prone to developing squamous cell carcinoma of the head and neck, with a corresponding poor prognosis in this patient group ${ }^{165-6} . \mathrm{TBI}$, for instance, has long been known to be an established risk factor for both cancer and late mortality in HSCT recipients ${ }^{158-9}$. This has supported the fairly recent move toward reduced intensity nonTBI- or low-dose TBI-based regimens. Likewise, T-cell depletion has decreased toxicity with less GVHD, which, in turn, may potentially contribute to a lower risk of late cancer, morbidity and mortality ${ }^{175}$. Of note, in a study by Eapen et al., 2012, including pediatric patients with primary immunodeficiencies and inborn errors of metabolism, late mortality (7\%) was found to plateau after a significant period of time post-transplant. In this cohort, as in other studies, chronic GVHD was found to be an important risk factor for these late complications ${ }^{176,177}$.

Overall, the available literature shows an invariable excess risk of both cancer and late mortality in children undergoing allogeneic HSCT for either malignant or non-malignant diseases. ${ }^{158-9,172,178-180}$ Nonetheless, since some secondary cancers are quite rare and most studies available are mostly retrospective analyses based on registry data, study populations are highly heterogeneous and details regarding chemotherapy and radiation therapy exposures prior to transplant are not always clear, larger studies are required to provide a better understanding of the incidence and risks of secondary cancers in post-HSCT patients.

In a large registry study by the Center for International Blood and Marrow Transplant Research (CIBMTR) ${ }^{181}$, Kahn JM et al., 2020 examined the risk of SNs and late mortality in 6028 children and adolescents undergoing allo-HSCT for non-malignant diseases (NMDs) between 1995-2012. Median age was 6 years (interquartile range, 1-11; range, 1 to 20). Standardized mortality ratios (SMRs) in 2-year survivors and standardized incidence ratios (SIRs) were calculated to compare mortality and SN rates with expected rates in the general population. Median follow-up of survivors was 7.8 years. Diagnoses included severe aplastic anemia (SAA; 24\%), FA (10\%), other marrow failure syndromes $(6 \%)$, hemoglobinopathy $(15 \%)$, immunodeficiencies (23\%), and metabolic/ leukodystrophy syndrome (22\%). The 10-year survival was $93 \%$ (95\%Cl, 92\% to $94 \%$; SMR, $4.2 ; 95 \% \mathrm{Cl}, 3.7-4.8)$. A total of 71 patients developed SNs (1.2\%), with the highest rates in FA (5.5\%), SAA (1.1\%), and other marrow failure syndromes (1.7\%); for other NMDs, incidence was $<1 \%$. SNs were predominantly hematologic (27\%), oropharyngeal (25\%), and skin cancers (13\%). Leukemia risk was highest within the first 5 
years post-transplant, as opposed to oropharyngeal, skin, liver, and thyroid tumors, which primarily occurred after 5 years. Despite the relatively low number of SNs, patients presented an 11-fold increased risk of SN (SIR, 11; 95\% Cl, 8.9-13.9) when compared to the general population. This study emphasized the excellent survival after transplantation for NMDs observed in a large cohort of children and adolescents after the first 2 years post-transplant and the fact that the cumulative incidence of SNs is low. Even so, as mentioned previously, it underscored the increased risk for SN development in those with FA and other bone marrow failure syndromes, highlighting the need for long-term post-transplantation surveillance in this population.

It has long been known that patients undergoing a myeloablative conditioning (MAC) regimen prior to allo-HSCT are at increased lifelong risk for second solid cancers ${ }^{158,174,182-84}$. There is typically a latency period of 3 to 5 years before second solid cancers start appearing after transplant, with the most recent and robust studies reporting cumulative incidence rates of $1-2 \%$ at 10 years and $3-5 \%$ at 20 years after

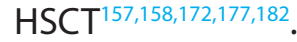

In a retrospective multicenter study by Kolb et al, 1999, 1036 consecutive patients who underwent transplantation for leukemia, lymphoma, inborn diseases of the hematopoietic and immune systems, or severe aplastic anemia and survived for more than 5 years were assessed for the incidence of malignant neoplasms and compared to the general population ${ }^{159}$. Median age was 21 years. Median follow-up since allo-HSCT was 10.7 years (range, 5 to 22.1 years), and malignant neoplasms were seen in 53 patients, with an actuarial incidence of $3.5 \%$ at 10 years and $12.8 \%$ at 15 years. This rate was 3.8 -fold higher than that in an age-matched control population $(P<0.001)$. The most incident neoplasms were that of the skin (14 patients), oral cavity (7 patients), uterus (including cervix) (5 patients), thyroid gland (5 patients), breast (4 patients), and glial tissue (3 patients). These were more frequent in older patients and in patients with chronic GVHD under immunosuppression with cyclosporine.

In the MAC allo-HSCT scenario, important risk factors for these cancers include exposure to high dose TBI, younger age at transplantation, use of an HLA-mismatched donor, and chronic GVHD ${ }^{158,175,182,183}$. As for the risk factors related to reduced intensity conditioning (RIC) transplants, age at the time of HSCT, gender, Karnofsky performance score at transplant, diagnosis/disease status, time from diagnosis to $\mathrm{HSCT}, \mathrm{TBI}$ dose (e.g., high dose and greater risk of breast cancer in women, donor/graft source, history of prior autologous transplant, GVHD prophylaxis regimen used, duration of immunosuppression, year of HSCT, and occurrence of acute (grade 2-4) or chronic GVHD are all potentially meaningful factors ${ }^{184-85}$. Given the increased survival rates observed in transplantation over the last few decades, in all such cases the incidence of secondary cancers continues to rise, for which lifelong surveillance is strongly recommended $91,158,172,175,181-82,186,187$. As a rule, RIC/NMA recipients should receive screening for solid cancers in a similar manner to what is typically recommended for MAC recipients, with extra awareness toward long-term survivors after RIC/NMA at an increased risk of cancers of the lip, tonsil, oropharynx, bone, soft tissue, vulva, and skin melanoma.

In the Blood or Marrow Transplant Survivor Study-2, a multicenter collaborative effort by Holmkvist et al., 2014, including a large cohort of children who had undergone an allo-HSCT between 1974 and 2010 and had lived for at least 2 years, investigators assessed the long-term outcome (all-cause mortality, relapse-related mortality - RRM, and non-RRM) of such patients ${ }^{188}$. In this study, individuals were stratified between three time periods: before 1990, 1990-1999, and 2000-2010. The SMR, a ratio of observed to expected number of deaths, was used to compare the mortality experienced by this cohort with the age-specific (5-year interval), sex-specific, and calendar specific (5-year interval) mortality of the US general population. Person-years at risk were computed from $>2$ years after all-HSCT to either the date of death or the date of censoring, whichever occurred first. In this cohort study of 1388 children, individuals living for $>/=2$ years after undergoing allo-HSCT during childhood, transplant recipients were at an elevated risk of early death compared with the general population. Overall, the cohort had a 14.4-fold increased risk for premature death (95\% $\mathrm{Cl}, 12.8-16.1)$ compared with the general population (292 deaths observed; 20.3 deaths expected). High relative mortality was noted across all primary diagnoses, with SMRs ranging from 4.6 for SAA to 28.2 for inborn errors of metabolism and was highest for patients who had undergone transplantation at age 5 to 9 years (SMR, 22.8; 95\% Cl, 17.9-28.4) and in the first 2- to 5 years after allo-HSCT (SMR, 522.0; 95\% Cl, 439.9-613.6), decreasing sharply thereafter. Nonetheless, it remained significantly elevated even $>/=$ 25 years after transplantation (SMR, 2.9; 95\% Cl, 2.04.1). As for the specific causes of death, subsequent malignant neoplasms accounted for $18.4 \%$ of cases, with a 10-year cumulative incidence of $1.6 \%(95 \% \mathrm{Cl}$, $1.0 \%-2.4 \%)$ for the occurrence of this event. The cumulative incidence of non-RRM was higher than that 
of RRM (13.2\% vs. $4.5 \%$ at 20 years after allo-HSCT). These findings underscore the need for close follow-up in respect to chronic GVHD and infections, as well as relapse, particularly during the first 10 years after transplantation. Additionally, given the significant proportion of deaths due to subsequent malignant neoplasms in this study, although the rate of late mortality was shown to decrease in the past three decades, lifelong proactive follow-up care of children (and adults) who live 2 or more years after transplant, including screening, preventive interventions, and counselling is strongly encouraged.

In a large, Brazilian, single-center, nested, case-control study by Tavares et al., 2016, aiming at determining the cumulative incidence of secondary neoplasms in HSCT recipients and the possibly associated risk factors for this complication, 520 patients who had undergone a related or unrelated donor transplant between 2000 and 2010 were assessed $^{173}$. All patients having a histopathological confirmation of neoplastic disease within this cohort were selected as cases and matched in a 2:1 ratio to transplant period-matched controls Among these, 19 recipients were found to have developed a post-HSCT neoplasm and were considered as cases, with the following neoplasms being identified: melanoma (3), basocellular carcinoma of the skin (3), squamous cell carcinoma of the esophagus (3), adenocarcinoma of the prostate (2), intraepithelial cervical carcinoma (2), squamous cell carcinoma of the uterus, breast cancer, diffuse-large B-cell non-Hodgkin lymphoma, choroidal carcinoma, squamous cell carcinoma of the tongue, and rectosigmoid adenocarcinoma (1 case each), Table 9. In the second malignancy group, the mean age at transplant was 39 (15-63) years, with a predominance of males (12). All cases were transplanted for a hematologic ma- lignancy, most of which with advanced disease at HSCT. Two patients had received radiotherapy prior to conditioning. Conditioning regimens were as follows: BU-CY (9), CY-TBI (5), Fludarabine (FLU)-CY (3) and FLU-MEL (2). Moderate to severe chronic GVHD was diagnosed in 13 cases. In the control group, the mean age at transplant was 26 (5- 58) years, with a predominance of males (24). Among these, 31 were transplanted for a hematologic malignancy (five of whom had received prior radiotherapy) and seven for bone marrow failure or immunodeficiency. Conditioning regimens comprised: BUCY (18), CY TBI $\geq$ 10Gy (11), FLUCY (4), FLUMEL (1), BUMEL (1) and CY + TBI 600cGy (1). Moderate to severe chronic GVHD was diagnosed in 24 of the controls. Multivariate analysis showed a direct and significant association between older age at transplant and diagnosis of moderate to severe chronic GVHD with the occurrence of secondary neoplasm, with a relative risk (RR) of 1.12 and 3.66 , respectively $(p<0.01)$, Table 10 . In contrast, type and status of the underlying disease, prior radiotherapy, conditioning intensity, use of TBI, type of donor, and graft source were not significantly associated with this complication. The cumulative incidence of secondary neoplasms in survivors at 14 years was $6.3 \%$, with a gradual increase over time, as seen in other studies. Tavares et al., 2016, concluded that, although it is clear that there has been in the incidence of secondary neoplasms after transplant due most probably to the improvement in post-HSCT survival rates in the last few decades, the heterogeneity of the study sample, with varying incidence and conflicting results preclude any definitive conclusions regarding the risk factors for secondary neoplasms, especially in respect to age (since some studies state younger age as a possible risk factor) and the use of TBI in this population. Further studies in this regard are hence warranted.

TABLE 9 - Histological types of second neoplasms in children undergoing HSCT $($ INCA, 2016) 173

\begin{tabular}{ll} 
Melanoma & 3 \\
Non-melanoma skin cancer & 3 \\
Esophagous carcinoma & 3 \\
Prostate dancer & 2 \\
Cervical in situ neoplasia & 2 \\
Uterine carcinoma & 1 \\
Breast cancer & 1 \\
Non-Hodgkin lymphoma & 1 \\
Choroidal carcinoma & 1 \\
Tongue carcinoma & 1 \\
Rectosigmoid adenocarcinoma & 1 \\
\hline
\end{tabular}

Legend: HSCT: hematopoietic stem cell transplantation; INCA: Instituto Nacional de Câncer. Adapted from: Tavares et al., 2016 ${ }^{173}$ (with permission). 
TABLE 10- Univariate and multivariate analyses of risk factors for second neoplasms in children undergoing HSCT (INCA, 2016) ${ }^{173}$

\begin{tabular}{|c|c|c|c|c|}
\hline & \multicolumn{2}{|c|}{ Univariate } & \multicolumn{2}{|c|}{ Multivariate } \\
\hline & $\mathrm{HR}(95 \% \mathrm{Cl})$ & $\mathrm{P}$-value & $\mathrm{HR}(95 \% \mathrm{Cl})$ & P-value \\
\hline \multicolumn{5}{|l|}{ Age } \\
\hline Each 10-year increase & $2,1(1,2-3,9)$ & 0,01 & $3,2(1,1-8,9)$ & 0,03 \\
\hline \multicolumn{5}{|l|}{ Chronic GVHD } \\
\hline None or not severe & Ref & & & \\
\hline Severe & $5,6(1,1-28)$ & 0,03 & $3,7(0,54-24)$ & 0,18 \\
\hline \multicolumn{5}{|l|}{ Donor } \\
\hline Sibling & Ref & & & \\
\hline Unrelated Donor & $0,7(0,2-2,9)$ & NS & $7,5(0,5-120)$ & 0,16 \\
\hline
\end{tabular}

Legend: HSCT: hematopoietic stem cell transplantation; INCA: Instituto Nacional de Câncer.

Adapted from: Tavares et al., 2016 (with permission)173

In a more recent retrospective study by Freycon et al., 2019, which included 71 childhood leukemia survivors (of whom 36 were females) undergoing allo-HSCT with $12 \mathrm{~Gy}$ fractionated TBI (fTBI), the number of severe late-effects was specified for each patient, with a median of 14.8 years since transplantation and a median age of 25.0 years at the time of follow-up ${ }^{189}$. Subsequent cancers $(n=14)$ were reported in 11 patients ( 8 women), as follows: 7 with thyroid carcinomas, 3 with multiple squamous cell carcinomas, 2 with tongue or lip carcinomas, 1 with bone sarcoma, and 1 with carcinoma of the breast). In this study, the average overall number of severe late effects was 2.3 , with a positive correlation with time since fTBI $(p<0.0002)$. Two-thirds of all patients had at least 2 late-effects (comprising neoplastic and non-neoplastic complications). These results suggest the need for a cautious reconsideration of the use of TBI in this population ${ }^{189}$.

Ringden et al., 2014, examined the risk of second solid cancers after allo-HSCT using RIC/non-myeloablative conditioning (NMA) regimens in recipients with leukemia/myelodysplastic syndrome (MDS) $(n=2833)$ and lymphoma $(n=1436)$ from 1995 to 2006 They also compared the results among, RIC/NMA recipients of $40-60$ years of age $(n=2138)$ with those of the same age receiving MAC $(n=6428)^{185}$. The cumulative incidence of solid cancers was $3.35 \%$ at 10 -years. Interestingly, there was no increase in overall cancer risk compared to the general population. However, risks were significantly increased in leukemia/MDS patients for cancers of the lip (SIR 14.28), tonsil (SIR 8.66), oropharynx (SIR 46.70), bone (SIR 23.53), soft tissue (SIR 12.92), vulva (SIR 18.55), and skin melanoma (SIR 3.04), whereas lymphoma patients had sig- nificantly higher risks of oropharyngeal cancer (SIR 67.35) and skin melanoma (SIR 3.52). Higher risks than the general population have also been reported at these sites in MAC recipients ${ }^{158,172,183}$. Among the RIC/NMA recipients, age $>50$ years was the only independent risk factor for solid cancers (hazard ratio $[\mathrm{HR}] 3.02, \mathrm{P}<0.001$. Among patients aged 40-60 years, when adjusted for patient, disease, and transplant variables, no difference in cancer risk between RIC/NMA and MAC in leukemia/MDS patients (HR $0.98,95 \% \mathrm{Cl}: 0.64-1.45 ; \mathrm{P}=0.905)$ was noted, while, in lymphoma patients, risks were marginally lower after RIC/NMA (HR 0.51, 95\% Cl: 0.26-0.99; P=0.047). The authors concluded that the overall risk of a second solid cancer in RIC/NMA recipients is similar to that in general population controls matched for age, gender, and region, although there is an increased risk of cancer at some sites and a longer follow-up is needed to better clarify these findings. In MAC recipients, second solid cancer risks do not start increasing until 5-10 years after-transplant ${ }^{172,158,159,190}$.

In a large, population-based cohort of 318 Australian children who underwent allo-HSCT for non-malignant disease, cancer occurrence and late mortality was assessed using SIRs and SMRs compared with matched population controls ${ }^{191}$. During follow-up (range, $0.0-25.4$ years) six (1.9\%) cancers were identified at a median of 9.2 years (range, $0.4-14.5$ years) post-HSCT, which represented a 15 -fold increase in the occurrence of cancer as compared to the age and sex-matched general population (SIR 15.4, 95\% $\mathrm{Cl}=6.9-34.2)$, with a progressively higher cumulative incidence of cancer of up to $5.4 \%$ at the end of follow-up, quite similar to that observed in a US cohort of HSCT children and adults, in which $5 \%-6 \%$ of 
patients undergoing transplant for a non-malignant condition developed a secondary cancer $^{187}$. In the Australian cohort, the cumulative incidence of second malignancy at 10 years was $15.9 \pm 10.1 \%$ for patients with FA and $1.1 \pm 0.8 \%$ for those without this disease. In this study, all malignancies developed in males, and one third of such patients were conditioned with the use of radiation. Among the 198 patients surviving at least 2 years post-HSCT, 11 (5.6\%) died at a median of 7.5 years after transplant, a mortality rate 17 times higher than that in the general population (SMR 17.5, 95\% Cl = 9.7-31.2). In both the US and the Australian cohort, the malignancies did not develop until a relatively late follow-up time, hence underscoring the need for evidence-based survivorship programs, with continued and vigilant long-term follow-up of patients, so as to reduce the excess morbidity and mortality observed in children transplanted for non-malignant conditions ${ }^{192}$.

According to Nelson et al., 2015, this follow-up should include, at a minimum, regular clinical review and monitoring for complications of treatment and risk of malignancy related to underlying disease, patient, and transplant covariates ${ }^{191}$. Careful counseling regarding potentially modifiable risk factors, including diet, exercise, and alcohol and tobacco avoidance, must be provided and worked upon at each clinical visit ${ }^{193}$.

Besides the overall findings reported above, a seemingly important association has been repeatedly shown between prior exposure of young women to TBI and higher risk of breast cancer after HSCT for hematologic malignancies ${ }^{189,184,194}$. Friedman et al., 2008, in a report from the Fred Hutchinson Cancer Research Center (FHCRC) and the EBMT-Late Effects Working Party, had already shown an increase in the risk of breast among survivors of allo-HSCT in 2008. In this study, which included 3337 female 5-year survivors who had undergone an allo-HSCT at one of 83 centers, 52 survivors developed breast cancer at a median of 12.5 (range: 5.7-24.8) years from transplant $(\mathrm{SIR}=2.2)$. The 25-year cumulative incidence of breast cancer was $11.0 \%$, higher among those receiving TBI (17\%) compared to those who did not receive TBI (3\%). The following factors were found to be associated with increased risk of cancer in multivariable analysis: longer time since transplantation ( $H R$ for $\geq 20$ years $\mathrm{HSCT}=10.8)$, use of $\mathrm{TBI}(\mathrm{HR}=4.0)$, and younger age at transplantation ( $\mathrm{HR}=9.5$ for $<18$ years), with a 2.5-fold increase in the hazard for death associated with breast cancer $(\mathrm{HR}=2.5 ; 95 \% \mathrm{Cl}: 1.1-5.8)$. This highlighted the need for female HSCT-survivors to be educated about the importance of regular breast cancer screening during long-term follow-up ${ }^{184}$.
In the Blood or Marrow Transplantation Survivor Study (BMTSS), a retrospective cohort study which included a total of 1,464 (allogeneic: $n=788$; autologous: $n=676$ ) female survivors transplanted between 1974 and 2014 and surviving for over 2 years post-HSCT, with the aim to assess the excess risk of subsequent breast cancer compared with that in the general population, 37 women (2.5\%) developed subsequent breast cancer (allogeneic: $n=19$; autologous: $n=18$ ), with a median follow-up of 9.3 years from transplant ${ }^{194}$. TBI was used in 660 patients (46\%) and was shown to be associated with an increased risk of breast cancer among both allogeneic ( $\mathrm{HR}, 3.7[95 \% \mathrm{Cl}, 1.2$ to 11.8]; $\mathrm{p}=$ .03 ) and autologous (HR, $2.6[95 \% \mathrm{Cl}, 1.0$ to 6.8]; $\mathrm{p}$ $=.048) \mathrm{HSCT}$ survivors. Moreover, pre-transplant exposure to alkylating agents was also associated with an increased risk of breast cancer among autologous HSCT recipients ( $\mathrm{HR}, 3.3[95 \% \mathrm{Cl}, 1.0$ to 9.0]; $p=.05$ ). Of note, compared with that in the general population, exposure to TBI at age < 30 years was associated with a 4.4-fold and a 4.6fold higher risk of subsequent breast cancer in allogeneic and autologous HSCT survivors, respectively, which corresponds to a roughly $13.9 \%$ risk of being diagnosed with breast cancer by age 50, as compared to a $2.38 \%$ risk in the average American population ${ }^{194,195}$. These findings suggest that women exposed to TBI, particularly at a young age ( $<30$ years), should be strongly considered for enhanced breast cancer screening strategies, with mammography and breast MRI for the early detection of this disease.

In summary, although indications for allo-HSCT and conditioning regimens have largely changed over time, the risk of secondary malignancy and late mortality continues to affect the pediatric population for a significant period of time after transplant. This emphasizes the need for evidence-based screening and lifelong follow-up care of these patients, focusing on the need for surveillance and early management of infections, chronic GVHD, and disease recurrence during the first decade after transplantation, as well as screening for early detection of subsequent malignant neoplasms and other complications to reduce the risk of late effects throughout life. In this regard, Inamoto et al., 2015, propose a consensus-based guideline applicable for screening and prevention of individual secondary solid cancers among HSCT recipients, as summarized in Table $11^{174}$. As a general rule, all HSCT recipients should be counselled in respect to the risks of secondary cancers on an annual basis and encouraged to undergo recommended screening based on their predisposition. 
TABLE 11 - Consensus guidelines for post-HSCT screening for secondary cancers (Inamoto, 2015) ${ }^{174}$

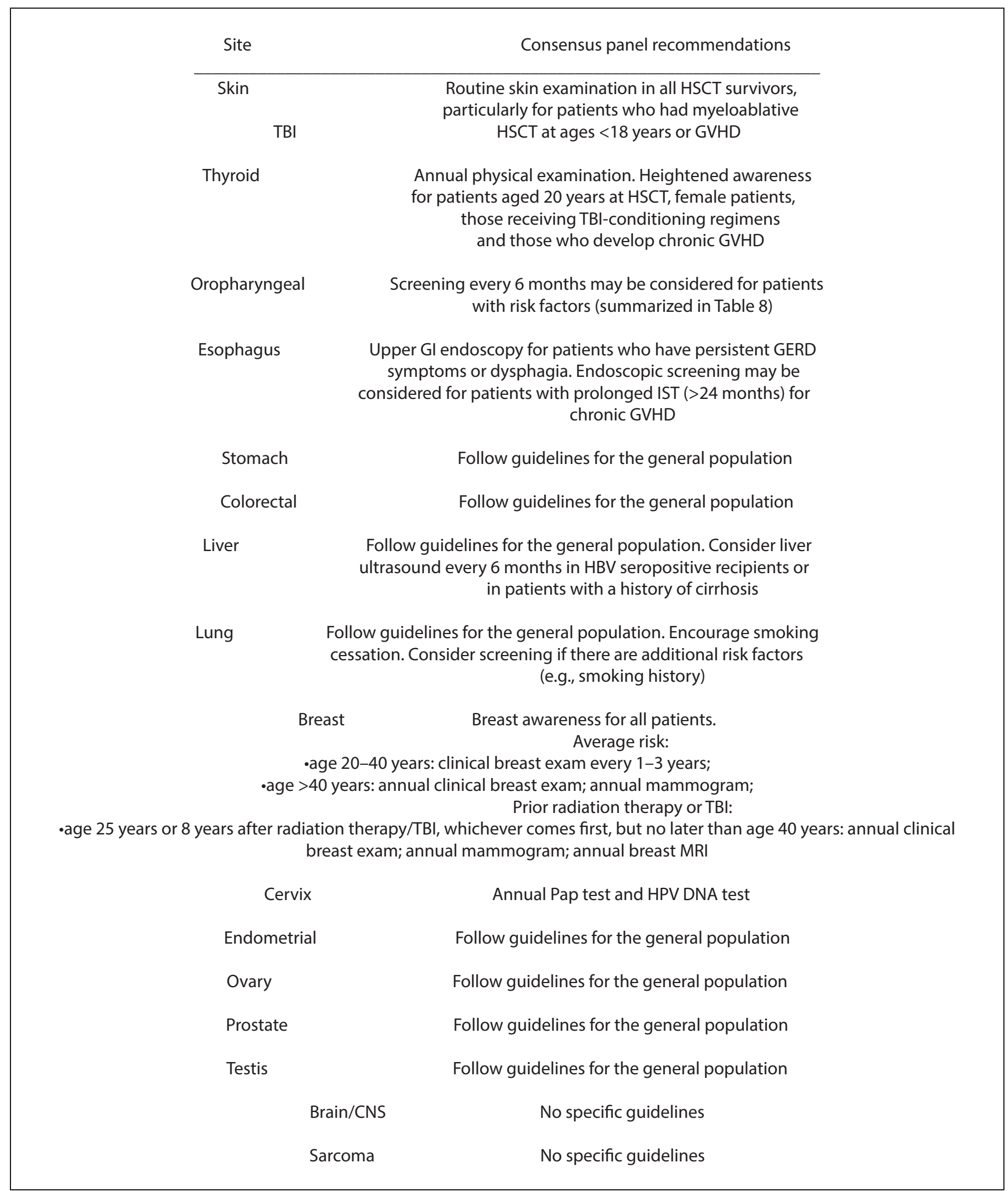

Legend: $\mathrm{HSCT}=$ hematopoietic stem cell transplant; TBI = total body irradiation; GVHD = graft-versus-host disease; $\mathrm{GI}=$ gastrointestinal; GERD= gastroesophageal reflux disease; IST = immunosuppressive treatment; HBV =hepatitis B virus; $\mathrm{MRI}=$ magnetic resonance imaging; $\mathrm{HPV}=$ human papillomavirus; Pap test = Papanicolaou test; Central Nervous System.

Adapted from: Inamoto, $2015^{174}$. 


\section{VITAMIN AND MINERAL SUPPLEMENTATION IN PEDIATRIC PATIENTS AFTER HSCT}

A good diet, including adequate levels of vitamins and minerals, plays a major role in the recovery and well-being of patients undergoing bone marrow transplantation.

Post-HSCT patients have a higher risk of food-related infections. The recommendation is to maintain a diet directed to immunosuppressed patients in allo-HSCT recipients while using immunosuppressive drugs or until they show signs of immune system reconstitution; and in autologous bone marrow transplant recipients the recommendation is to follow the diet for immunosuppressed patients up to one month after discontinuation of corticosteroids (if they are using) or three months after the $\mathrm{HSCT}^{148}$.

Patients who have had severe graft versus host disease of the gastrointestinal tract usually present some degree of malnutrition, enteropathy with loss of proteins and needy changes; deficiencies of vitamins D, B12 and zinc. Therefore, it is important to dose vitamins and zinc in these patients for diagnosis of a possible deficit and adequate replacement.

Deficiency of some vitamins may culminate in severe conditions, such as in patients with neurological symptoms and who are not receiving adequate nutrition may have vitamin B1 deficiency (Wernicke's encephalopathy). The low level of vitamin B1 along with the clinical improvement of the patient after vitamin $B 1$ replacement will give the diagnosis of this condition. The replacement of vitamin B1 (thiamine) should be done intravenously until improvement of the condition, which is usually fast. After improvement, oral vitamin $B 1$ replacement is maintained at a dose of $300 \mathrm{mg} /$ day for approximately 2 to 3 months. The oral dose has to be higher due to lower intestinal absorption $^{149}$.

Vitamin $\mathrm{D}$ is a liposoluble vitamin necessary for bone and calcium homeostasis. Vitamin D receptors are found in almost every cell in the body, including immune system cells. Immunomodulatory effects resulting from vitamin $D$ reduce inflammation and mediate activation and damage of endothelial cells ${ }^{196,197}$. Inflammation due to activation of endothelial cells during HSCT is related to serious complications such as GVHD, hepatic VOD, and TMA. Immunological dysregulation in the setting of vitamin $D$ deficiency during HSCT may therefore predispose patients to these complications associated with bone marrow transplantation ${ }^{198}$.

Vitamin D deficiency is a well-described phenomenon in pediatric patients undergoing bone marrow transplantation. Some factors that are associated with this deficiency are: lower sun exposure, use of various medications that potentially affect vitamin $D$ absorption, compromised intestinal epithelium and mucositis. Up to $70 \%$ of pediatric patients have vitamin $\mathrm{D}(<30 \mathrm{ng} / \mathrm{mL})$ deficiency before HSCT and over D+100; many, including, despite being in replacement therapy ${ }^{192}$. Vitamin D modulates inflammation, and deficiency in pre-HSCT and in D+100 have already been associated with graft-versus-host disease and worse survival ${ }^{198}$. There are reports of an association between vitamin $\mathrm{D}$ deficiency and immune-mediated complications, including GVHD and VOD. In addition, there is also little data to guide the recommendations for monitoring and supplementing vitamin D during bone marrow transplantation. In an article published in 2020, the association between vitamin D and post-HSCT complications in pediatric patients was evaluated and the routine use and efficacy of vitamin D monitoring and supplementation practices were also evaluated ${ }^{199}$. Vitamin D level was correlated with overall survival and each increase of $10 \mathrm{ng} / \mathrm{mL}$ was associated with a $28 \%$ reduction in the risk of death ${ }^{199}$. This same study showed that the vitamin $D$ supplementation regimens currently accepted for children who have had bone marrow transplantation do not reach sufficient vitamin $D$ values in most cases. Vitamin D status was associated with all causes of mortality, but not with individual comorbidities ${ }^{199}$. Prospective studies are needed to establish the connection between vitamin $D$ status, immune-mediated HSCT complications, and the potential benefit of vitamin D supplementation before and after HSCT. These studies are necessary so that we can have evidence of how to adequately monitor and supplement vitamin D during bone marrow transplantation.

Other publications have shown the association between vitamin $D$ deficiency with a higher incidence of acute ${ }^{200-01}$ and chronic ${ }^{202-03}$ GVHD, as well as cytomegalovirus reactivation ${ }^{207}$. However, the impact of vitamin $D$ on the survival is more controversial; some studies have shown that vitamin $D$ deficiency is associated with a decrease in overall survival after $\mathrm{HSCT}^{202,204}$, while others have not been able to reproduce these findings ${ }^{205,203,205}$. This inconsistency could have been caused by small cohorts in existing studies and differences in population characteristics; thus, further research with a larger and more homogeneous number of patients is clearly necessary.

There is a recommendation in the FHCRC Guideline to dose the level of vitamin D (25-hydroxy) in the blood between 80-100 days after bone marrow transplantation for all patients ${ }^{148}$. As it is a popula- 
tion at risk, it is recommended that this group of patients maintain a target serum level between 30-60 $\mathrm{ng} / \mathrm{mL}$. Vitamin D levels are usually checked again 2 to 3 months after the start of replacement therapy ${ }^{148}$.

Vitamin D deficiency is a risk factor that can be modified in patients after HSCT, with low cost and negligible side effects ${ }^{206,207}$ and has the great potential to restore immune tolerance and prevent some complications after $\mathrm{HSCT}^{208}$.

Therefore, it is important to perform routine evaluation and nutritional follow-up of all patients submitted to bone marrow transplantation, since they are patients at risk for vitamin and mineral deficiencies.

Biochemical tests (biomarkers) can help in risk assessment, diagnosis and nutritional follow-up of children and adolescents, including patients with associated morbidities, such as overweight, dyslipidemia, changes in glucose metabolism, among others. It is important to emphasize that the child's clinical condition may interfere in the interpretation of biochemical test results. In addition, previous nutritional status and the presence of inflammatory response, in addition to water balance, are factors that may interfere in the interpretation of these tests ${ }^{196}$. Table 12 describes the most common nutritional deficiencies according to clinical signs and symptoms ${ }^{196}$.

Specific micronutrient dosages can help assess nutritional status. With the early identification of possible deficiencies, it is possible to perform an adequate treatment, contributing undeniably to the nutritional recovery of the patient.

TABLE 12: Most frequent signs of nutritional deficiencies ${ }^{196}$

\begin{tabular}{|c|c|c|}
\hline Areas & Clinical signs & Diagnosis \\
\hline Hair & $\begin{array}{l}\text { Natural brightness loss: dry and ugly } \\
\text { Thin and sparse } \\
\text { brittle } \\
\text { Depigmented } \\
\text { Easy to boot } \\
\text { Flag sign }\end{array}$ & $\begin{array}{l}\text { Kwashiorkor and, less } \\
\text { often, marasmus }\end{array}$ \\
\hline Face & $\begin{array}{l}\text { Nasolabial seborrhea (dry skin around the nostrils) } \\
\text { Swollen face ("full moon") / Pallor }\end{array}$ & $\begin{array}{l}\text { riboflavin } \\
\text { Kwashiorkor } \\
\quad \text { iron }\end{array}$ \\
\hline Eyes & $\begin{array}{c}\text { Pale conjunctiva } \\
\text { Red membranes } \\
\text { Bitot's spots } \\
\text { Conjunctival xerosis } \\
\text { Corneal xerosis } \\
\text { Keratomalacia } \\
\text { Redness and fissure of epicanthi } \\
\text { Corneal arch (white ring around the eyes) } \\
\text { Xantelasma (small yellowish bags around the eyes) }\end{array}$ & $\begin{array}{c}\text { iron } \\
\text { vitamin C } \\
\text { vitamin A } \\
\text { riboflavin, } \\
\text { hyperlipidemia }\end{array}$ \\
\hline Lips & $\begin{array}{c}\text { Angular stomatitis (rosy or white lesions in the corners of } \\
\text { the mouth) } \\
\text { Queilose (redder or lip edema) }\end{array}$ & riboflavin \\
\hline Tongue & $\begin{array}{c}\text { Scarlet and inflamed tongue } \\
\text { Magenta language (purple) } \\
\text { Edematous tongue } \\
\text { Filiform papillae, atrophy and hypertrophy }\end{array}$ & $\begin{array}{l}\text { nicotinic acid } \\
\text { riboflavin } \\
\text { niacin } \\
\text { folic acid and vitamin } \\
\text { B12 }\end{array}$ \\
\hline
\end{tabular}




\begin{tabular}{|c|c|c|}
\hline Teeth & Stained enamel & fluorine \\
\hline Gums & Spongy: bleeding and leaking & vitamin C \\
\hline Glands & $\begin{array}{l}\text { Thyroid enlargement } \\
\text { Increased parathyroid }\end{array}$ & $\begin{array}{l}\text { iodine } \\
\text { starvation }\end{array}$ \\
\hline \multirow{7}{*}{ Skin } & $\begin{array}{c}\text { Xerosis } \\
\text { Follicular hyperkeratosis (skin on sandpaper) }\end{array}$ & vitamin A \\
\hline & Petechiae (minor bleeding on the skin) & vitamin C \\
\hline & $\begin{array}{l}\text { Dermatosis, pelagra (reddish edematous pigmentation in } \\
\text { sun exposure areas) }\end{array}$ & niacin \\
\hline & Excess bruises & vitamin $\mathrm{K}$, vitamin $\mathrm{C}$ \\
\hline & Desquamative cosmetic dermatosis & Kwashiorkor \\
\hline & Vulvar and scrotal dermatosis & riboflavin, vitamin $\mathrm{B} 2$ \\
\hline & $\begin{array}{l}\text { Xantomas (fat deposit under the skin and around the } \\
\text { joints) }\end{array}$ & hyperlipidemia \\
\hline \multirow{2}{*}{ Nails } & Koilonychia (spoon shape), brittle and rough. & iron \\
\hline & With small white spots & zinc \\
\hline \multirow{6}{*}{ Skeletal muscle system } & Muscle wear & starvation, marasmus \\
\hline & Epifisaria enlargement (increased extremities) & rickets \\
\hline & $\begin{array}{l}\text { Front-parietal boss (front edema / lateral head) } \\
\text { Persistence of the opening of the anterior fontanel }\end{array}$ & vitamin D \\
\hline & X leg or pie & vitamin C \\
\hline & Musculoskeletal hemorrhages & thiamin \\
\hline & $\begin{array}{l}\text { Calf laxity } \\
\text { Rickety rosary }\end{array}$ & vitamin D \\
\hline
\end{tabular}




\begin{tabular}{|c|c|c|}
\hline & Scurvy rosary & vitamin C \\
\hline Cardiovascular system & Heart augmentate & thiamin \\
\hline \multirow{3}{*}{ Digestive system } & Hepatosplenomegaly & Kwashiorkor \\
\hline & Psychomotor changes & Kwashiorkor \\
\hline & $\begin{array}{l}\text { depression } \\
\text { Sensory loss }\end{array}$ & $\begin{array}{l}\text { pyridoxine, vitamin } \\
\text { B12 }\end{array}$ \\
\hline Nervous system & $\begin{array}{c}\text { Motor weakness } \\
\text { Loss of sense of position } \\
\text { Loss of vibratory sensitivity } \\
\text { Loss of wrist and ankle contraction } \\
\text { Paraesthesia (Tingling of hands and feet) }\end{array}$ & thiamin \\
\hline
\end{tabular}

Therefore, biochemical tests in association with clinical examination enrich the diagnosis of the nutritional status of patients after bone marrow transplantation. The analysis of these data should always take into account the clinical condition of the patient, the use of medications, mainly corticosteroids and other immunosuppressive agents, among other factors that can influence the results and guide the treatment.

There is data in the literature that recommend the use of supplements with vitamins and amino acids in order to increase immunity and reduce inflammation and oxidative stress ${ }^{209}$. It has a meta-analysis published in 2016 that assesses the impact of this supplementation on the incidence of GVHD and infections associated with $\mathrm{HSCT}^{210}$. There were ten randomized clinical studies involving 681 HSCT recipients, 332 of whom received supplementation with vitamins and minerals with glutamine, n-acetylcysteine, selenium, and eicosapentaenoic acid (which is a fatty acid in the omega 3 family) and 349 received standard nutrition. Most of the studies included in this meta-analysis used parenteral nutrition; only two studies used enteral administration. Patients receiving vitamin supplementation had a 19\% decrease in the incidence of GVHD and there was no significant difference in the incidence of infections. The conclusion of the study was that the use of these supplements is associated with a reduced risk of GVHD probably as a result of better immune support and elimination of free radicals ${ }^{209}$. However, although the results of this meta-analysis are significant, there are limitations to this study, including the fact that the patient sample is relatively small. Therefore, further studies will be necessary to better evaluate the route, efficacy and duration of treatment ${ }^{209}$.

\section{VACCINATION IN HSCT RECIPIENTS}

In HSCT, patients reconstitute the immune system from new hematopoietic stem cells. Thus, the entire pre-transplant immune memory is lost. Memory $T$ and B-cells acquired by vaccination have thus to be reestablished, with the downside of a less favorable thymic and splenic environment due to the toxicity derived from the chemotherapy and/or radiotherapy used in the preparative regimen ${ }^{211}$.

Neutrophils are the first to recover within the first 15 to 20 days after transplantation. Next, there is an increase in the number of natural killer lymphocytes, but the production of $T$ lymphocytes and B lymphocytes from the new bone marrow takes months, even years to normalize. It is therefore necessary to restart the entire basic vaccination schedule so that specific antibodies are produced from the new mature plasmocytes.

Three months after transplantation it is already possible to start vaccination schedule, detailed in the Manual of Reference Centers for Special Immunobiologicals (CRIEs) ${ }^{212}$, spread throughout Brazil. It is important to note that vaccines against oral poliomyelitis (Sabin), Bacillus Calmette-Guérin (BCG), cholera, Oral typhoid fever and rotavirus are permanently contraindicated ${ }^{211,212}$, and we should always be cautious with regard to the yellow fever vaccine, as it can cause severe encephalitis if the patient is still immunosuppressed, being hence contraindicated in the first two years after transplantation or in the 
presence of immunosuppressive treatment, even in epidemic situations. Immunosuppressed patients should be removed for 45 days from home contacts receiving oral polio vaccine to prevent vaccine virus disease. All donors can update their vaccination card, except with live viruses, before donation. Patients and home contacts should be immunized annually against influenza.

It is important to emphasize that pneumococcus 23 vaccine should be used only as reinforcement, as it is less immunogenic than other pneumococcal vac- cines. Although the triple viral vaccine is usually offered from two years after transplantation, it can be started earlier, safely, in epidemic situations. There is an international recommendation for seasonal administration of palivizumab, monoclonal antibody against respiratory syncytial virus, devastating and fatal disease in young children after transplantation, although we have not yet obtained its approval in the public system of Brazil. ${ }^{212}$

Tables 13 and 14 illustrate the proposed vaccination schedules for patients who have undergone $\mathrm{HSCT}^{212}$.

TABLE 13: Recommendations of the Brazilian Society of Immunizations (SBIm) for children after hematopoietic stem cell transplantation (HSCT)212

\begin{tabular}{|c|c|c|c|}
\hline \multicolumn{4}{|c|}{ For children over 1 year and under 7 years of age } \\
\hline Inactivated vaccines & $\begin{array}{l}\text { Time to start } \\
\text { revaccination after } \\
\text { HSCT }\end{array}$ & $\begin{array}{l}\text { Dose scheme } \\
\text { Considering months } \\
\text { after HSCT }\end{array}$ & Comments \\
\hline Influenzae & $\begin{array}{l}\text { Ideal: six months } \\
\text { Minimum: three } \\
\text { months }\end{array}$ & $\begin{array}{c}\text { Prefer } 4 \mathrm{~V} \text { vaccine } \\
\text { Two doses: } 6 \text { - } 7 \text { months }\end{array}$ & $\begin{array}{l}\text {-Prefer 4V (if available) for providing } \\
\text { greater coverage of circulating } \\
\text { strains } \\
\text {-Vaccinate contacts in the same } \\
\text { household }\end{array}$ \\
\hline $\begin{array}{c}\text { Hexa acellular } \\
\text { (DTaP, polio inactivated, H. } \\
\text { Influenzae type B, Hepatitis B) } \\
\text { DTaP: acelular Pertussis-Tetanus- } \\
\text { Diphtheria }\end{array}$ & Six months & $\begin{array}{l}\text { Three doses: } 6-8-10 \\
\text { months }\end{array}$ & $\begin{array}{l}\text {-In case the Hexa vaccine is } \\
\text { unavailable, administer each of the } \\
\text { components separately. } \\
\text {-The use of polio vaccine (OPV) is } \\
\text { contraindicated } \\
\text {-Contactors should receive the IPV (if } \\
\text { indicated) }\end{array}$ \\
\hline $\begin{array}{l}\text { Pneumococcal conjugate } 13 \\
\text { (PCV13) or Pneumococcal } \\
\text { conjugate } 10 \text { (PCV10) }\end{array}$ & Six months & $\begin{array}{l}\text { Three doses: } 6 \text { - } 8 \text { - } 10 \\
\text { months }\end{array}$ & $\begin{array}{l}\text { Preferential use of PCV13 in order } \\
\text { to extend protection for the three } \\
\text { additional serotypes } \\
\text {-PCV10: for children under } 5 \text { years } \\
\text { old }\end{array}$ \\
\hline $\begin{array}{c}\text { Pneumococcal polysaccharide } \\
\text { vaccine } 23 \text { (PPSV 23) }\end{array}$ & $\begin{array}{l}\text { Two months after } \\
\text { last dose of PCV10 } \\
\text { or PCV13 }\end{array}$ & $\begin{array}{l}\text { For }>2 \text { years of age: } 2 \\
\text { doses. The first dose is } \\
\text { from } 12 \text { months after } \\
\text { HSCT. The second dose, } \\
\text { five years after the first }\end{array}$ & $\begin{array}{l}\text { The first dose should be applied at } \\
\text { least two months after the last dose } \\
\text { of PCV10 or PCV13 }\end{array}$ \\
\hline $\begin{array}{l}\text { Meningococcal ACWY or } \\
\text { Meningococcal C }\end{array}$ & Six months & $\begin{array}{l}\text { Two doses: } 7 \text { - } 9 \text { months } \\
\text { Apply a booster } \\
\text { five years later and } \\
\text { follow the scheme } \\
\text { recommended for age }\end{array}$ & $\begin{array}{l}\text { Whenever possible, prefer the } \\
\text { MenACWY vaccine for extended } \\
\text { protection }\end{array}$ \\
\hline Meningococcal B & Six months & Two doses: 7 - 9 months & - \\
\hline Hepatitis A & Six months & $\begin{array}{l}\text { Two doses: } 7 \text { and } 13 \\
\text { months }\end{array}$ & - \\
\hline
\end{tabular}




\begin{tabular}{|c|c|c|c|}
\hline Attenuated vaccines & $\begin{array}{l}\text { Time to start } \\
\text { revaccination after } \\
\text { HSCT }\end{array}$ & $\begin{array}{l}\text { Dose scheme } \\
\text { Considering months } \\
\text { after HSCT }\end{array}$ & Comments \\
\hline Measles/Mumps/Rubella (MMR) & $12-24$ months & $\begin{array}{c}\text { Two doses: } 24-25 \\
\text { months }\end{array}$ & $\begin{array}{l}\text {-If epidemiological risk and immune } \\
\text { status permits, it can be applied } \\
\text { from } 12 \text { months. Otherwise, wait } \\
24 \text { months or evidence of immune } \\
\text { system reconstitution } \\
\text {-Vaccinate contacts in the same } \\
\text { household }\end{array}$ \\
\hline Varicella-Zoster & 24 months & $\begin{array}{c}\text { Two doses: } 24 \text { - } 27 \\
\text { months }\end{array}$ & $\begin{array}{c}\text {-Vaccinate ifseronegative status } \\
\text {-Vaccinate contacts in the same } \\
\text { household }\end{array}$ \\
\hline Yellow fever & 24 months & One dose: 24 months & $\begin{array}{l}\text { If first dose applied before } 5 \text { years } \\
\text { of age, take two doses, with a } \\
\text { minimum of } 30 \text { days interval } \\
\text { between them }\end{array}$ \\
\hline
\end{tabular}

TABLE 14: Recommendations of the Brazilian Society of Immunizations (SBIm) for children, adolescents, and adults after hematopoietic stem cell transplantation (HSCT) 212

\begin{tabular}{|c|c|c|c|}
\hline \multicolumn{4}{|c|}{ Children aged $7>$, adolescents, adults, and the elderly } \\
\hline Inactivated vaccines & $\begin{array}{l}\text { Time to start } \\
\text { revaccination after } \\
\text { HSCT }\end{array}$ & $\begin{array}{l}\text { Dose scheme } \\
\text { Considering months } \\
\text { after HSCT }\end{array}$ & Comments \\
\hline Influenzae & $\begin{array}{l}\text { Ideal: six months } \\
\text { Minimum: three } \\
\text { months }\end{array}$ & $\begin{array}{l}\text {-Prefer } 4 \mathrm{~V} \text { vaccine } \\
\text { Children from } 7 \text { to } 8 \\
\text { years: two doses with } \\
\text { 30-day interval } \\
\text {-From } 9 \text { years: single } \\
\text { dose }\end{array}$ & $\begin{array}{c}\text {-Prefer } 4 \mathrm{~V} \text { (if available) for providing } \\
\text { greater coverage of circulating strains } \\
\text {-Vaccinate contacts in the same } \\
\text { household }\end{array}$ \\
\hline $\begin{array}{l}\text { DTaP/Polio inactivated } \\
\text { Polio inactivated: IPV }\end{array}$ & Six months & $\begin{array}{l}\text { Three doses: } 6 \text { - } 8 \text { - } 10 \\
\text { months }\end{array}$ & $\begin{array}{l}\text {-If the DTaP vaccine is not available, } \\
\text { administer dTpa and IPV separately } \\
\text {-Use of the polio vaccine (VOP) is } \\
\text { contraindicated } \\
\text {-Contactors should receive the IPV } \\
\text { (where indicated) }\end{array}$ \\
\hline $\begin{array}{l}\text { Pneumococcal conjugate } 13 \\
\text { (PCV13) }\end{array}$ & Six months & $\begin{array}{l}\text { Three doses: } 6 \text { - } 8 \text { - } 10 \\
\text { months }\end{array}$ & - \\
\hline H. Influenza B (Hib) & Six months & $\begin{array}{l}\text { Three doses: } 6 \text { - } 8 \text { - } 10 \\
\text { months }\end{array}$ & - \\
\hline $\begin{array}{l}\text { Pneumococcal polysaccharide } \\
\text { vaccine } 23 \\
\text { (PPSV 23) }\end{array}$ & $\begin{array}{l}\text { Two months after } \\
\text { last dose of PCV13 }\end{array}$ & $\begin{array}{l}\text { Two doses. The first } \\
\text { dose is from } 12 \\
\text { months of HSCT. The } \\
\text { second dose five } \\
\text { years after the first }\end{array}$ & $\begin{array}{l}\text { The first dose should be applied at least } \\
\text { two months after the last dose of PCV13 }\end{array}$ \\
\hline
\end{tabular}




\begin{tabular}{|c|c|c|c|}
\hline $\begin{array}{l}\text { Meningococcal ACWY or } \\
\text { Meningococcal C }\end{array}$ & Six months & $\begin{array}{l}\text { Two doses: } 7 \text { - } 9 \\
\text { months } \\
\text { Apply reinforcement } \\
\text { five years later } \\
\text { and follow the } \\
\text { recommended } \\
\text { scheme for age } \\
\text { for children and } \\
\text { adolescents }\end{array}$ & $\begin{array}{c}\text { Whenever possible, prefer the MenACWY } \\
\text { vaccine for extended protection }\end{array}$ \\
\hline Meningococcal B & Six months & $\begin{array}{l}\text { Two doses: } 7 \text { - } 9 \\
\text { months }\end{array}$ & - \\
\hline Hepatitis A & Six months & $\begin{array}{l}\text { Two doses: } 11 \text { and } 17 \\
\text { months }\end{array}$ & - \\
\hline Hepatitis B & Six months & $\begin{array}{l}\text { Three doses: } 11-12- \\
17 \text { months }\end{array}$ & - \\
\hline HPV & Six months & $\begin{array}{l}\text { Three doses: } 11-12 \text { - } \\
17 \text { months }\end{array}$ & From 9 years of age \\
\hline Attenuated vaccines & $\begin{array}{l}\text { Time to start } \\
\text { revaccination after } \\
\text { HSCT }\end{array}$ & $\begin{array}{l}\text { Dose scheme } \\
\text { Considering months } \\
\text { after HSCT }\end{array}$ & Comments \\
\hline $\begin{array}{l}\text { Measles/Mumps/Rubella } \\
\text { (MMR) }\end{array}$ & $12-24$ months & $\begin{array}{l}\text { Two doses: } 24-25 \\
\text { months }\end{array}$ & $\begin{array}{l}\text {-If epidemiological risk and immune } \\
\text { status permits, it can be applied } \\
\text { from } 12 \text { months. Otherwise, wait } 24 \\
\text { months or evidence of immune system } \\
\text { reconstitution } \\
\text {-Vaccinate contacts in the same } \\
\text { household }\end{array}$ \\
\hline Varicella Zoster & 24 months & $\begin{array}{l}\text { Two doses: } 24-25 \\
\text { months }\end{array}$ & $\begin{array}{c}\text {-Vaccinate seronegative patients }<50 \\
\text { years old } \\
\text {-Vaccinate contacts in the same } \\
\text { household }\end{array}$ \\
\hline Yellow fever & 24 months & Single dose & - \\
\hline Herpes Zoster & 24 months & Single dose & For $>50$ year-olds \\
\hline
\end{tabular}

\section{Key messages related to post-HSCT} vaccination: ${ }^{148,213}$

- Some centers start vaccination with inactivated vaccines six months after HSCT; however, it may be started three months after HSCT (depending on the risk-benefit ratio).

- Check titers for Streptococcus pneumoniae (IgG, 23 serotypes). If titer not checked at 12 months, check it at 24 months.

- In patients with chronic GVHD who are unlikely to respond to the Pneumococcal polysaccharide vaccine (Pneumo23), it is preferable to administer a 4th dose of the Pneumococcal-conjugate vaccine (Pneumo13).

\section{- Check anti-tetanus toxoid titer.}

- Hepatitis B: titer at the 24-month visit if not done at 20 months. Post-vaccination testing for antibody to hepatitis B surface antigen is recommended 1-2 months after the 3rd dose to ensure protection. Patients who do not respond to the primary vaccine series should receive a second three-dose series.

- For inactivated ("dead") virus vaccines, vaccination should be at least 2 months after the last dose of IVIG.

- The Meningococcal $B$ vaccine is recommended for patients with anatomic or functional asplenia conditions (i.e., chronic GVHD) or increased environmental risk. 
- For live virus vaccines, vaccination should be at least 5 months after the last dose of IVIG.

- To receive live virus vaccines: not until 2 years postHSCT and $>1$ year off all immunosuppressive therapy and at least 5 months since the last dose of IVIG/ VZIG (if possible).

- Check varicella serology at least 1-2 months after the second dose of the vaccine to ensure seroconversion of the VZV seronegative patient.

- For patients receiving immunotherapy, consider the vaccines after immunotherapy is completed. Counsel patients regarding risks/benefits

- Factors that might influence a decision to delay a series of vaccinations include:

- Delay of T cell recovery: CD4 T cells $<200 / \mu L$, active GVHD, IVIG therapy $<2$ months before, and patients receiving chemotherapy comprising therapeutic biological agents.

- Delay of B cell recovery: CD19 ou CD20 B cells < $20 / \mu \mathrm{L}$, anti CD20 antibody < 6 months, moderate to severe GVHD and patients receiving chemotherapy comprising therapeutic biological agents.

- If a patient is on disease-associated maintenance therapy that can affect $T$ or $B$ cell numbers, then before beginning vaccination: check CD19 or CD20 B cells to determine $>20 / \mu \mathrm{L}$ and check CD4 T cells to determine $>200 / \mu \mathrm{L}$.

- Inactivated vaccine injections should be used for family members who need vaccinations against polio. Isolation is necessary if live (oral) polio vaccine is administered to family members or other persons in close contact with the patient during the first year after the transplant or at any time during treatment with immunosuppressive medications. The virus can be shed for 8 to 12 weeks after vaccination.

- The smallpox vaccine is comprised of live vaccinia virus. Smallpox vaccination is contraindicated in HSCT recipients because it may result in the development of generalized vaccinia or inadvertent inoculation at other sites, such as the face, eyelid, nose, mouth, genitalia, and rectum. The smallpox vaccine should not be administered to any family members or other persons who share living space with the patient during the first year after transplant and beyond one year if the patient continues on treatment with immunosuppressive medications. If smallpox vaccination is administered to these close contacts, then these individuals should be prevented from having close contact with the immunocompromised HSCT recipient.
- All patients exposed to chickenpox or zoster during the first year after the transplant or during treatment with immunosuppressive medications should be evaluated. VZV seronegative patients and those not receiving prophylactic acyclovir should be treated with valacyclovir or acyclovir from days 3 to 22 after exposure unless treatment with ganciclovir, foscarnet or cidofovir is being given for another reason. In seronegative recipients, administrations of VZIG within 96 hours of exposure should also be used, if available, in addition to valacyclovir.

\section{PSYCHOLOGIC ASPECTS AND QUALITY OF LIFE IN PEDIATRIC PATIENTS UNDERGOING HSCT}

HSCT has become the only curative option for a myriad of life-threatening disorders in pediatric patients. Advances in this procedure (medical, technological, and pharmacological) over the past few decades have allowed for an increased ${ }^{214}$ number of transplants each year, with a dramatic improvement of pediatric HSCT survival rates. Even so, the literature is scarce as to the psychological and psychosocial effects HSCT on patients (and also on their siblings and parents) ${ }^{215}$. Children and adolescents experience a number of acute and long-term emotional, cognitive, social and familial reactions throughout the whole transplant process, from the pre-HSCT period, through hospitalization and the procedure itself, and during and after the recovery process ${ }^{216,217}$. Anxiety, depression, behavioral and social problems, and post-traumatic stress reactions are among the most commonly witnessed ones ${ }^{214,216}$. Of note, since a significant proportion of transplants depend on the patients' siblings as the best stem cell donor candidates or HLA-match for these patients, sibling donors, as well as parents, are also at risk of developing psychological distress, such as post-traumatic stress reactions, anxiety, and low self-esteem ${ }^{214,215}$. Parents of children undergoing allo-HSCT are also prone to psychological disturbances, with increased levels of anxiety and depression, particularly for those whose healthy child is also involved in the HSCT process as a stem cell donor.

This has raised the need for developing interventions for both pediatric patients and their families, with a view to devising interventions capable of decreasing distress and improving emotional and psychosocial functioning for children undergoing HSCT, siblings and parents. In this regard, a number of strategies have been proposed:

Cognitive behavioral interventions: the bulk of experience already gained with this strategy in caring 
for children with cancer and chronic illness has set a promising arena for furthering this approach to the HSCT pediatric population, with the aim of improving emotional distress, compliance with treatment, and behavioral issues related to transplant, thus improving social skills and overall emotional well-being.

Familial interventions: these aim at fostering protective factors, improving communication skills, and decreasing parental anxiety and depression.

Cancer-specific interventions: these may serve as a template for the development of HSCT-specific interventions.

\section{PSYCHOLOGICAL REACTIONS TO HSCT}

As mentioned previously, escalating anxiety tends to appear days to weeks before the actual transplant period in $\sim 40 \%$ of children, peaking around a week post-transplant ${ }^{218}$. According to Meyers et al., such levels of distress decrease sharply during the hospitalization period and remains at low levels eight months post- $\mathrm{HSCT}^{217}$. Another study assessing the psychosocial effects in HSCT survivors indicated that, at 3 months post-transplant, over $80 \%$ of children displayed moderate emotional distress symptoms ${ }^{219}$ Pot Mees et al., 1989, in turn, observed that around $40 \%$ of children undergoing HSCT exhibited significant increases in anxiety, depression, peer isolation, and behavioral problems, including aggression, during the first 6 months after transplant, compared with only $15 \%$ pre-HSCT. These authors point out that the numberless behavioral symptoms found in patients 6-months after transplant suggests an "after-stress reaction", similar to what is denoted "post-traumatic stress disorder ${ }^{219}$ Importantly, this post-traumatic stress reaction persisted for over a third (35\%) of these patients at 1-year post-transplant, thus underscoring the potential for long-term persistence of such distressful effects. ${ }^{219}$

There is ample evidence that depression heightens during hospitalization, worsens with prolonged hospital stay, and may endure for months after HSCT. $^{216,217,219,221}$

\section{PSYCHOSOCIAL PREDICTORS OF PSYCHOSOCIAL OUTCOMES AND ADJUSTMENT AFTER HSCT}

Identifying possible psychosocial factors present in children before HSCT as possible predictors of psychological outcomes in the post-transplant period may be of particular help in the post-HSCT management of this complication, by providing physicians and the multidisciplinary team with the necessary tools to better assess this vulnerable population as to the need for a more intensive or specialized strategies in the post-transplant period ${ }^{222}$. Adopting a more holistic approach may help in the post-traumatic adjustment process of both the patients and their families. In a study of 103 HCST patients from 3 to 17 years of age suggested that age at the time of transplant influences educational and cognitive outcomes, with older age being seemingly associated with better outcomes ${ }^{223}$. Patients who are at increased emotional distress, with extreme worrying and poor communication prior to HSCT, exhibit worse health-related quality of life (HRQL) after transplant ${ }^{225}$. On the other hand, certain patients and parent characteristics seem to help minimize the psychosocial impact of HSCT. Children who show greater optimism and resilience, for instance, tend to have better HRQL outcomes ${ }^{224}$ Barrera et al., 2008, showed that specific maternal factors, such as older maternal age and fewer maternal depression symptoms, are also associated with more favorable outcomes. Some familial attributes, such as the quality of family communication, may even affect $\mathrm{HRQL}$ to a greater degree than disease-specific factors ${ }^{224}$. Maternal anxiety after transplant is also associated with poorer HRQL in this population ${ }^{226}$. These findings highlight the need for an attentive approach to both patients and families to better identify potential pre-transplant factors that can be amenable to a timely and more focused approach in the post-HSCT period $^{217}$.

\section{EFFECT OF HSCT ON QUALITY OF LIFE}

HRQL is potentially affected during all stages of HSCT, starting at the pre-transplant phase, escalating in the acute post-HSCT phase (where rejection rates are high), persisting in the longer-term hospitalization period (with prolonged social isolation), and extending in the reintegration phase to life outside the hospital ${ }^{220}$.

Children undergoing HSCT tend to report low baseline levels of HRQL during hospitalization, with some studies showing that improvement ensues as early as 4 months post-transplant and that $\mathrm{HRQL}$ returns to baseline within 1 year of HSCT $^{214}$ However, this behavior may be modulated by certain factors, as follows:

1) Younger children (aged 5-12 years) experience higher HRQL than older children (aged 13-21 years). In one study, overall emotional functioning scores declined by 1.3 points on the emotional functioning domain for every 1 -year increase in age ${ }^{229}$; 
2) Children with lower socioeconomic (SE) status report lower HRQL between 3 and 6 months post$\mathrm{HSCT}^{230}$;

3) Lower intelligence quotient (IQ) and social competence have also been associated with a worse HRQL at 1-year post-transplant ${ }^{231}$;

4) Children undergoing an unrelated allo-HSCT were shown to report lower HRQL 3 months post-HSCT; nonetheless, no difference between allo-HSCT and autologous HSCT was observed 3 years post-HSCT; the effects on the HRQL of children undergoing HSCT may thus be short lived ${ }^{229,232}$;

Of note, factors such as gender, age at time of HSCT or pre-transplant disease symptoms were not consistently related to $\mathrm{HRQL}^{233}$.

\section{EFFECT OF HSCT ON PSYCHOSOCIAL FUNCTIONING AND COGNITIVE ABILITIES}

As in other chronic illnesses affecting children, both the baseline disease (e.g., relapse) and the potential post-transplant complications related to HSCT (e.g., chronic graft-versus-disease) may hinder a child's development by limiting the opportunities to participate in developmental and psychosocial behaviors $^{234}$. These children are particularly subject to cumbersome emotional and psychosocial adjustment processes. Absence from school after a prolonged period of time may diminish their social competence and self-esteem ${ }^{222}$. Even though most pediatric HSCT survivors return to school within 1-year of transplant, these children tend to exhibit increased behavioral problems, as well as social isolation and lower academic level functioning compared to their same age counterparts ${ }^{219}$. This may either be due to actual cognitive effects or to the prolonged period of absence from school itself $f^{219,235}$.

The presence of neurological and cognitive sequelae of the HSCT process, including that resulting from the preparative regimens, is critical for the reintegration of both patients and families to the outside world ${ }^{236}$. The extent of such deficits is intrinsically related to the ability of pediatric survivors to transition back to school and society as a whole ${ }^{235}$.

The current evidence is inconsistent in regard to the topic of neurological deterioration after HSCT. Although earlier studies suggested that significant, global declines in pre- and post-cognitive function- ing did occur after transplant, more research findings suggest that the impact of HSCT on pediatric patients' cognitive abilities may actually be more modest, based on baseline to post-HSCT measurements ${ }^{229-242}$. This may vary depending on certain patient and HSCT-related factors, such as age at the time of HSCT and use of total body irradiation (TBI) in the condition regimen or not ${ }^{236}$. Younger age (i.e., $<2$ years) at transplantation has been related to a worse cognitive outcome, with a higher risk for deficits in IQ scores, academic achievement, fine motor skills, and memory 238,243 . It is noteworthy, though, that children who are more fully developed at the time of HSCT are less likely to exhibit significant deterioration in their cognitive and functioning skills after transplant ${ }^{236,244}$.

In summary, HSCT affects virtually all aspects of a child's life, with long-term effects on the psychosocial arena and on overall quality of life. This highlights the need for a systematic assessment of preHSCT psychosocial factors that may allow for timely, targeted interventions to undermine the effects of such factors on overall, post-transplant functioning. Unfortunately, almost all of the known protective or unfavorable characteristics that affect HSCT outcomes in the pediatric population are constitutional and, hence, cannot be modified by specific interventions. Nonetheless, identifying non-constitutional characteristics in these children may help modulate the deleterious impact of HCST and enable a better plan for the future of these patients.

\section{CONCLUSIONS}

HSCT offers a curative approach for otherwise lethal diseases. Today, the long-term prognosis has greatly improved. Nevertheless, there are still a number of malignant and non-malignant late effects that can cause substantial morbidity, with considerable impact on the health status and quality of life of long-term survivors. A broad expertise is mandatory to manage long-term survivors. Aftercare of longterm survivors includes a standardized screening, counselling of the patients as well as prevention and treatment of late effects.

Beyond immediate survival, HSCT is a lifelong commitment between long-term survivors and the transplant team, involving the recipient's family and the general healthcare providers. 


\section{REFERENCES:}

1. Bradfield, Y. S.; Kushner, B. J.; Gangnon, R. E. Ocular complications after organ and bone marrow transplantation in children. Journal of AAPOS: the official publication of the American Association for Pediatric Ophthalmology and Strabismus, oct 2005, v. 9, n. 5, p. 426-432.

2. Inamoto $Y$, Petricek I, Burns L, Chrabra S, DeFelipp Z, Hematti P, et al. Non-GVHD ocular complications after hematopoietic cell transplantation: expert review from the Late Effects and Quality of Life Working Committee of the CIBMTR and Transplant Complications Working Party of the EBMT. Bone Marrow Transplantation, may 2019, v. 54 , n. 5 , p. 648-661.

3. Teär fahnehjelm K, Tornquist AL, Olsson M, Backstrom I, Gronlund MA,Winiarski J. Cataract after allogeneic hematopoietic stem cell transplantation in childhood. Acta Paediatrica, jan 2016, v. 105, n. 1, p. 82-89.

4. Kosrirukvongs, P. Chirapapaisan N, Visuthisakcai S, Issaragrisil S, Gonggetayai. Sjögren-like syndrome after bone marrow transplantation. Journal of the Medical Association of Thailand = Chotmaihet Thangphaet, nov 2008, v. 91, n. 11, p. 1739-1747.

5. Avery, R, Jabs DA, WIngard JR, Vogelsang G, Saral R, Santos G. Optic Disc Edema after Bone Marrow Transplantation: Possible Role of Cyclosporine Toxicity. Ophthalmology, 1 aug 1991, v. 98, n. 8, p. 1294-1301.

6. Yoo Y-S, Na S-K, Shin JA, Park YH, Lee JW. Posterior eye segment complications related to allogeneic hematopoietic stem cell transplantation. Retina, jan 2017, v. 37, n. 1, p. 135-143.

7. Green, W, Rao K P, Harocopos G. J. Extramedullary Relapse of Acute Myelogenous Leukemia Presenting as a Large Serous Retinal Detachment. Ocular Oncology and Pathology, jul 2017 v. 3, n. 2, p. 95-100.

8. Hormigo A, Abray L, Heinemann M-H, DeAngelis L. Ocular presentation of primary central nervous system lymphoma: diagnosis and treatment. British Journal of Haematology, 2004, v. 126, n. 2, p. 202-208.

9. Takeda A, Shigematsu N, Suzuki S, Fujii M, Kawaguchi O, Takano $\mathrm{H}$, et al. Late retinal complications of radiation therapy for nasal and paranasal malignancies: relationship between irradiated-dose area and severity. International Journal of Radiation Oncology, Biology, Physics, 1 jun 1999, v. 44, n. 3, p. 599-605.

10. Da Fonseca, M. A. Long-term oral and craniofacial complications following pediatric bone marrow transplantation. Pediatric Dentistry, feb 2022, v. 22, n. 1, p. 57-62.

11. Dahllöf G, Forsberg CM., Borgström, B. Changes in craniofacial development induced by growth hormone therapy in children treated with bone marrow transplantation. Acta Paediatrica (Oslo, Norway: 1992), nov 1994, v. 83, n. 11, p. $1165-$ 1169.

12. Wingard, J. R. Opportunistic infections after blood and marrow transplantation. Transplant Infectious Disease: An Official Journal of the Transplantation Society, mar 1999, v. 1, n. 1, p. 3-20.

13. Luiz, AC, Eduardo FP, Bezinelli LM, Correa L. Alterações bucais e cuidados orais no paciente transplantado de medula óssea. Revista Brasileira de Hematologia e Hemoterapia, dec 2008, v. 30, n. 6.

14. Sanders JE, Woolfrey AE, Carpenter PA, Storer $B E$, Hoffmeister PA, Deeg HJ, et al. Late effects among pediatric patients followed for nearly 4 decades after transplantation for severe aplastic anemia. Blood, 4 aug 2011, v. 118, n. 5, p. 14211428.

15. Dvorak CC, Gracia CR, Sanders JE, Cheng EY, Baker KS, Pulsipher MA, et al. NCl, NHLBI/PBMTC First International Conference on Late Effects after Pediatric Hematopoietic Cell Transplantation: Endocrine Challenges-Thyroid Dysfunction, Growth Impairment, Bone Health, \&amp; Reproductive Risks [internet]. Elsevier Enhanced Reader. Dec 2011. v.17, p.1725-1738. Available from: <https://reader.elsevier.com/reader/sd/pii/ S1083879111004095?token=216DAFC78999F7799D64A1AA413F7B09D3DF4445345FB78DFE ED87D49A395F14DAEAC3A7AF757393E8782DEA09C1436C\&originRegion=us-east-1 \&originCreation $=20210610011230>$ Accessed: June 9th, 2021.

16. Ruble K, Hayat MJ, Stewart KJ, Chen AR. Bone Mineral Density after Bone Marrow Transplantation in Childhood: Measurement and Associations [internet] Elsevier Enhanced Reader. oct 2010, v.16, p.1451-1457. Available from: <https://reader.elsevier. 
com/reader/sd/pii/S1083879110001655?token $=9$ B9CB5DF6735B0A369CE37F61BDE5F64463A034EB20E82B7A6650AD10DD2 3E2C4C12E5363AA979ED59D218E481DA3B86\&originRegion=us-east-1\&originCreation=20210610013315>. Accessed: June 9th, 2021.

17. Vierucci F, Saggese G, Cimaz R. Osteoporosis in childhood. Current Opinion in Rheumatology, sep 2017 , v. 29, n. 5, p. 535-546.

18. Ward L. M, Konji VN, Ma J. The management of osteoporosis in children. Osteoporosis International, jul 2016, v. 27, n. 7, p. 2147-2179.

19. Rodd C, Land B, Ramsay T, Alos N, Huber AM, Cabral DA. et al. Incident vertebral fractures among children with rheumatic disorders 12 months after glucocorticoid initiation: a national observational study. Arthritis Care \& Research, jan 2012, v. 64, n. 1, p. 122-131.

20. Specker B, Thiex NW, Sudhagoni RG. Does Exercise Influence Pediatric Bone? A Systematic Review. Clinical Orthopaedics and Related Research, nov 2015 , v. 473, n. 11, p. 3658-3672.

21. Institute of Medicine (US) Committee to Review Dietary Reference Intakes for Vitamin D and Calcium; Ross AC, Taylor CL, Yaktine AL, et al., editors. Dietary Reference Intakes for Calcium and Vitamin D. Washington (DC): National Academies Press (US); 2011. Available from: https:// www.ncbi.nlm.nih.gov/books/NBK56070/ doi: $10.17226 / 13050$

22. Simm PJ, Biggin A, Zacharin MR, Rodda CP, Tham E, Siafarikas A. et al. Consensus guidelines on the use of bisphosphonate therapy in children and adolescents: Bisphosphonates in young people. Journal of Paediatrics and Child Health, mar 2018, v. 54, n. 3, p. 223-233.

23. Carpenter PA, Hoffmeister $\mathrm{P}$, Chesnut $\mathrm{CH}$, Storer $B$, Charuhas PM, Woolfrey AE, et al. Bisphosphonate Therapy for Reduced Bone Mineral Density in Children with Chronic Graft-versus-Host Disease. Biology of Blood and Marrow Transplantation, jun 2007, v. 13, n. 6, p. 683-690.

24. Mcclune B, Majhail NS, Flowers MED. Bone Loss and Avascular Necrosis of Bone After Hematopoietic Cell Transplantation. Seminars in Hematology, jan 2012, v. 49, n. 1, p. 59-65.

25. Chow EJ, Anderson L, Baker KS, Bhatia S, Guilcher GMT, Huang JT, et al. Late Effects Sur- veillance Recommendations among Survivors of Childhood Hematopoietic Cell Transplantation: A Children's Oncology Group Report. Biology of Blood and Marrow Transplantation, may 2016 , v. 22, n. 5, p. 782-795.

26. Li X, Brazauskas R, Wang Z, Al-Seraihy A, Baker KS, Cahn JY, et al. Avascular Necrosis of Bone after Allogeneic Hematopoietic Cell Transplantation in Children and Adolescents. Biology of Blood and Marrow Transplantation, apr 2014, v. 20, n. 4, p. 587-592.

27. Long-Term Follow-Up After Hematopoietic Stem Cell Transplant General Guidelines for Referring Physician. Version Jun 2021. Available from: https://www.fredhutch.org/content/dam/ www/research/patient-treatment-and-support/ Itfu/LTFU_HSCT_guidelines_physicians.pdf . Accessed: June 9th, 2021.

28. Ullmann AJ, Schmidt-Hieber M, Bertz H, Heinz WJ, Kiehl M, Kruger W. On behalf of the infectious diseases working party of the german society for hematology and medical oncology (agiho/dgho) and the dag-kbt (german working group for blood and marrow transplantation) et al. Infectious diseases in allogeneic haematopoietic stem cell transplantation: prevention and prophylaxis strategy guidelines 2016. Annals of Hematology, sep 2016, v. 95, n. 9, p. 1435-1455.

29. Bacigalupo A, Metafuni E, Amato V, Marquez Algaba E, Pagano L. Reducing infectious complications after allogeneic stem cell transplant. Expert Rev Hematol. 2020 Nov 13(11):1235-1251. doi: 10.1080/17474086.2020.1831382. Epub 2020 Nov 3. PMID: 32996342.

30. Bordon V, Bravo S, Renterghem LV, Moerloose $B$, Benoit Y, Laureys G, et al. Surveillance of cytomegalovirus (CMV) DNAemia in pediatric allogeneic stem cell transplantation: incidence and outcome of CMV infection and disease. Transplant Infectious Disease, feb 2008, v. 10, n. 1, p. 19-23.

31. Jerry Teng CL, Wang PN, Chen YC, Ko BS. Cytomegalovirus management after allogeneic hematopoietic stem cell transplantation: A mini-review. J Microbiol Immunol Infect. Jun 2021, 54(3):341-348. doi: 10.1016/j.jmii.2021.01.001. Epub 2021 Jan 13. PMID: 33514495.

32. Ljungman $P$, de la Camara R, Robin $C$, Crocchiolo R, Einsele H, Hill JA, et al; 2017 European Conference on Infections in Leukaemia group. 
Guidelines for the management of cytomegalovirus infection in patients with haematological malignancies and after stem cell transplantation from the 2017 European Conference on Infections in Leukaemia (ECIL 7). Lancet Infect Dis. 2019 Aug 19, (8):e260-e272. doi: 10.1016/S14733099(19)30107-0. Epub 2019 May 29. PMID: 31153807.

33. Mendes AVA, Carlasse F, Schirmer MR, Garnica M, Batista MV, Cappellano P, et al. CONSENSO SBTMO 2015 - MANEJO DE INFECÇÕES EM TRANSPLANTE DE CÉLULAS TRONCO-HEMATOPOIÉTICAS CONSENSO SBTMO 2015. p. 141, [s.d.]. [internet]. SBTMO, 2015. Available from: https:// sbtmo.org.br/consensos-sbtmo/\#uagb-tabs__ tab0. Accessed: June 9th, 2021.

34. Shigle TL, Handy VW, Chemaly RF. Letermovir and its role in the prevention of cytomegalovirus infection in seropositive patients receiving an allogeneic hematopoietic cell transplant. Therapeutic Advances in Hematology, jun 2020, v. 11, p. 2040620720937150.

35. Prentice HG, Gluckman E, Powles RL, Lugnman P, Milpied N, Ranada JMF, et al. Impact of long-term acyclovir on cytomegalovirus infection and survival after allogeneic bone marrow transplantation. European Acyclovir for CMV Prophylaxis Study Group. Lancet (London, England), mar 1994, v. 343, n. 8900, p. 749-753, 26.

36. Ljungman P, Camara RL, Milpied N, Volin L, Russell CA, Crisp A, et al. Randomized study of valacyclovir as prophylaxis against cytomegalovirus reactivation in recipients of allogeneic bone marrow transplants. Blood, apr 2002, v. 99, n. 8, p. 3050-3056, 15.

37. Hazar V, Karasu GT, Uygun V, Ozturk G, Kiliç SC, Kupesiz A, et al. Risks and outcomes of invasive fungal infections in pediatric allogeneic hematopoietic stem cell transplant recipients receiving fluconazole prophylaxis: a multicenter cohort study by the Turkish Pediatric Bone Marrow Transplantation Study Group. Medical Mycology, feb 2019, v. 57, n. 2, p. 161-170.

38. Groll A, Castagnola E, Cesaro S, Dalle JH, Engelhard D, Hope W, et al. Fourth European Conference on Infections in Leukaemia (ECIL-4): guidelines for diagnosis, prevention, and treatment of invasive fungal diseases in paediatric patients with cancer or allogeneic haemopoietic stemcell transplantation. The Lancet Oncology, jul 2014, v. 15, n. 8, p. e327-e340.
39. Shalitin S, Pertman L, Yackobovitch-Gavan M, Yaniv I, Lebenthal Y, Phillip M, et al. Endocrine and Metabolic Disturbances in Survivors of Hematopoietic Stem Cell Transplantation in Childhood and Adolescence. Horm Res Paediatr. 2018;89(2):108-121. doi: 10.1159/000486034. Epub 2018 Jan 19. PMID: 29353275.

40. Matsumoto $M$, Ishiguro $H$, Tomita $Y$, Inoue $\mathrm{H}$, Yasuda $\mathrm{Y}$, Shimizu $T$, et al. Changes in thyroid function after bone marrow transplant in young patients. Pediatr Int. 2004 Jun;46(3):2915. doi: 10.1111/j.1442-200x.2004.01894.x. PMID: 15151545.

41. Shalitin S, Phillip M, Stein J, Goshen Y, Carmi D, Yaniv I. Endocrine dysfunction and parameters of the metabolic syndrome after bone marrow transplantation during childhood and adolescence. Bone Marrow Transplantation, jun 2006, v. 37, n. 12, p. 1109-1117.

42. Siviero-miachon AA, Spinola-castro AM, Guerra-junior $G$. Detection of metabolic syndrome features among childhood cancer survivors: A target to prevent disease. Vascular Health and Risk Management, aug 2008, v. 4, n. 4, p. 825836.

43. Matsumoto $M$, Shinonara O, Ishiguro $H$, Shimizu T, Hattori K, Ichikawa M, et al. Ovarian function after bone marrow transplantation performed before menarche. Archives of Disease in Childhood, may 1999, v. 80, n. 5, p. 452-454.

44. Majhail NS, Rizzo JD, Lee SJ, Aljurf M, Atsuta Y, Bonfim C, et al. Recommended Screening and Preventive Practices for Long-term Survivors after Hematopoietic Cell Transplantation. Bone Marrow Transplantation, mar 2012, v. 47, n. 3, p. 337-341.

45. Ishiguro $H$, Yasuda $Y$, Shinagawa $T$, Shimizu $T$, Morimoto T, Hattori K, et al. Gonadal shielding to irradiation is effective in protecting testicular growth and function in long-term survivors of bone marrow transplantation during childhood or adolescence. Bone Marrow Transplantation, apr 2007, v. 39, n. 8, p. 483-490.

46. Jadoul P, Donnez J. How does bone marrow transplantation affect ovarian function and fertility? Current Opinion in Obstetrics \& Gynecology, jun 2012 , v. 24, n. 3, p. 164-171.

47. Crowne $E$, Gleeson $H$, Benghiat $H$, Sanghera P,Toogood A. Effect of cancer treatment on hypothalamic-pituitary function. The Lancet. Di- 
abetes \& Endocrinology, jul 2015, v. 3, n. 7, p. $568-576$.

48. Mayson SE, Parker VER, Schutta MH, Semple RK, Rickels MR. Severe insulin resistance and hypertriglyceridemia after childhood total body irradiation. Endocrine Practice: Official Journal of the American College of Endocrinology and the American Association of Clinical Endocrinologists, feb 2013, v. 19, n. 1, p. 51-58.

49. Styczynski J, van der Velden W, Fox CP, Engelhard D, de la Camara R, Cordonnier C, et al; Sixth European Conference on Infections in Leukemia, a joint venture of the Infectious Diseases Working Party of the European Society of Blood and Marrow Transplantation (EBMT-IDWP), the Infectious Diseases Group of the European Organization for Research and Treatment of Cancer (EORTC-IDG), the International Immunocompromised Host Society (ICHS) and the European Leukemia Net (ELN). Management of Epstein-Barr Virus infections and post-transplant lymphoproliferative disorders in patients after allogeneic hematopoietic stem cell transplantation: Sixth European Conference on Infections in Leukemia (ECIL-6) guidelines. Haematologica. 2016 Jul;101(7):803-11. doi: 10.3324/haematol.2016.144428. PMID: 27365460; PMCID: PMC5004459.

50. Dharnidharka VR, Webster AC, Martinez OM, Preiksaitis JK, Leblond V, Choquet S. Post-transplant lymphoproliferative disorders. Nat Rev Dis Primers. (2016) 2:1508810.1038/nrdp.2015.88

51. Styczynski J, Giebel S, Carreras E, Dufour C, Mohty M, Kroger N. Posttransplant Lymphoproliferative Syndromes. In: Carreras E, Dufour C, Mohty M, et al., editors. The EBMT Handbook: Hematopoietic Stem Cell Transplantation and Cellular Therapies [Internet]. 7th edition. Cham (CH): Springer; 2019. Chapter 45. Available from: https:// www.ncbi.nlm.nih.gov/books/NBK553957/ doi: 10.1007/978-3-030-02278-5_45

52. Comoli P, Basso S, Zecca M, Pagliara D, Baldanti $F$, Bernardo ME, et al. Preemptive therapy of EBV-related lymphoproliferative disease after pediatric haploidentical stem cell transplantation. Am J Transplant. 2007; 7(6):1648-55. 10.1111/j.1600-6143.2007.01823.

53. Cheson BD, Fisher RI, Barrington SF, Cavalli F, Schwartz LH, Zucca E et al. Recommendations for initial evaluation, staging, and response assessment of Hodgkin and non-Hodgkin lym- phoma: the Lugano classification. J Clin Oncol. 2014;32(27):3059-3068

54. Allen UD, Preiksaitis JK. Post-transplant lymphoproliferative disorders, Epstein-Barr virus infection, and disease in solid organ transplantation: Guidelines from the American Society of Transplantation Infectious Diseases Community of Practice. Clin Transplant. 2019 Sep;33(9):e13652. doi: 10.1111/ctr.13652. Epub 2019 Jul 23.

55. Cesaro S, Pegoraro A, Tridello G, Calore E, PilIon $\mathrm{M}$, Varotto $\mathrm{S}$, et al. A prospective study on modulation of immunosuppression for epstein-barr virus reactivation in pediatric patients who underwent unrelated hematopoietic stem-cell transplantation. Transplantation;2010; 89(12):1533-40. doi:10.1097/TP.0b013e3181dd6c0a

56. Styczynski J, Einsele H, Gil L, Ljungman P. Outcome of treatment of Epstein-Barr virus-related post-transplant lymphoproliferative disorder in hematopoietic stem cell recipients: a comprehensive review of reported cases.Transpl Infect Dis. 2009; 11(5):383-92

57. Styczynski J, Gil L, Tridello G, Ljungman P, Donnelly JP, van der Velden W, et al. Response to rituximab-based therapy and risk factor analysis in Epstein Barr virus-related lymphoproliferative disorder after hematopoietic stem cell transplant in children and adults: a study from the infectious diseases working party of the European group for blood and marrow transplantation. Clin Infect Dis. (2013) 57(6):794-802. doi:10.1093/cid/cit391

58. Al Hamed R, Bazarbachi AH, Mohty M. Epstein-Barr virus-related post-transplant lymphoproliferative disease (EBV-PTLD) in the setting of allogeneic stem cell transplantation: a comprehensive review from pathogenesis to forthcoming treatment modalities. Bone Marrow Transplant. 2020 Jan; 55(1):25-39.

59. Prockop S, Doubrovina E, Suser S, Heller G, Barker J, Dahi P, et al. Off-the-shelf EBV-specific $T$ cell immunotherapy for rituximab-refractory EBV-associated lymphoma following transplantation. J Clin Invest. 2020;130(2):733-47. doi: 10.1172/JCl121127

60. Lucarelli G, Angelucci E, Giardini C, Baronciani D, Galimberti M, Polchi P et al. Fate of iron stores in thalassaemia after bone-marrow transplantation. Lancet. 1993;4;342(8884):1388-91. 
61. Busca A, Falda M, Manzini P, D'Antico S, Valfrè A, Locatelli F et al. Iron Overload in Patients Receiving Allogeneic Hematopoietic Stem Cell Transplantation: Quantification of Iron Burden by a Superconducting Quantum Interference Device (SQUID) and Therapeutic Effectiveness of Phlebotomy. Biology of Blood and Marrow Transplantation, 2010; 16(1):115-122

62. Angelucci E. Iron Overload. In: Carreras E, Dufour C, Mohty M, et al., editors. The EBMT Handbook: Hematopoietic Stem Cell Transplantation and Cellular Therapies [Internet]. 7th edition. Cham (CH): Springer; 2019. Chapter 46.

63. Quinn CT, Pierre TGS. MRI Measurements of Iron Load in Transfusion-Dependent Patients: Implementation, Challenges, and Pitfalls. Pediatr Blood Cancer. 2016 May; 63(5): 773-780.

64. Christian R, Olivier E, Bernard H, Maboudou P, Renom P, Noel MP et al. Quantification by magnetic resonance imaging and liver consequences of post-transfusional iron overload alone in long-term survivors after allogeneic hematopoietic stem cell transplantation. Haematologica June 2007 92(6): 850-853; doi:10.3324/haematol. 11063

65. Angelucci, E and Pilo, F. Management of iron overload before, during, and after hematopoietic stem cell transplantation for thalassemia major. Annals of the New York Academy of Sciences. 2016, 1368(1), 115-121. doi:10.1111/nyas.13027

66. Li CK, Lai DH, Shing MM, Chik KW, Lee V, Yuen PM. Early iron reduction programme for thalassaemia patients after bone marrow transplantation. Bone Marrow Transplant, 2000, 25(6): 653-656.

67. Giardini, CM, Galimberti G, Lucarelli, Polchi P, Angelucci $E$ et al. Desferrioxamine therapy accelerates clearance of iron deposits after bone marrow transplantation for thalassaemia. Br. J. Haematol, 1995; 89(4): 868-873

68. Trottier BJ, Burns LJ, DeFor TE, Cooley S, Majhail NS. Association of iron overload with allogeneic hematopoietic cell transplantation outcomes: a prospective cohort study using R2-MRI-measureed liver content. Blood. 2013:122(9): 16781684

69. Hockenbery DM., Strasser SI \& McDonald GB, 2016. Gastrointestinal and Hepatic Complications. Thomas' Hematopoietic Cell Transplantation, 1140-1160. doi:10.1002/9781118416426.ch94
70. Strasser SI, Shulman HM, Flowers MED, Reddy $\mathrm{R}$, Margolis DA, Prumbaum $\mathrm{M}$ et al. Chronic graft-vs-host disease of the liver: Presentation as an acute hepatitis. Hepatology, 2000, 32(6): $1265-1271$

71. Wingard JR, Vogelsang GB, Deeg HJ. Stem cell transplantation: supportive care and long-term complications. Hematology (Am Soc Hematol Educ Program) 2002:422-444

72. Campo L, Leon NG, Palacios DC, Lagana C, Tagarro D. Abdominal Complications Following Hematopietic Stem Cell Transplantation. RadioGraphics 2014; 34(2): 396-412.

73. Filipovich AH, Weisdorf D, Pavletic S, Socie G, Wingard JR, Lee SJ et al. National Institutes of Health consensus development project on criteria for clinical trials in chronic graftversus-host disease. I. Diagnosis and staging working group report. Biol Blood Marrow Transplant 2005; 11(12):945-956.

74. Benya EC, Goldman S. Bone Marrow Transplantation in Children. Pediatr. Clin. North Am. 1997;44(3):741-761. doi: 10.1016/S00313955(05)70502-2.

75. Dulamea A.O., Lupescu IG. Neurological complications of hematopoietic cell transplantation in children and adults. Neural Regen. Res. 2018;13(6):945-954. doi: 10.4103/16735374.233431.

76. Sostak P, Padovan C, Yousry T, Ledderose G, Kolb HJ, Straube A. Prospective evaluation of neurological complications after allogeneic bone marrow transplantation. Neurology. 2003;60(5):842-848.

77. Weber C, Schaper J, Tibussek D, Adams O, Mackenzie $C R$, Dilloo $D$ et al. Diagnostic and therapeutic implications of neurological complications following paediatric haematopoietic stem cell transplantation. Bone Marrow Transplant. 2008;41(3):253-9. doi: 10.1038/sj.bmt.1705905. Epub 2007 Nov 5. PMID: 17982498.

78. Dowling MR, Li S, Dey BR, McAfee SL, Hock HR, Spitzer TR et al. Neurologic complications after allogeneic hematopoietic stem cell transplantation: Risk factors and impact. Bone Marrow Transplant. 2017, 53(2), 199-206.

79. Kang J-M, Kim YJ, Kim, JY, Cho EJ, Le JH, Lee MH et al. Neurologic Complications after Allogeneic Hematopoietic Stem Cell Transplantation in Chil- 
dren: Analysis of Prognostic Factors. Biol. Blood Marrow Transplant. 2015, 21(6), 1091-1098.

80. Schmidt-Hieber M, Silling G, Schalk E, Heinz W, Panse J, Penack $O$ et al. CNS infections in patients with hematological disorders (including allogeneic stem-cell transplantation) — Guidelines of the Infectious Diseases Working Party (AGIHO) of the German Society of Hematology and Medical Oncology (DGHO). Ann. Oncol. 2016, 27(7), 1207-1225.

81. Uckan D, Cetin M, Yigitkanli, I, Tezcan I, Tuncer $M$, Karasimav $D$ et al. Life-threatening neurological complications after bone marrow transplantation in children. Bone Marrow Transplant. 2004, 35(1), 71-76

82. Grauer O, Wolff D, Bertz H, Greinix H, Kuhl JS, Lawitschka $A$ et al. Neurological manifestations of chronic graft-versus-host disease after allogeneic haematopoietic stem cell transplantation: Report from the Consensus Conference on Clinical Practice in chronic graft-versus-host disease. Brain 2010, 133(10), 2852-2865.

83. Unal S, Sag E, Kuskonmaz B, Kesici S, Bayrakci $B$, Ayvaz DC et al. Successful treatment of severe myasthenia gravis developed after allogeneic hematopoietic stem cell transplantation with plasma exchange and rituximab. Pediatr Blood Cancer. 2014;61(5):928-930.

84. Tse S, Saunders EF, Silverman E, Vajsar J, Becker L, Meaney B. Myasthenia gravis and polymyositis as manifestations of chronic graftversus-host-disease. Bone Marrow Transplant. 1999;23(4):397-399.

85. Meadows AT, Friedman DL, Neglia JP, Mertens AC, Donaldson SS, Stovall M et al. Second neoplasms in survivors of childhood cancer: findings from the Childhood Cancer Survivor Study cohort. J Clin Oncol. 2009;27(14):2356-2362.

86. Sharafeldin N, Bosworth A, Patel S, Chen Y, Morse $\mathrm{E}$, Mather $\mathrm{M}$ et al. Cognitive functioning after hematopoietic cell transplantation for hematologic malignancy: results from a prospective longitudinal study. J. Clin Oncol. 2018;36(5):463-475.

87. Yen KT, Lee AS, Krowka MJ, Burger CD. Pulmonary complications in bone marrow transplantation: a practical approach to diagnosis and treatment. Clin Chest Med. 2004; 25(1):189-201

88. Tichelli A, Rovó A, Gratwohl A. Late pulmonary, cardiovascular and renal complications after he- matopoietic stem cell transplantation and recommended screening practices. Hematology Am Soc Hematol Educ Program 2008; 125-33

89. Yoshihara S, Yanik G, Cooke KR, Mineishi S. Bronchiolitis obliterans syndrome (BOS), bronchiolitis obliterans organizing pneumonia (BOOP) and other lase-onset noninfectious pulmonary complications following allogeneic hematopoietic stem cell transplantation. Biol Blood Marrow Transplant. 2007; 13(7):749-759.

90. American Thoracic Society/European Respiratoty Society International Multidisciplinary Consensus Classification of the Idiopathic Interstitital Pneumonias. This Joint Statement of the Amercan Thoracic Society (ATS), and the European Respiratory Society (ERS) was adopted by the ATS Board of Directors, June 2001 and by the ERS Executive Committee, June 2001. American Thoracic Society; European Respiratory Society. Am J Respir Crit Care Med. 2002; 165(2):277-304.

91. Majhail NS, Rizzo JD, Lee SJ, Alijurf M, Atsuta Y, Bonfim $C$ et al. Recommended screening and preventive practices for longterm survivors after hematopoietic cell transplantation. Biol Blood Marrow Transplant. 2012; 18(3):348-371.

92. Cerveri I, Fulgoni P, Giorgiani G, Zoia MC, Beccaria $M$, Tinelli $C$ et al. Lung function abnormalities after bone marrow transplantation in children: has the trend recently changed?. Chest, 2001; 120(6):1900-1906.

93. Uderzo C, Pillon M, Corti P, Tridello G, Tana F, Zintl F et al. Impact of cumulative anthracycline dose, preparative regimen and chronic graft versus host disease on pulmonar and cardiac function in children 5 years after allogeneic hematopoietic stem cell transplantation: a prospective evaluation on behalf of the EBMT Pediatric Diseases and Late Effects Working Parties. Bone Marrow Transplant. 2007; 39(11):667-675.

94. Wolff D, Reichenberger F, Steiner B, Kahl C, Leithauser M, Skibbe T et al. Progressive interstitial fibrosis of the lung in sclerodermoid chronic graft versus host disease. Bone Marrow Transplant. 2002; 29(4):357-360.jagasia

95. Jagasia $\mathrm{MH}$, Hildegard TG, Arora M, Williams KM, Wolff D, Cowen EW et al. National Institutes of Health Consensus Development Project on Criteria for Clinical Trials in Chronic Graft-versusHost Disease: I. The 2014 Diagnosis and Staging Working Group Report. Biol Blood Marrow Transplant, 2015; 21(3): 389-401. 
96. Williams KM, Chien JW, Gladwin MT, Pavletic SZ. Bronchiolitis obliterans after allogeneic hematopoietic stem cell transplantation. JAMA. 2009; 302(3):306-314.

97. Au BK, Au MA, Chien JW. Bronchiolitis obliterans syndrome epidemiology after allogeneic hematopoietic cell transplantation. Biol Blood Marrow Transplant. 2011; 17(7):1072-1078.

98. Dudek AZ, Mahaseth H, DeFor TE, Weisdorf DJ. Bronchiolitis obliterans in chronic graft-versushost disease: analysis of risk factors and treatment outcomes. Biol Blood Marrow Transplant. 2003; 9(10):657-666.

99. Soubani AO Uberti JP. Bronchiolitis obliterans following haematopoietic stem cell transplantation. Eur REspir J. 2007; 29(5):1007-1019.

100. Bashoura L, Gupta S, Jain A, Couriel DR, Komanduri KV, Eapen GA et al. Inhaled corticosteroids stabilize constrictive bronchiolitis after hematopoietic stem cell transplantation. Bone Marrow Transplant. 2008; 41(1):63-67.

101. Bergeron A, Belle A, Chevret S, Ribaud P, Devergie $A, E S p e r o u ~ H$ et al. Combined inhaled steroids and bronchodilators in obstructive airway disease after allogeneic stem cell transplantation. Bone Marrow Transplant. 2007; 39(9):547553

102. Williams KM, Cheng GS, Pusic I, Jagasia M, Burns L, Ho VT et al. Fluticasone, Azithromycin and Montelukast Treatment for New-Onst Bronchiolitis Obliterans Syndrome after Hematopoietic Cell Transplantation. Biol Blood Marrow Transplant. 2016; 22(4): 710-716.

103. Bankier AA, Van MA, Knoop C, Estenne M, Gevenois PA. Bronchiolitis obliterans syndrome in heart-lung transplant recipients: diagnosis with expiratory CT. Radiology. 2001; 218(2):533539.

104. Lee ES, Gotway MB, Reddy GP, Golden JA, Keith FM, Webb WR et al. Early bronchiolits obliterans following lung transplantation: accuracy of expiratory thin-section CT for diagnosis. Rardiology. 2000; 216(2):472-477.

105. Marras T, Chan C. Obliterative bronchiolitis complicating bone marrow transplantation. Semin Resp Crit Care Med. 2003; 24(5):531-542.

106. Alasaly K, Muller N, Ostrow DN, Champion P, FitzGerald JM. Cryptogenic organizing pneu- monia. A reporto $f 25$ cases and a review of the literature. Medicine (Baltimore). 1995; 74(4):201211.

107. Bhatia S, Armenian SH, Landier W. How I monitor long-term and late marrow transplantation. Blood, 2017; 130(11): 1302-1314.

108. Jodele S, Hirsch R, Laskin B, Davies S, Witte D, Chima R. Pulmonary arterial hypertension in pediatric patients with hematopoietic stem cell transplant-associated thrombotic microangiopathy. Biol Blood Marrow Transplant, 2013; 19(2): 202-207.

109. Dandoy CE, Hirsch R, Chima R, Davies SM, Jodele S. Pulmonary hypertension after hematopoietic stem cell transplantation. Biol Blood Marrow Transplant. 2013;19(11): 1546-1556.

110. Parimon T, Madtes DK, Au DH, Clark JG, Chien JW. Pretransplant lung function, respiratory failure and mortality after stem cell transplantation. Am J Respir Crit Care Med, 2005; 172(3): 384-390.

111. Cheng GS, Storer B, Chien JW, Jagasia M, Hubbard JJ, Burns L et al. Lung Function Trajectory in Bronchiolitis Obliterans Syndrome after Allogeneic Hematopoietic Cell Transplantation. Ann Am Thorac Soc. 2016;13(11): 1932-1939

112. Inamoto $Y$, Lee SJ. Late effects of blood and marrow transplantation. Haematologica, 2017, volume 102(4): 614-625.

113. Flowers ME, Martin PJ. How we treat chronic graft-versus-host disease. Blood 2015;125(4): 606-615.

114. Tichelli A, Bhatia S, Socié G. Cardiac and cardiovascular consequences after haematopoietic stem cell transplantation. $\mathrm{Br} J$ Haematol. 2008; 142(1):11-26.

115. Tichelli A, Passweg J, Wójcik D, Rovó A, Harousseau JL, Masszi T et al. Late cardiovascular events after allogeneic hematopoietic stem cell transplantation: a retrospective multicenter study of the Late Effects Working Party of the European Group for Blood and Marrow Transplantation. Haematol. 2008;93(8):1203-1210.

116. Norkin M, Ratanatharathor V, Ayash L, Abidi $\mathrm{MH}$, Al-Kadhimi Z, Lum LG et al. Large pericardial effusion as a complication in adults undergoing SCT. Bone Marrow Transplant. 2011;46(10): 1353-1356.

117. Rackley C, Schultz KR, Goldman FD, Chan KW, 
Serrano Am, Hulse JE et al. Cardiac manifestations of graft-versus-host disease. Biol Blood Marrow Transplant. 2005; 11(10):773-780.

118. Armenian SH, Sun CL, Mills G, Teh JB, Francisco L, Durand JB et al. Predictors of Late Cardiovascular Complications in Survivors of Hematopoietic Cell Transplantation. Biol Blood Marrow Transplant. 2010; 16(8):1138-1144.

119. Armenian SH, Sun CL, Kawashima T, Arora M, Leisenring W, Sklar CA et al. Long-term health-related outcomes in survivors of childhood cancer treated with HSCT versus conventional therapy: a report from the Bone Marrow Transplant Survivor Study (BMTSS) and Childhood Cancer Survivor Study (CCSS). Blood. 2011; 118(5):1413-1420.

120. Bhatia S, Armenian SH, Landier W. How I monitor long-term and late marrow transplantation. Blood, 2017; 130(11): 1302-1314.

121. Baker KS, Armenian S, Bhatia S. Long-Term Consequences of Hematopoietic Stem Cell Transplantation: Current State of the Science. Biol Blood Marrow Transplant. 2010;16(1 Suppl): S90-S96.

122. Tichelli A, Rovó A, Passweg J,Schwarze CP, Van Lint MT, Arat $M$ et al. Late complications after hematopoietic stem cell transplantation. Expert Rev Hematol. 2009, 2(5):583-601.

123. Armand P, Kim HT, Cutler CS, Ho VT, Koreth J, Alyea EP, Soiffer RJ, Antin JH. Prognostic impact of elevated pretransplantation serum ferritin in patients undergoing myeloablative stem cell transplantation. Blood. 2007; 109:4586-4588.

124. Leung W, Ahn H, Rose SR, Phipps S, Smith T, Gan K et al. A prospective cohort study of late sequelae of pediatric allogeneic hematopoietic stem cell transplantation. Medicine (Baltimore). 2007; 86(4):215-224.

125. Uderzo C, Pillon M, Corti P, Tridello G, Tana F, Zintl $F$ et al. Impact of cumulative anthracycline dose, preparative regime and chronic graftversus-host disease on pulmonary and cardiac function in children 5 years after allogeneic hematopoietic stem cell transplantation: a prospective evaluation on behalf of the EBMT Pediatric Diseases and Late Effects Working Parties. Bone Marrow Transplant. 2007; 39(11):667-675.

126. Santos MVCD, Cioni CH, Gouveia RV, Moises VA, Lederman HM, Carvalho AC et al. Fatores de risco na predição de sinais precoces de atero- sclerose em pacientes pediátricos submetidos a transplante de medula óssea. Rev Bras Hematol Hemoter. 2009;31(5):265.

127. Tichelli A, Rovó A, Gratwohl A. Late pulmonary, cardiovascular and renal complications after hematopoietic stem cell transplantation and recommended screening practices. Hematology Am Soc Hematol Educ Program 2008; 125-33.

128. Rovó A, Tichelli A on behalf of the Late Effects Working Party of the European Group for Blood and Marrow Transplantation. Cardiovascular complications in long-term survivors after allogeneic hematopoietic stem cell transplantation. Semin Hematol. 2012, jan;49(1): 25-34.

129. Inamoto $Y$, Lee SJ. Late effects of blood and marrow transplantation. Haematologica, 2017, volume 102(4): 614-625.

130. Hingorani S. Chronic kidney disease in longterm survivors of hematopoietic cell transplantation: epidemiology, pathogenesis, and treatment. J Am Soc Nephrol. 2006;17(7):1995-2005.

131. Choi M, Sun CL, Kurian S, Carter A, Francisco $\mathrm{L}$, Forman SJ et al. Incidence and predictors of delayed chronic kidney disease in long-term survivors of hematopoietic cell transplantation. Cancer 2008; 113(7): 1580-1587.

132. Hingorani S, Guthrie KA, Schoch G, Weiss NS, McDonald GB. Chronic kidney disease in longterm survivors of hematopoietic cell transplant. Bone Marrow Transplant. 2007;39(4):223-229.

133. Bhatia S, Armenian SH, Landier W. How I monitor long-term and late marrow transplantation. Blood, 2017, 130(11):1302-1314.

134. Inamoto $Y$, Lee SJ. Late effects of blood and marrow transplantation. Haematologica, 2017, volume 102(4): 614-625.

135. National Kidney Foundation. F/DOQI Clinical practice guidelines for chronic kidney disease: evaluation, classification and stratification. Am J Kidney dis, 2002;39(2 Suppl 1): S1-266.

136. Hingorani S, Guthrie KA, Schoch G, Weiss NS, McDonald GB. Chronic kidney disease in longterm survivors of hematopoietic cell transplant. Bone Marrow Transplant, 2007;39(4): 223-229.

137. Verghese OS, Finn LS, Englud JA, Sanders JE, Hingorani SR. BK nephropathy in pediatric hematopoietic stem cell transplant recipients. Pediatr Transplant, 2009;13(7):913-918. 
138. Ho VT, Cutler C, Carter S, Martin P, Adams R, Horowitz $\mathrm{M}$ et al. Blood and Marrow Transplant clinical trials network toxicity committee consensus summary: thrombotic microangiopathy after hematopoietic stem cell transplantation. Biol Blood Marrow Transplant, 2005; 11(8): 571575.

139. Ruutu T, Barosi G, Benjamin RJ, Clark RE, George JN, Gratwohl A et al. Diagnostic criteria for hematopoietic stem cell transplant associated microangiopahty: results of a consensus process by an International Working Group Haematologica, 2007; 92(1): 95-100.

140. Fuge R, Bird JM, Fraser A, Hart D, Hunt L, Cornish $J M$ et al. The clinical features risk factors and outcome of thrombotic thrombocytopenic purpura occurring after bone marrow transplantation. Br J Haematol, 2001; 113(1): 58-64.

141. Abboud I, Peraldi MN, Hingorani S. Chronic kidney diseases in long-term survivors after allogeneic hematopoietic stem cell transplantation: monitoring and managemente guidelines. Semin Hematol. 2012; 49(1): 73-82.

142. Oran B, Donato $M$, Aleman A, Hosing C, Korbling $M$, Detry MA et al. Transplant associated microangiopathy in patients receiving tacrolimus following allogeneic stem cell transplantation: risk factors and response to treatment. Biol Blood Marrow Transplant. 2007;13(4): 469-477.

143. Srinivasan R, Balow JE, Sabnis S,Lundqvist A, Igarashi T, Takahashi $Y$ et al. Nephrotic syndrome: an under-recognised imune-mediated complication of nomyeloablative allogeneic haematopoietic cell transplantation. Br J Haematol. 2005;131(1):74-79.

144. Colombo AA, Rusconi C, Esposito C, Bernasconi $\mathrm{P}$, Caldera D, Lazzarino $\mathrm{M}$ et al. Nephrotic syndrome after allogeneic hematopoietic stem cell transplantion as a late complication of chronic graft-versus host disease. Transplantation. 2006;81(8): 1087-1092.

145. Brukamp K, Doyle AM, Bloom RD, Bunin N, Tomaszewski JE, Cizman B. Nephrotic syndrome after hematopoietic cell transplantation: do glomerular lesions represent renal graft-versus-host disease? Clin J Am Soc Nephrol. 2006;1(4):685694.

146. Weiss AS, Sandmaier BM, Storer B, Storb R, McSweeney PA, Parikh CR. Chronic kidney disease following non-myeloablative hemato- poietic cell transplantation. Am J Transplant. 2006;6(1):89-94.

147. Chang A. Hingorani S, Kowalewska J, Flowers MED, Aneja T, Smith KD et al. Spectrum of renal pathology in hematopoietic cell transplantation: a series of 20 patients and review of the literature. Clin J Am Soc Nephrol. 2007;2(5): 10141023

148. Fred Hutchinson Cancer Research Center/Seattle Cancer Care Alliance - Long Term Follow Up after hematopoietic stem cell transplant. General guidelines for referring physicians, version 2020.

149. Uptodate Wolters Kluwer - 2011-2021. Available from:

https://www.wolterskluwer.com/en/solutions/uptodate Accessed: July 4th, 2021.

150. Flynn JT, Kaelber DC, Baker-Smith C, Blowey $D$, Carroll AE, Daniels SR et al. Subcommittee on screening and management of high blood pressure in children. Clinical Practice Guideline for Screening and Management of High Blood Pressure in Children and Adolescents. American Academy of Pediatrics. Pediatrics, 2017 140(3): e20171904.

151. D'Souza A, Lee S, Zhu X, Pasquini M. Current use and trends in hematopoietic cell transplantation in the United States. Biol Blood Marrow Transplant. 2017;23(9):1417-1421. doi:10.1016/j. bbmt.2017.05.035.

152. Khandelwal $P$, Millard HR, Thiel E, Abdel-Azim $\mathrm{H}$, Abraham AA, Auletta JJ et al. Hematopoietic stem cell transplantation activity in pediatric cancer between 2008 and 2014 in the United States: a Center for International Blood and Marrow Transplant research report. Biol Blood Marrow Transplant. 2017;23(8):1342-1349. doi:10.1016/j.bbmt.2017.04.018.

153. Miano M, Labopin M, Hartmann O, Angelucci E, Cornish J, Gluckman E et al. Paediatric Diseases Working Party of the European Group for Blood and Marrow Transplantation. Haematopoietic stem cell transplantation trends in children over the last three decades: a survey by the paediatric diseases working party of the European Group for Blood and Marrow Transplantation. Bone Marrow Transplant. 2007;39(2):89-99. doi:10.1038/sj.bmt.1705550.

154. Socie G, Curtis RE, Deeg HJ, Sobocinski KA, Fi- 
lipovich AH, Travis LB et al. New malignant diseases after allogeneic marrow transplantation for childhood acute leukemia. J Clin Oncol 2000; 18(2): 348-357.

155. Baker KS, DeFor TE, Burns LJ, Ramsay NKC, Neglia JP, Robison LL. New malignancies after blood or marrow stem-cell transplantation in children and adults: incidence and risk factors. J Clin Oncol. 2003; 21(7):1352-1358.

156. Schechter T, Pole JD, Darmawikarta D, Doyle J, Ali M, Egeler $M$ et al. Late mortality after hematopoietic SCT for a childhood malignancy. Bone Marrow Transplant. 2013;48(10):1291-1295. doi:10.1038/bmt.2013.64.

157. Nivison-Smith I, Bradstock KF, Dodds AJ, Hawkins PA, Ma DD, Moore JJ et al. Hematopoietic stem cell transplantation in Australia and New Zealand, 1992-2004. Biol Blood Marrow Transplant 2007; 13(8): 905-912.

158. Rizzo JD, Curtis RE, Socie G, Sobocinski KA, Gilbert $\mathrm{E}$, Landgren $\mathrm{O}$ et al. Solid cancers after allogeneic hematopoietic cell transplantation. Blood 2009; 113(5): 1175-1183.

159. Kolb HJ, Socie G, Duell T, Van Lint MT, Tichelli A, Apperley JF et al. Malignant neoplasms in longterm survivors of bone marrow transplantation. Late Effects Working Party of the European Cooperative Group for Blood and Marrow Transplantation and the European Late Effect Project Group. Ann Intern Med 1999; 131(10): 738-744.

160. Wingard JR, Majhail NS, Brazauskas R, Wang $Z$, Sobocinski KA, Jacobsohn $D$ et al. Longterm survival and late deaths after allogeneic hematopoietic cell transplantation. J Clin Oncol. 2011;29(16):2230-2239. doi:10.1200/ JCO.2010.33.7212.

161. Martin PJ, Counts GW Jr, Appelbaum FR, Lee SJ, Sanders JE, Deeg HJ et al. Life expectancy in patients surviving more than 5 years after hematopoietic cell transplantation. J Clin Oncol. 2010;28(6):1011-1016. doi:10.1200/ JCO.2009.25.6693.

162. Socié G, Stone JV, Wingard JR, Weisdorf D, Henslee-Downey PJ, Bredeson C et al. Late Effects Working Committee of the International Bone Marrow Transplant Registry. Long-term survival and late deaths after allogeneic bone marrow transplantation. N Engl J Med. 1999;341(1):1421. doi:10.1056/NEJM199907013410103.
163. Bhatia S, Francisco L, Carter A, Sun CL, Baker KS, Gurney JG et al. . Late mortality after allogeneic hematopoietic cell transplantation and functional status of long-term survivors: report from the Bone Marrow Transplant Survivor Study. Blood. 2007;110(10):3784-3792. doi:10.1182/ blood-2007-03-082933

164. Pond GR, Lipton JH, Messner HA. Long-term survival after blood and marrow transplantation: comparison with an age- and gender-matched normative population. Biol Blood Marrow Transplant. 2006;12(4):422-429. doi:10.1016/j. bbmt.2005.11.518.

165. Vajdic CM, Mayson E, Dodds AJ, O'Brien T, Wilcox L, Nivison-Smith I, et al. CAST study investigators. Second cancer risk and late mortality in adult Australians receiving allogeneic hematopoietic stem cell transplantation: a population-based cohort study. Biol Blood Marrow Transplant. 2016;22(5):949-956. doi:10.1016/j. bbmt.2016.01.027.

166. Atsuta Y, Hirakawa A, Nakasone H, Kurosawa S, Oshima K, Sakai R et al. Late Effect and Quality of Life Working Group of the Japan Society for Hematopoietic Cell Transplantation. Late mortality and causes of death among long-term survivors after allogeneic stem cell transplantation. Biol Blood Marrow Transplant. 2016;22(9):17021709. doi:10.1016/j.bbmt.2016.05.019.

167. Bhatia S, Louie AD, Bhatia R, O'Donnell MR, Fung $\mathrm{H}$, Kashyap $\mathrm{A}$ et al. Solid cancers after bone marrow transplantation. J Clin Oncol 2001; 19(2): 464-471.

168. Wilhelmsson M, Vatanen A, Borgström B, Gustafsson B, Taskinen M, Saarinen-Pihkala UM et al. Adverse health events and late mortality after pediatric allogeneic hematopoietic SCT-two decades of longitudinal follow-up. Bone Marrow Transplant. 2015;50(6):850-857. doi:10.1038/ bmt.2015.43.

169. Nelson AS, Ashton LJ, Vajdic CM, Mrsney REL, Daniels B, Nivison-Smith I et al. CAST study investigators. Second cancers and late mortality in Australian children treated by allogeneic HSCT for haematological malignancy. Leukemia. 2015;29(2):441-447. doi:10.1038/leu.2014.203

170. Nelson AS, Vajdic CM, Ashton LJ, Marsney REL, Nivison-Smith I, Wilcox L et al. CAST investigators. Incident cancers and late mortality in Australian children treated by allogeneic stem 
cell transplantation for non-malignant diseases. Pediatr Blood Cancer. 2017;64(1):197-202. doi:10.1002/pbc.26219.

171. Ferry C, Gemayel G, Rocha V, Labopin M, Esperou $\mathrm{H}$, Robin $\mathrm{M}$ et al. Long-term outcomes after allogeneic stem cell transplantation for children with hematological malignancies. Bone Marrow Transplant. 2007;40(3):219-224. doi:10.1038/ sj.bmt.1705710.

172. Majhail NS, Brazauskas R, Rizzo JD, Sobecks RN, Wang Z, Horowitz MM et al. Secondary solid cancers after allogeneic hematopoietic cell transplantation using busulfan-cyclophosphamide conditioning. Blood. 2011; 117(1):316-322.

173. Tavares RCBS, Silva MM, Arcuri LJ, Kussumi VM; Moreira MCR, Lerner D; Castro R. Risk factors for second solid cancers in allogeneic haematopoietic cell recipients: a Brazilian case-control study. EBMT, 2016.

174. Inamoto, Y, Shah, N, Savani, B, Shaw BE, Abraham AA, Ahmed IA et al. Secondary solid cancer screening following hematopoietic cell transplantation. Bone Marrow Transplant, 2015; 50(8), 1013-1023.

175. Curtis RE, Rowlings PA, Deeg HJ, Shriner DA, Socíe G, Travis LB et al. Solid cancers after bone marrow transplantation. N Engl J Med. 1997; 336(13):897-904.

176. Eapen M, Ahn KW, Orchard PJ, Cowan MJ, Davies SM, Fasth $A$ et al. Long-term survival and late deaths after hematopoietic cell transplantation for primary immunodeficiency diseases and inborn errors of metabolism. Biol Blood Marrow Transplant. 2012;18(9):1438-1445. doi:10.1016/j. bbmt.2012.03.003

177. Curtis RE, Metayer C, Rizzo JD, Socie G, Sobocinski KA, Flowers ME et al. Impact of chronic GVHD therapy on the development of squamous-cell cancers after hematopoietic stem-cell transplantation: an international case-control study.Blood 2005; 105(10): 3802-3811.

178. Iyer JG, Storer BE, Paulson KG, Lemos B, Phillips $\mathrm{JL}$, Bichakjian CK et al. Relationships among primary tumor size, number of involved nodes, and survival for 8044 cases of Merkel cell carcinoma. J Am Acad Dermatol 2014; 70(4): 637-643.

179. Schwartz JL, Kopecky KJ, Mathes RW, Leisenring WM, Friedman DL, Deeg HJ. Basal cell skin cancer after total-body irradiation and hema- topoietic cell transplantation. Radiat Res 2009; 171(2): 155-163.

180. Bilmon IA, Ashton LJ, Le Marsney RE, Dodds AJ, O'Brien TA, Wilcox $L$ et al. Second cancer risk in adults receiving autologous haematopoietic SCT for cancer: a population-based cohort study. Bone Marrow Transplant 2014; 49(5): 691-698.

181. Kahn JM, Brazauskas R, Tecca HR, Bo-Subait $S$, Buchbinder D, Battiwala $M$, etal. Subsequent neoplasms and late mortality in children undergoing allogeneic transplantation for nonmalignant diseases. Blood Adv. 2020 May 12;4(9):20842094. doi: 10.1182/bloodadvances. 2019000839 .

182. Witherspoon RP, Fisher LD, Schoch G, Martin P, Sullivan KM, Sanders J et al. Secondary cancers after bone marrow transplantation for leukemia or aplastic anemia. N Engl J Med. 1989; 321(12):784-789.

183. Majhail NS. Secondary cancers following allogeneic haematopoietic cell transplantation in adults. Br J Haematol. 2011; 154(3):301-310.

184. Friedman DL, Rovo A, Leisenring W, Locasciulli A, Flowers ME, Tichelli A, Sanders JE, Deeg HJ, Socie G; FHCRC; EBMT-Late Effect Working Party. Increased risk of breast cancer among survivors of allogeneic hematopoietic cell transplantation: a report from the FHCRC and the EBMT-Late Effect Working Party. Blood. 2008 Jan 15;111(2):93944. doi: 10.1182/blood-2007-07-099283. Epub 2007 Oct 2.

185. Ringdén O, Brazauskas R, Wang Z, Ahmed I, Atsuta $Y$, Buchbinder D, et al. Second solid cancers after allogeneic hematopoietic cell transplantation using reduced-intensity conditioning. Biol Blood Marrow Transplant. 2014 Nov;20(11):177784. doi: 10.1016/j.bbmt.2014.07.009.

186. Yokota A, Ozawa S, Masanori T, Akiama H, Ohsima K, Kanda Y et al. Secondary solid tumors after allogeneic hematopoietic SCT in Japan. Bone Marrow Transplant. 2012; 47(1):95-100.

187. Bhatia S, Ramsay NK, Steinbuch M, Dusenbery KE, Shapiro RS, Weisdorf DJ et al. Malignant neoplasms following bone marrow transplantation. Blood 1996; 87(9): 3633-3639.

188. Holmqvist AS, Chen Y, Wu Jessica, Battles K, Bathia R, Francisco $L$ et al. Assessment of late mortality risk after allogeneic blood or marrow transplantation performed in childhood. JAMA Oncol. 2018 dec 1;4(12):e182453 
189. Freycon F, Casagranda L, Trombert-Paviot $B$. The impact of severe late-effects after $12 \mathrm{~Gy}$ fractionated total body irradiation and allogeneic stem cell transplantation for childhood leukemia (1988-2010). Pediatr Hematol Oncol. 2019 Mar;36(2):86-102. doi: 10.1080/08880018.2019.1591549. Epub 2019 Apr 12. PMID: 30978121.

190. Majhail NS. Old and new cancers after hematopoietic-cell transplantation. Hematology Am Soc Hematol Educ Program. 2008:142-149.

191. Nelson AS, Vajdic CM, Ashton LJ, Le Marsney RE, Nivison-Smith I, Wilcox L, et al; CAST investigators. Incident cancers and late mortality in Australian children treated by allogeneic stem cell transplantation for non-malignant diseases. Pediatr Blood Cancer. 2017 Jan;64(1):197-202. doi: 10.1002/pbc.26219.

192. Cohen A, Rovelli A, Merlo DF, Van Lint MT, Lanino $E$, Bresters $D$ et al. Risk for secondary thyroid carcinoma after hematopoietic stem-cell transplantation: an EBMT Late Effects Working Party Study. J Clin Oncol 2007; 25(17): 2449-2454.

193. Nelson AS, Ashton LJ, Vajdic CM, Le Marsney RE, Daniels B, Nivison-Smith I et al. Second cancers and late mortality in Australian children treated by allogeneic HSCT for haematological malignancy. Leukemia. 2015; 29(2):441-447.

194. McDonald AM, Chen Y, Wu J, Hageman L, Francisco $L$, Kung $M$ et al. Total Body Irradiation and Risk of Breast Cancer After Blood or Marrow Transplantation: A Blood or Marrow Transplantation Survivor Study Report. J Clin Oncol. 2020 Sep 1;38(25):2872-2882. doi: 10.1200/ JCO.20.00231. Epub 2020 Jul 16. Erratum in: J Clin Oncol. 2021 Apr 20;39(12):1414.

195. Windsor, M. BMT survivor study finds significant breast cancer risk in young women who received total body irradiation. July 31st, 2020. Available at: https://www.uab.edu/news/ research/item/11460-bmt-survivor-studyfinds-significant-breast-cancer-risk-in-youngwomen-who-received-total-body-irradiation. Accessed August 2nd, 2021.

196. Manual de Orientação - Avaliação nutricional da criança e do adolescente - Departamento científico de nutrologia e Sociedade Brasileira de Pediatria - 2021

197. Van Etten E, Mathieu C. Immunoregulation by 1,25-dihydroxyvitamin D3: basic concepts. J Ste- roid Biochem Mol Biol. 2005; 97(1-2):93-101.

198. Arain A, Matthiesen C. Vitamin D deficiency and graft-versus-host disease in hematopoietic stem cell transplant population. Hematol Oncol Stem Cell Ther. 2018; 12(3):133-139.

199. Rusha Bhandari, Jemily Malvar, Amy Sacapano, Paibel Aguayo-Hiraldo, Sonatao Jodele, Etan Orgel. Association between vitamina D and Risk for Early and Late Post Transplant Complications. Biol Blood Marrow Transplant, 2020; 26(2): 343-350

200. Wallace G, Jodele S, Howell J, Myers KC, Teusink A, Zhao $X$ et al. Vitamin D Deficiency And Survival In Children After Hematopoietic Stem Cell Transplant. Biol Blood Marrow Transplant. 2015; 21(9):1627-1631.

201. Urbain P, Ihorst G, Biesalski H-K, Bertz H. Course of serum 25-hydroxyvitamin D3 status and its influencing factors in adults undergoing allogeneic hematopoietic cell transplantation. Ann Hematol. 2012; 91(5):759-766.

202. Kreutz M, Eissner G, Hahn J, Andreesen R, Drobnik W, Holler E. Variations in 1a,25-dihydroxyvitamin D3 and 25-hydroxyvitamin D3 serum levels during allogeneic bone marrow transplantation Bone. Bone Marrow Transplant. 2004; 33(8):871-873.

203. Von Bahr L, Blennow O, Alm J, Bjorklund A, Malmberg K-J, Le Blanc A. Increased incidence of chronic GVHD and CMV disease in patients with vitamin $D$ deficiency before allogeneic stem cell transplantation. Bone Marrow Transplant. 2015;Sep;50(5): 1217-23.

204. Glotzbecker B, Ho VT, Aldridge J, Kim HT, Horowitz G, Ritz J et al. Low levels of 25-hydroxyvitamin $D$ before allogeneic hematopoietic SCT correlate with the development of chronic GVHD. Bone Marrow Transplant. 2013;48(4):593-597.

205. Van der Meij BS, de Graaf P, Wierdsma NJ, Langius JAE, Janssen JJWM, van Leeuwen PAM et al. Nutritional support in patients with GVHD of the digestive tract: state of the art. Bone Marrow Transplant. 2013;48(4):474-482.

206. Wood CL, Cheetham TD. NICE guideline PH56 - Vitamin D: increasing supplement use among at-risk groups. Arch Dis Child Educ Pract Ed. 2014;101 (1):1-51. 
207. Autier P, Gandini SP. Vitamin D supplementation and total mortality. Arch Intern Med. 2007;167(16):1730-1737.

208. Spiller HA, Good TF, Spiller NE, Aleguas A. Vitamin $D$ exposures reported to US poison centers 2000-2014: temporal trends and outcomes. Hum Exp Toxicol. 2016;35(5):457-461.

209. J. Ros-Soto, J.A. Snowden, N. Salooja, M. Gilleece, A. Parker, D.M. Greenfield, C et al on behalf of the Transplant Complications Working Party of the EBMT. Current Practice in Vitamin D Management in Allogeneic Hematopoietic Stem Cell Transplantation: A Survey by the Transplant Complications Working Party of the European Society for Blood and Marrow Transplantation. Biol Blood Marrow Transplantat, 2019; 25(10): 2079-2085

210. Harshitha Kota, Ronald S Chamberlain. Immunonutrition is associated with a decrerased incidence of graft-versus-host disease in bone marrow transplant recipients: a meta-analysis. Journal of Parenteral and Enteral Nutrition, 2017 nov; 42(8): 1286-1292

211. Hibberd P, Boeckh M, Bond Sheila. Immunizations in hematopoietic cell transplant candidates and recipients - UpToDate - www.uptodate.com 2021

212. Manual dos centros de referência para imunobiológicos especiais - 5 a edição, 2019 - Ministério da Saúde. Secretaria de Vigilância em Saúde. Departamento de Imunização e Doenças Transmissíveis

213. Kamboj M, Shah MK. Vaccination of the stem cell transplant (SCT) recipient and the hematologic malignancy patient. Infect Dis Clin North Am. 2019 June; 33(2): 593-609.

214. Clarke SA, Eiser C, Skinner R. Health-related quality of life in survivors of BMT for paediatric malignancy: a systematic review of the literature. Bone Marrow Transplant 2008; 42: 73-82.

215. MacLeod KD, Whitsett SF, Mash EJ, Pelletier W. Pediatric sibling donors of successful and unsuccessful hematopoietic stem cell transplants (HSCT): a qualitative study of their psychosocial experience. J Pediatr Psychol 2003; 28: 223-230.

216. Patenaude AF. Psychological impact of bone marrow transplantation: current perspectives. Yale J Biol Med 1990; 63: 515-519.
217. Meyers CA, Weitzner M, Byrne K, Valentine A, Champlin RE, Przepiorka D. Evaluation of the neurobehavioral functioning of patients before, during, and after bone marrow transplantation. J Clin Oncol 1994; 12: 820-826.

218. Phipps S, Dunavant M, Lensing S, Rai SN. Acute health related quality of life in children undergoing stem cell transplant: II. Medical and demographic determinants. Bone Marrow Transplant 2002; 29: 435-442.

219. Pot-Mees C. The Psychological Effects of Bone Marrow Transplantation in Children. Eburon Delft: Delft, The Netherlands, 1989.

220. Stuber M, Nader K, Yasuda P, Pynoos R, Cohen $S$. Stress responses after pediatric bone marrow transplantation: preliminary results of a prospective longitudinal study. J Am Acad Child Adoles Psychiatr 1991; 30: 952-957.

221. Pot-Mees C, Zeitlin H. Psychosocial consequences of bone marrow transplantation in children: a preliminary communication. J Psychosoc Oncol 1987; 52: 73-81.

222. Phipps S, Brenner M, Heslop H, Krance R, Jayawardene D, Mulhern R. Psychological effects of bone marrow transplantation on children and adolescents: preliminary report of a longitudinal study. Bone Marrow Transplant 1995; 15: 829-835.

223. Rodrigue JR, Pearman TP, Moreb J. Morbidity and mortality following bone marrow transplantation: predictive utility of pre-BMT affective functioning, compliance, and social support stability. Int J Behav Med 1999; 6: 241-254.

224. Barrera M, Atenafu E, Andrews GS, Saunders F. Factors related to changes in cognitive, academic and visual motor integration in children who undergo hematopoietic stem cell transplant. J Pediatr Psychol 2008; 33: 536-546.

225. Wallander J, Varni J. Effects of pediatric chronic physical disorders on child and family adjustment. J Child Psychol Psychiatry 1998; 39: 29-46.

226. Felder-Puig R, di Gallo A, Waldenmair M, Norden $\mathrm{P}$, Winter A, Gadner $\mathrm{H}$ et al. Health-related quality of life of pediatric patients receiving allogeneic stemcell or bone marrow transplantation: results of a longitudinal, multi-center study. Bone Marrow Transplant 2006; 38: 119-126.

227. Barrera M, Pringle LA, Sumbler K, Saunders F. 
Quality of life and behavioural adjustment after pediatric bone marrow transplantation. Bone Marrow Transplant 2000; 26: 427-435.

228. Arvidson J, Larsson B, Lonnerholm G. A longterm follow-up study of psychosocial functioning after autologous bone marrow transplantation in childhood. Psycho Oncol 1999; 8:123-134.

229. Parsons SK, Shih M, DuHamel KN, Ostroff J, Mayer DK, Austin J et al. Maternal perspectives on children's health related quality of life during the first year after pediatric hematopoietic stem cell transplant. J Pediatr Psychol 2006; 31: 11001115.

230. Phipps S, Dunavant M, Garving PA, Lensing S, Rai SN. Acute health related quality of life in children undergoing stem cell transplant: I. Descriptive outcomes. Bone Marrow Transplant 2002; 29: 425-434.

231. Phipps S, Mulhern R. Family cohesion and expressiveness promote resilience to the stress of pediatric bone marrow transplant: a preliminary report. J Dev Behav Pediatr 1995; 16: 257-263.

232. Badell I, Igual L, Gomez E, Burco JJ, Ortega J, Cubells A. Quality of life in young adults having received a BMT during childhood: a GETMON study. Bone Marrow Transplant 1998; 21(Suppl 2): S68-S71.

233. Kupst MJ, Penati B, Debban B, Camitta B, Pietrga $D$, Margolis $D$ et al. Cognitive and psychosocial functioning of pediatric hematopoietic stem cell transplant patients: a prospective longitudinal study. Bone Marrow Transplant 2002; 30: 609-617.

234. Sandler A. Deficits in social skills. In: Levine MD, Carey WB, Crocker AC (eds). Developmental Behavioral Pediatrics.WB Saunders Company: Philadelphia, PA, 1992.

235. Golomb VA. Cognitive and psychological sequelae of pediatric bone marrow transplant. PhD 9943611, USA, Hahnemann University, 2000.
236. Packman W, Weber S, Wallace J, Bugescu N. Psychological effects of hematopoietic SCT on pediatric patients, siblings and parents: a review. Bone Marrow Transplant. 2010 Jul;45(7):113446. doi: 10.1038/bmt.2010.74. Epub 2010 Apr 12. PMID: 20383219.

237. Vannatta K, Zeller M, Noll RB, Koontz K. Social functioning of children surviving bone marrow transplantation. J Pediatr Psychol 1998; 23: 169-178.

238. Ruthruff LD. The effects of bone marrow transplantation on the psychosocial development of infants. PhD 3249643 Pacific Graduate School of Psychology: Palo Alto, CA, USA, 2006.

239. Smedler AC, Ringden K, Bergman H, Bolme $P$. Sensorymotor and cognitive functioning in children who have undergone bone marrow transplantation. Acta Paediatrica Scand1990; 79: 613-621.

240. McGuire T, Sanders JE, Hill D, Buckner CD, Sullivan K.Neuropsychological function in children given total-body irradiation for marrow transplantation. Exp Hematol 1991; 19: 578.

241. Phipps S, Dunavant M, Srivastava DK, Bowman L, Mulhern RK. Cognitive and academic functioning in survivors of pediatric bone marrow transplantation. J Clin Oncol 2000; 18: 1004-1011.

242. Barrera M, Atenafu E. Cognitive, educational, psychosocial adjustment and quality of life of children who survive hematopoietic SCT and their siblings. Bone Marrow Transplant 2008; 42: $15-21$.

243. Cool V. Long-term neuropsychological risks in pediatric bone marrow transplant: What do we know? Bone Marrow Transplant 1996; 18: S45S49.

244. Peters C, Balthazor M, Shapiro E, King R, Kollman $C$, Hegland $J$ et al. Outcome of unrelated bone marrow transplantation in 40 children with Hurler syndrome. Blood 1996; 87: 4894-4902. 